\title{
A NEW DESIGN OF SOLID STATE CIRCUIT BREAKER FOR HVDC APPLICATIONS
}

\author{
By \\ Shahram Negari \\ BGS Indiana Purdue University, IN, USA, 2008
}

MBA, Edinburgh Business School, Heriot-Watt University, Scotland, UK, 2010

\author{
A thesis \\ presented to Ryerson University \\ in partial fulfillment of the \\ requirements for the degree of \\ Master of Applied Science \\ in the program of
}

Electrical and Computer Engineering

Toronto, Ontario, Canada, 2015

(c) Shahram Negari 2015 


\section{Author's Declaration}

I hereby declare that I am the sole author of this thesis. This is a true copy of the thesis, including any required final revisions, as accepted by my examiners.

I authorize Ryerson University to lend this thesis to other institutions or individuals for the purpose of scholarly research.

I further authorize Ryerson University to reproduce this thesis by photocopying or by other means, in total or in part, at the request of other institutions or individuals for the purpose of scholarly research.

I understand that my thesis may be made electronically available to the public. 


\title{
A New Design of Solid State Circuit Breaker For HVDC Applications
}

\author{
MASc in Electrical and Computer Engineering, 2015 \\ Shahram Negari \\ Electrical and Computer Engineering \\ Ryerson University
}

\begin{abstract}
The global energy consumption is soaring at an unprecedented rate over the past three decades, in part due to rapid socioeconomic advancement in developing countries. This enormous demand, in turn, has pushed the energy production methods to their limits. Therefore, huge investments are predicted to be put in the energy sector to increase production at one end and enhance consumption efficiency at the other. Currently a considerable portion of electric energy is produced by power plants who consume some kind of fossil based energy carrier. However, dependency on fossil based energy carriers has brought up its own serious drawbacks including ecological problems such as global warming, increased $\mathrm{CO}_{2}$ emission, and alarming pollution levels.

As a remedy, many economies have diverted from traditional means of energy production by embracing new sustainable energy production methods and simultaneously improving consumption habits. Currently, among technically available and economically viable solutions, generating energy from renewable sources, in particular wind and solar are pioneering. Finding the appropriate
\end{abstract}


locations and building large scale wind farms or solar farms in urban areas, which are already suffering from congestion, has turned to be a major challenge. Consequently, many investors are now turning toward construction of off-shore farms. Transferring the electric energy from the offshore farm to the mainland in a safe and reliable way is the next challenge. Having taken into account several technical and economic reasons, laying submarine HVDC cables at sea substrate to evacuate the power from offshore wind farms is the best available method at the present.

Utilizing HVDC requires installation of AC/DC converters, which due to grid characteristics in particular in remote areas, will be mainly based on utilizing voltage source converters. Yet, as to integration of antiparallel diodes in their valves, voltage source converters are intrinsically vulnerable against massive short circuit currents and backflow of energy from transmission line to the converter. Thus developing a reliable circuit breaker topology, which is the frontline protection device for both submarine transmission line and converter seems to be essential. In this research, existing topologies and solutions for circuit breakers, including their features and drawbacks are discussed and then a new topology for HVDC circuit breaker is introduced.

Many solid-state topologies have been proposed by academia and rolled out by manufacturers so far. A feature common to all existing designs is utilization of surge arrester for absorbing the energy stored in the system. However, the new topology that is put forward in this research is based on a combination of solid-state switch and a mutual inductance, which diverts the energy stored in the transmission line at the time of short circuit current to a resistor. The resistor then damps and absorbs the energy which is finally dissipated as heat. Both simple and complex Simulink models are developed to test the performance of the proposed topology. Results of both simulation scenarios corroborate and validate the functionality and reliability of the suggested design. 


\section{Acknowledgement}

I would like to extend my genuine thanks to my supervisor, Professor David Xu who gave me the opportunity to learn and gain from his valuable knowledge and expertise in the field of power electronics and renewable energy systems. I am duly grateful for his consistent support, priceless comments and guidance, and patience and understanding throughout the research work.

I also thank all my beloved family members in particular my wife and my two sons for their love, support, continuous encouragement, and inspiration. 


\section{Contents}

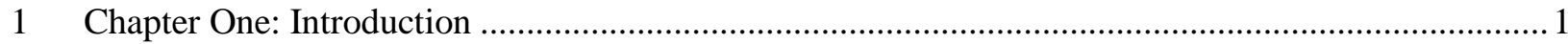

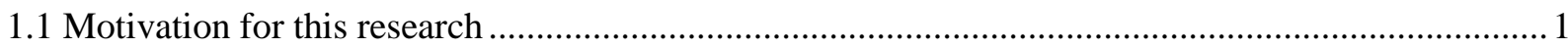

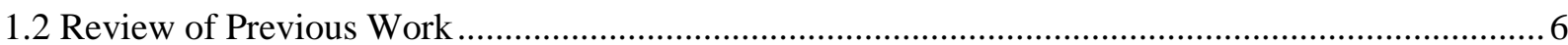

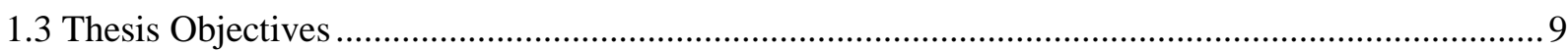

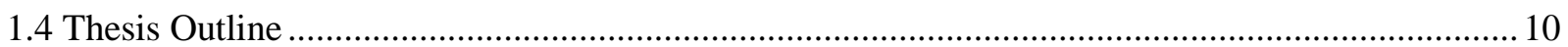

2 Chapter Two: Analysis of Existing Circuit Breaker Designs .......................................................... 12

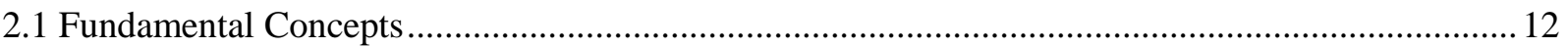

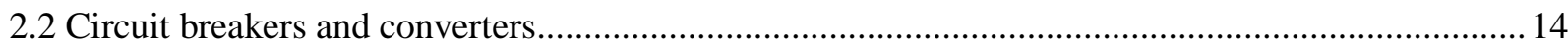

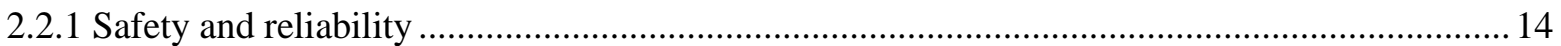

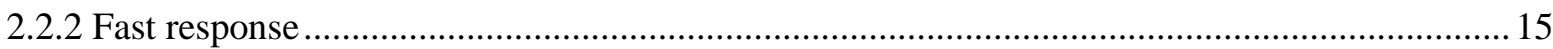

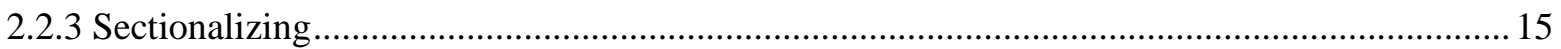

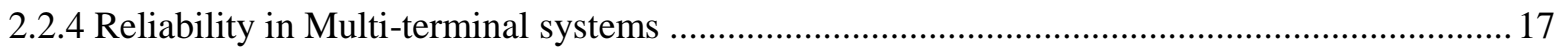

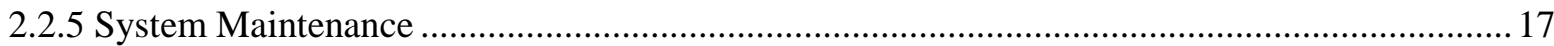

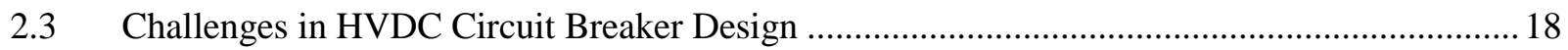

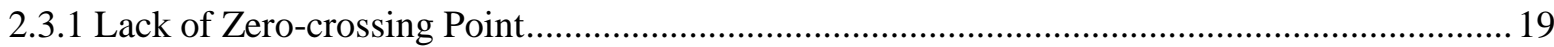

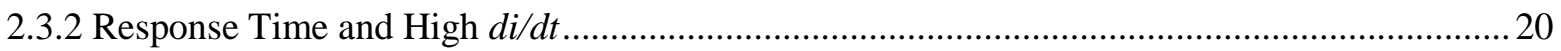

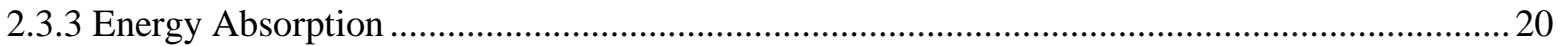

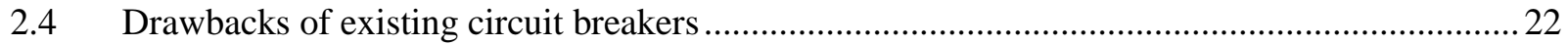

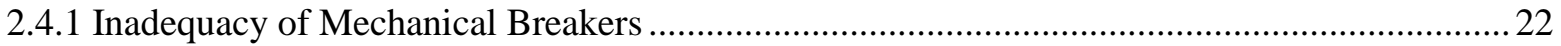

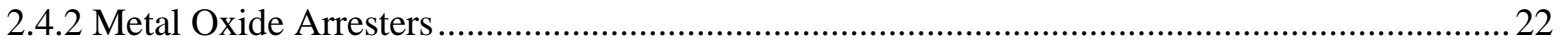

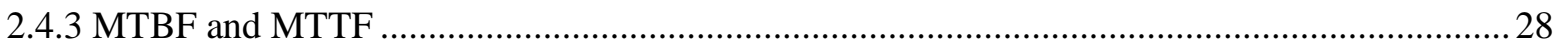

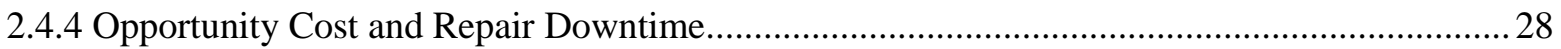

3 Chapter Three: Offshore Wind Farms and HVDC Technology …................................................ 32

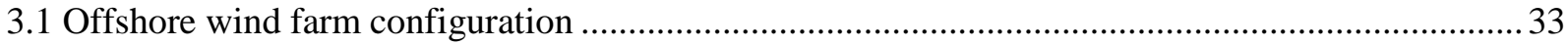

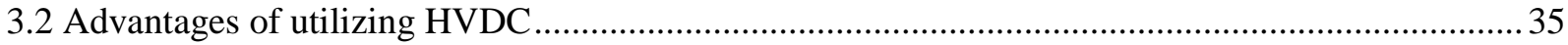

3.3 Applications of Voltage Source Converters in Renewable Energy .................................................35

3.4 Vulnerability of Voltage Source Converters against External Faults .............................................. 38

4 Chapter Four: Proposed Circuit Breaker Design …....................................................................... 41

4.1 Structural Analysis of the Circuit Breaker ................................................................................... 42

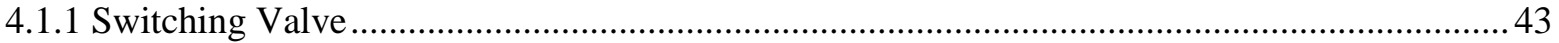




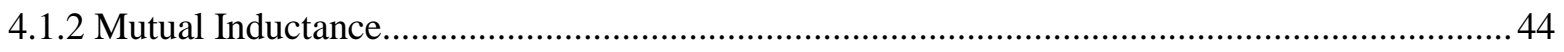

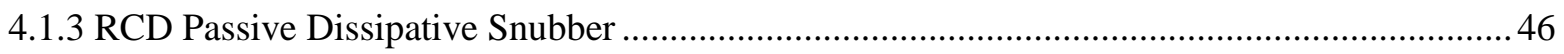

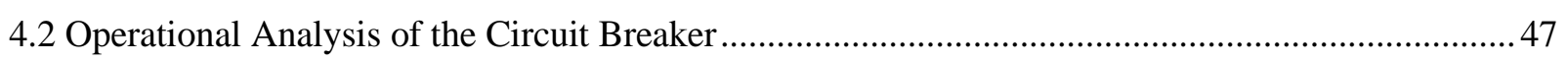

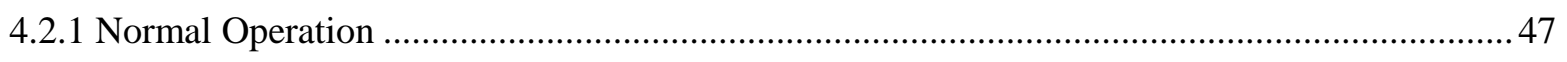

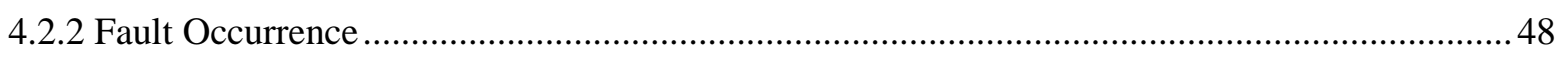

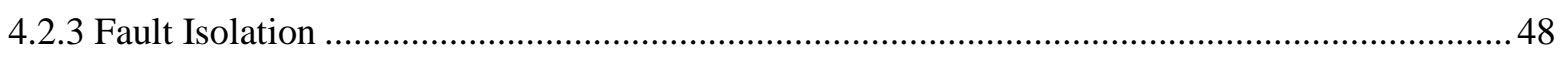

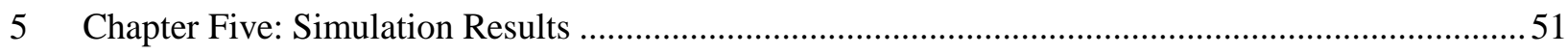

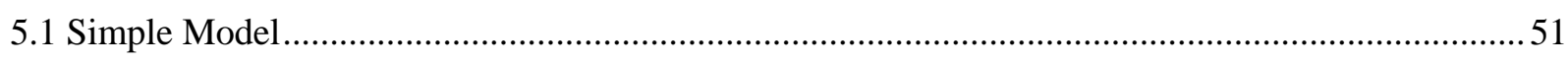

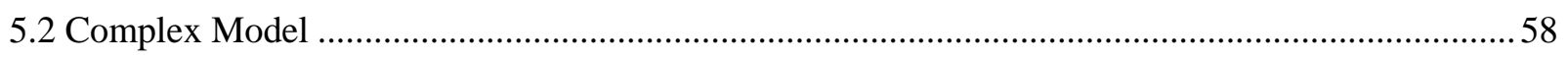

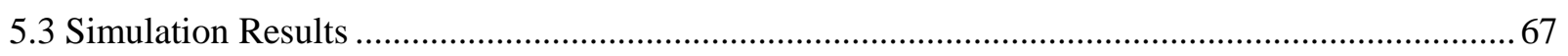

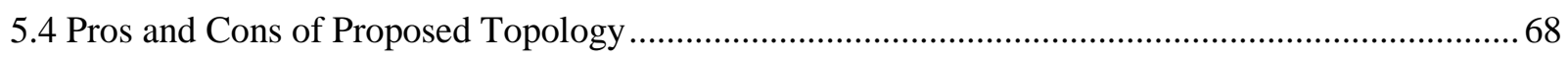

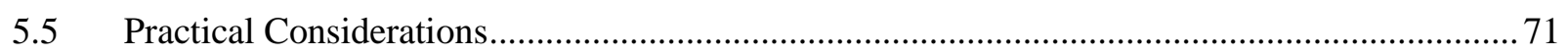

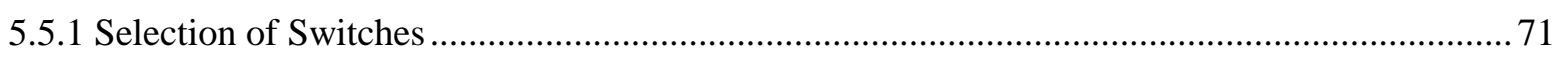

5.5.2 Combining Mutual Inductance and Dumping Resistor....................................................... 75

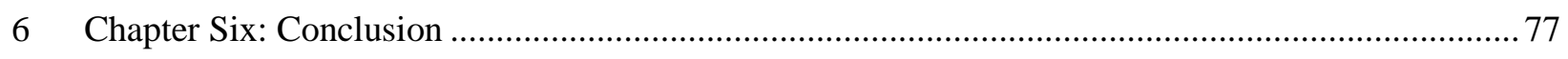

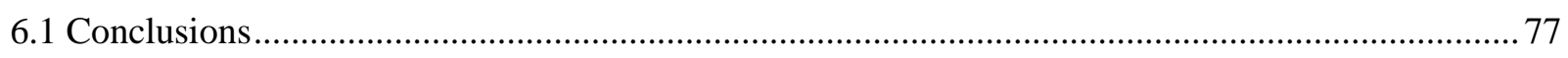

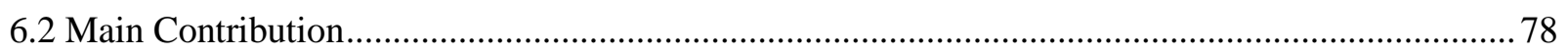

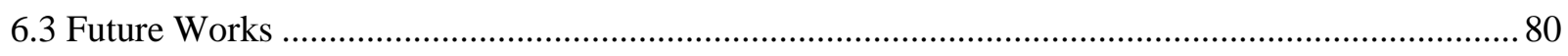

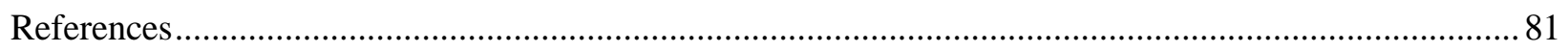

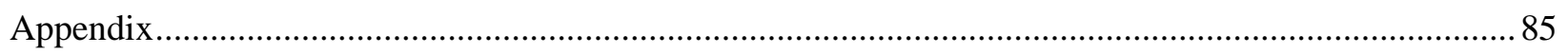

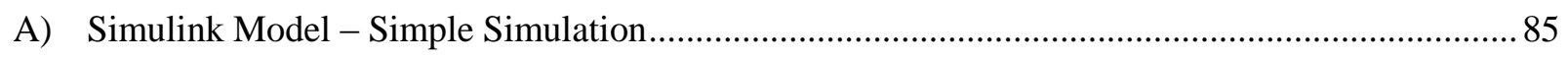

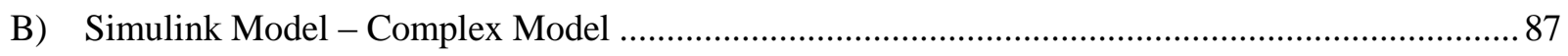




\section{List of Figures}

Figure 1-1

Figure 1-2

Figure 1-3

Figure 2-1

Figure 2-2

Figure 2-3

Figure 2-4

Figure 2-5

Figure 2-6

Figure 2-7

Figure 2-8

Figure 2-9

Figure 3-1

Figure 3-2

Figure 3-3

Figure 3-4

Figure 3-5

Figure 4-1

Figure 4-2

Figure 4-3

Figure 4-4

Figure 5-1

Figure 5-2

Figure 5-3

Figure 5-4

Figure 5-5

Figure 5-6

Figure 5-7

Figure 5-8

Figure 5-9

Figure 5-10
US average wind power

Photovoltaic solar resources, USA

Power Cables Used in HV Transmission Lines 5

Single line diagram of a typical substation $\quad 12$

$\begin{array}{ll}\text { Single busbar substation design } & 16\end{array}$

DC circuit breaker with commutation / resonant feature 19

$\begin{array}{ll}\text { Mechanical circuit breaker with } \mathrm{ZnO} \text { arresters } & 21\end{array}$

$\mathrm{ZnO}$ arresters, porcelain clad 23

Residual voltage for EXLIM P surge arresters 25

Porcelain housing exploded 26

Buck converter concept - delegating fault energy to transmission line 27

London Array offshore substation 31

London Array offshore wind farm 33

Schematic diagram of an offshore wind farm 34

Solid-state valves and anti-parallel diodes, three phase legs 38

Staircase quality output of voltage source converters 39

Multilevel converter and anti-parallel diodes $\quad 40$

Schematic diagram of proposed circuit breaker design $\quad 42$

Circuit breaker during normal operation $\quad 43$

Circuit breaker after fault detection and isolation $\quad 44$

$\begin{array}{ll}\text { Operational analysis of circuit breaker } & 47\end{array}$

Schematic diagram of circuit breaker, simple simulation scheme 51

HVDC line current, simple simulation $\quad 55$

Fault detection and isolation, simple simulation 55

Circuit equivalent for HVDC submarine cable line 56

Distributed model for transmission line 56

Line energy steered toward and absorbed by resistor 57

Current passing through protective RCD snubber 56

Schematic diagram of circuit breaker in complex model simulation $\quad 60$

HVDC line current during fault and clearance $\quad 61$

HVDC line current, fault, and reclosing attempts 62 
Figure 5-11

Figure 5-12

Figure 5-13

Figure 5-14

Figure 5-15

Figure 5-16

Figure 5-17

Figure 5-18
Scenario A, system protected by circuit breaker

63

Scenario B, system NOT protected by circuit breaker

63

Onshore VSC output during fault and clearance

65

Three-phase voltage on AC grid bus

66

Typical solid-state valve

72

IGBT pack type 5SNA 2000K450300

73

Typical on-state characteristics for 5SNA 2000K450300

74

Gate driver module for IGBT

75 


\section{List of Tables}

Table 1-1

Table 2-1

Table 3-1

Table 5-1

Table 5-2
US renewable resources $\quad 2$

$\begin{array}{ll}\text { Challenges in designing HVDC circuit breaker } & 18\end{array}$

Advantages of using HVDC over HVAC 37

International Standard Conductor Sizes 53

$\begin{array}{ll}\text { Pros and cons of proposed circuit breaker topology } & 70\end{array}$ 


\section{List of Appendices}

Appendix A

Appendix B
Simulink Model, Simple Simulation

Simulink Model, Complex Model 


\section{Glossary of Acronyms}

AC

APOD

CB

CSC

DC

GTO

HVAC

HVDC

IGBT

IGCT

LCC

MI

MOV

MTBF

MTTF

PSC

PWM

$\mathrm{SC}$

SF6

SLD

SVM

THD

VSC

WTG

XLPE

$\mathrm{ZnO}$
Alternating Current

Alternative Phase Opposition Disposition

Circuit Breaker

Current Source Converter

Direct Current

Gate-Turn-Off Thyristor

High Voltage Alternating Current

High Voltage Direct Current

Insulated Gate Bipolar Transistor

Integrated Gate-Commutated Thyristor

Line Commutated Converter

Mutual Inductance

Metal Oxide Varistor

Mean Time Before Failure

Mean Time To Failure

Phase-Shifted Carrier

Pulse-Width Modulation

Short Circuit

Sulfur hexafluoride

Single Line Diagram

Space Vector Modulation

Total Harmonic Distortion

Voltage Source Converter

Wind Turbine Generator

Cross-linked Poly Ethylene

Zinc Oxide 


\section{Chapter One: Introduction}

\subsection{Motivation for this research}

The outlook of energy production and consumption has dramatically changed over the past few decades. We have been witnessing an ever increasing demand for energy especially in emerging economies, which in turn has led to higher investment in energy sector. Simultaneously, a global trend toward reducing dependency on fossil based energy carriers by harvesting energy from renewable sources seems to be in full swing in most countries. This initiative has gained significant momentum due to both recent technological advancement in harnessing wind and solar energies on one side, and higher oil and gas prices on the other side. Moreover, ecological concerns and problems such as global warming, increased $\mathrm{CO}_{2}$ emission, and unprecedented pollution levels call for immediate attention to imminent ecological catastrophe and readjustment of our attitude towards natural resources by implementing sustainable consumption patterns. Although wide variety and sometimes exotic solutions have been offered to generate energy from renewable sources, among them wind and solar farms are pioneering.

Some may doubt the abundance of such sustainable resources, and consider them miniscule compared to the total energy demand. However, many researched funded by governments and conducted by impartial government agencies proved otherwise. Table 1-1 summarizes the total extractable energy from renewable resources within the United States of America, which exceeds 208,000 GW. After examining the table, it is obvious that solar and wind resources are the most promising sources by far. For instance, Fig. 1-1 illustrates the average annual wind power available across the United States, and Fig. 1-2 depicts the enormous solar energy that could be extracted by photovoltaic solar farms. Just to emphasis on the gigantic role that such resources can play in our production portfolio, it is necessary to draw the attention of the reader to the fact that even the harvestable capacity of offshore wind farms is estimated to be 4,200 GW. 


\begin{tabular}{|c|c|c|c|c|c|}
\hline Resource & Solar PVICSP) & Wind & Geothermal & Water Power & Biopower \\
\hline $\begin{array}{c}\text { Theoretical } \\
\text { Potential }\end{array}$ & $\begin{array}{l}155,000 \mathrm{GW} \\
(\mathrm{PV}) \\
38,000 \mathrm{GW} \\
(\mathrm{CSP})\end{array}$ & $\begin{array}{l}11,000 \mathrm{GW} \\
\text { (onshore) } \\
4,200 \mathrm{GW} \\
\text { (offshore to } \\
50 \mathrm{~nm} \text { ) }\end{array}$ & $\begin{array}{l}38 \mathrm{GW} \\
\text { (conventional) } \\
4,000 \mathrm{GW} \\
(\mathrm{EGS})\end{array}$ & $68 \mathrm{GW}$ & $62 \mathrm{GW}$ \\
\hline
\end{tabular}

Table 1-1 US renewable resources (www.nrel.gov)

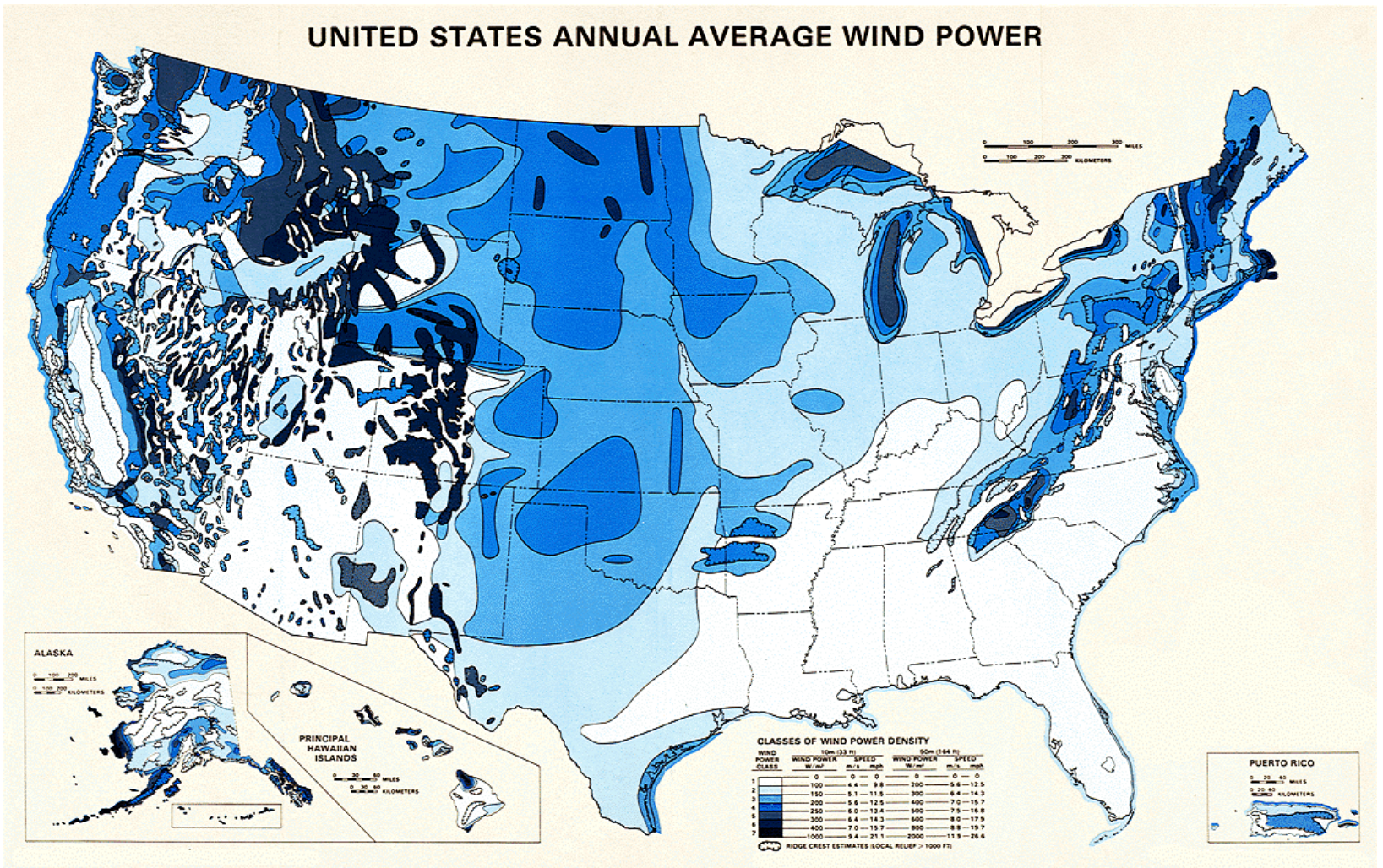

Fig. 1-1 US Average wind power (http://rredc.nrel.gov) 


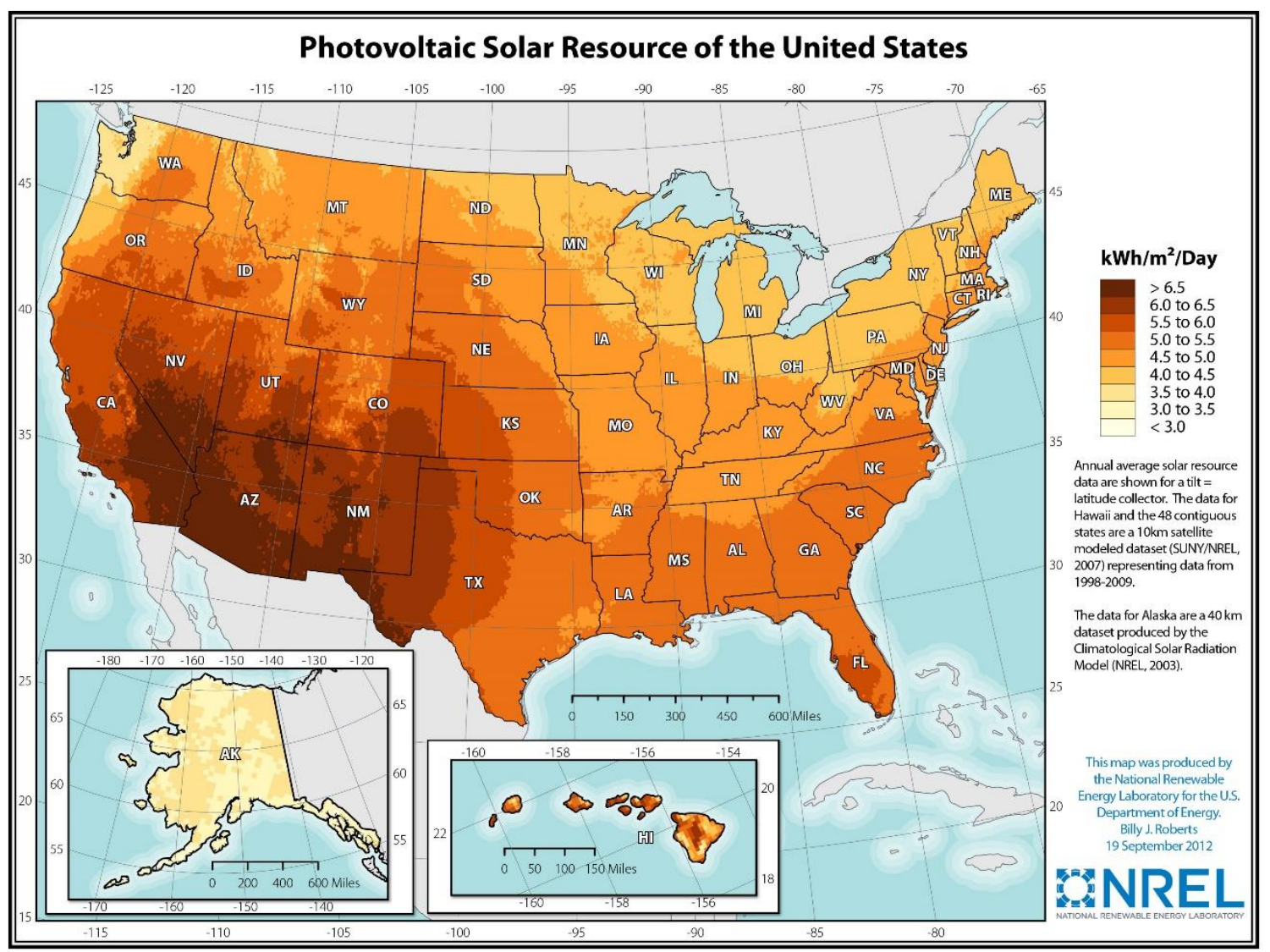

Fig. 1-2 Photovoltaic Solar Resources, USA (www.nrel.gov)

At the present time numerous wind and solar farm projects have been built in Europe and North America, and more projects will be realized in coming years. In a recent study nicknamed as "The $80 \%$ Study", NREL showed the feasibility of producing $80 \%$ of US energy consumption from renewable resources; mainly from wind and solar sources [1]. It is worth mentioning that remote solar farms and offshore wind farms are of particular interest, because if located sufficiently far from the mainland or urban areas they don't lead to allegedly health problems caused by the noise generated by turbines of on-shore wind farms [2]. Nevertheless, apart from alleged health problems, building a large scale wind farm or solar farm in urban areas, which are already suffering from congestion, would be a major challenge. Moreover, 
higher real estate prices in urban areas and city suburbs put another high economic hurdle into the equation.

On the flip side, building a wind farm off the shore, requires reliable means to transfer the electric energy from the farm to the mainland. At a first glance, building HVAC transmission line sounds to be the obvious choice. Engineering knowledge and technology pertinent to transmission of alternating current at high voltages has been around for many decades and all equipment needed to build such a line are commercially available. But, construction of overhead lines is not usually a viable option due to obvious reasons such as obstructing marine lines, costs of constructing water-anchored pylons, harsh environmental conditions, maintenance issues, difficulty in obtaining right of way, and several other regulatory barriers. Therefore, the best solution would be laying submarine cables at sea substrate to evacuate the power from offshore wind farms. In doing so, HVDC proves to be a more efficient method than its rival HVAC. Nonetheless, employing direct current transmission lines led to identification of new challenges and issues that should be solved.

HVDC is considered to be the most efficient way to connect remote offshore energy sources to the grid. Because as mentioned transferring electric energy from such distant sources is typically done by submarine cables. Power cables inherently constitute a large capacitive element between the voltage carrying conductor and grounded sheath or screen of the cable. Fig. 1-3 illustrates a typical power cable used in transmission lines. As depicted, the cable constitutes a main conductor to carry the current, main insulation, semi-conductive layers, a metallic screen which is usually grounded at least at one end, and a jacket. It is obvious that a capacitance forms between the current carrying conductor and the metallic sheath of the cable. The longer the cable, the larger the capacitive element. Therefore, in offshore wind farms where the distance between the generation and point of contact with the grid is in the order of few tens of kilometers, the capacitance is large enough to limit the current carrying capacity of the cable in ac systems. 


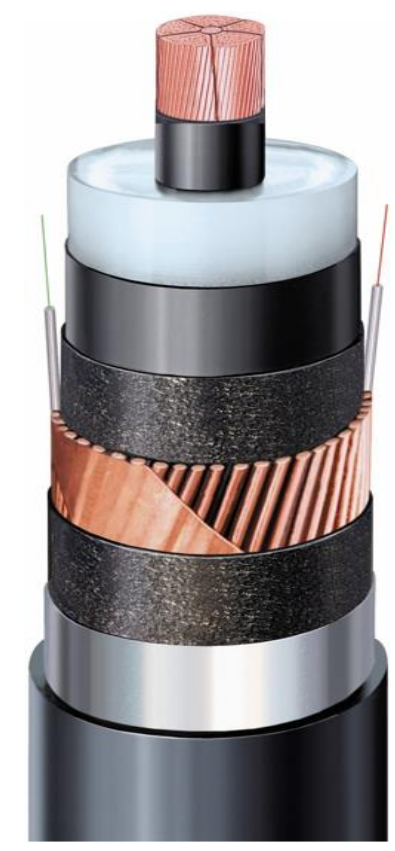

Fig. 1-3 Power Cables Used in HV Transmission Lines

As stated, obviously in ac transmission line, the longer the cable the higher its capacitive charging current which is directly translated into considerable amounts of reactive power. Yet, as this charging current flows through the cable conductor which possesses some resistance, there will be a sharp increase in total system loss, especially for longer lines. In addition, there is another limiting factor, which is called critical length, where the charging current of the cable equals its current carrying capacity or "ampacity". Once the line is longer than the critical length, the cable is not capable of transferring any current other than its own charging current. Therefore, long high voltage cables usually require fixed or variable shunt devices to compensate the reactive power [3]. However, in dc transmission there is no continuous charging current, therefore, theoretically no limit to the length of the transmission cable. Thus, using high voltage dc current is a superior choice to connect energy harvested from offshore wind farm to the grid. Besides the ampacity issues, there is another downside to the use of submarine cables in long HVAC systems. The large capacitance of the cable leads to very low frequency resonances within the system that negatively impacts the stability of the system. 
There have been many notable advancements in HVDC technology, very sophisticated yet more efficient converter topologies are developed and higher power rating semiconductor devices are put out to the market. Especially development of voltage source converters, which are very suitable for connecting sources to the network where the grid is not robust enough has been a very important achievement. Nonetheless, a rugged and reliable circuit breaker topology, which is supposed to be to be the frontline protection device for both submarine transmission line and converter seems to be absent. In this research, existing topologies and solutions, and their features and drawbacks are analyzed and discussed. As all existing topologies whether mechanical, hybrid, or pure solid-state designs rely on surge arresters to absorb line energy during fault clearance, a new topology for hvdc circuit breaker which is based on utilizing solidstate valves and mutual inductance is introduced. The novelty of the proposed design is that it does not require any $\mathrm{ZnO}$ or other type of surge arrester to dump the energy stored in the lump inductance of the system. Instead, the energy is diverted by the mutual inductance to a simple resistor, where the energy is eventually dissipated as heat. Compared to metallic oxide arresters, resistors happen to be safer and much more reliable in operation over the long run.

\subsection{Review of Previous Work}

Most technical research initiatives are aimed at enhancing existing knowledge and developing current technology in some ways. Therefore, identifying existing ideas, conducting a thorough review and critical examination of the literature, and then defining and refining research objectives accordingly are all integral parts of a rigorous scientific research. By the same token, in order to develop a new circuit breaker topology, a comprehensive analysis of existing engineering literature and previous works done by other researchers has been done prior to developing the design proposed in this thesis. In this section, a brief review on offshore wind farm configuration, and then a review and assessment of prevailing approaches to HVDC circuit breaker designs are presented. A more thorough examination of existing breaker designs follow in the next section.

A circuit breaker is basically a protective device that disconnects the power supply from load, or disengages one part of the system from the rest to interrupt flow of electric current in 
case short circuit or overload happens. Various reliable circuit breaker designs for alternating current are developed over the past decades. In most cases the insulating medium is either air, oil, or SF6. The arc that is produced at the time of disconnection is easily controlled and quenched as the alternating current inevitably crosses zero. To the contrary, there is no zerocrossing point in dc current, therefore functioning of a dc circuit breaker is substantially different from ac breaker [4]. Numerous design have been developed to incorporate a momentarily resonating current into the dc current at the time of fault occurrence, hence artificially forming a zero crossing current and making the break less problematic. Circuit breakers either based upon active or passive circuit can utilize this method [5]. However in both cases, the fundamental concept remains the same; using the fault current to stimulate an AC current in a resonant circuit and pushing the DC line current to cross the zero point.

From another perspective, we can classify circuit breakers based upon the type of devices used to interrupt the current. The disconnecting element could be purely mechanical, or solidstate, or even a combination of both; the latter is a topology called hybrid. Obviously, utilizing a mechanical switch lowers the total loss of the circuit breaker in normal operation - closed status - to a virtually negligible amount because the resistance of the metallic contact is almost insignificant. This is the greatest advantage of all mechanical breakers compared to their counter parts that use semiconductor valves, as such valves possess a conduction resistance that is usually in the order of tens of milliohms. When huge amount of energy is to be transferred through the circuit breaker, the negligible conduction resistance of mechanical breakers is the prominent feature that outweighs all other types of circuit breaker designs.

Nevertheless, there are a number of important drawbacks attributed to mechanical breakers in particular in de circuits. For instance accelerated wear of contacts due to absence of zero current crossing, bigger actuator size hence higher mass that should be displaced within few milliseconds [6], higher manufacturing cost of the circuit breaker, need for a much bigger foot print, and finally greater maintenance costs. For applications such as offshore wind farms, wear and tear of equipment which can be translated to lower mean time before failure (MTBF) and shorter mean time to failure (MTTF), and also large foot print are substantial downsides. 
In addition to the above, mechanical breakers like their solid-state counterparts suffer from another significant problem; they lack the capability to absorb the energy stored in the line at the time of disconnecting the circuit. Due to large capacitance and inductance of the transmission line, disconnecting an HVDC line in a very short period of time, say a few millisecond, generates a destructive transient overvoltage that could damage the converter and other elements of the system. Therefore, it is imperative to absorb and damp the energy stored in the line at the time of interruption in a safe way. The most common solution is connecting a surge arrestor between the line and ground. Such surge arresters are made of metal oxides which have a nonlinear voltage-resistance characteristics. This is why they are usually called metal oxide varistors (MOV). As the voltage rises, MOV's resistance sharply drops and bypass the overvoltage spike to the ground.

Needless to say, developing new circuit breakers purely based on semiconductor valves is of high interest specifically for VSC-HVDC transmission systems that are going to connect large scale wind farms to the grid, because a circuit breaker near the dc bus would be much faster than any breaker on ac side, therefore could be the primary protection device [7].

A main challenge in HVDC circuit breaker is absorption of the energy stored in the transmission line once the converter is disconnected from the line [8]. As soon as a short circuit or fault occurs in the system, the current rises rapidly until the breaker disconnects the line from the converter. However, to avoid generation of large values of $\mathrm{di} / \mathrm{dt}$ that could be disastrous to the system, a trade-off between the desired duration of switching time and acceptable values of voltage surge would be necessary [9]. The most common means of limiting the steep rises of $d i / d t$ is inclusion of an inductance in circuit breaker design.

As already indicated various $\mathrm{CB}$ topologies have relied on addition of a resonance circuit to create a counter current forcing the main dc current to cross zero, and also presence of a sure arrester as the energy absorption element. In the proposed topology shown in 4.1., we have used a mutual inductance to steer the energy surge away from the semiconductor switch and dissipate it in a resistive element. A diode is also added to the circuit to bypass any reverse voltage impulse, hence keeping the switching IGBT safeguarded against voltages spikes. 
A full review and analysis of circuit breaker concepts and existing models are presented in chapter two of the thesis.

\subsection{Thesis Objectives}

Existing mechanical and hybrid circuit breakers that are used in hvdc lines, are quite bulky, expensive, and yet unreliable due to wear and tear of mechanical parts. Therefore, many researchers are endeavouring to depart from mechanically based breakers by developing new designs which purely harness solid-state devices. Solid-state breakers provide higher modularity, ease of communication, coordination, and relaying. However, all such designs are using metal oxide varistors as the means to suppress and damp the energy stored in the line. This energy, at the time of current interruption can cause serious damages to the converter or other apparatus installed on the line. Therefore, functionality, safety, and reliability of the converters heavily depends on the metal oxide varistor.

On the other hand, despite the designed life expectancy of surge arresters is $30+$ years, it does not mean that they will be fault free and can be relied on for thirty years [10]. If fact, zinc oxide varistors or surge arresters like many other electrical apparatus have an estimated service life of 100,000 hours, which definitely reduces their applicability in offshore wind farms. The main objective of this thesis is to develop a new topology for HVDC circuit breaker that eliminates use of any mechanical part or MOV. The main objective could be broken down to the followings:

i. Using solid-state valve instead of mechanical switch in circuit breaker topology.

ii. Developing a design that can actuate rapidly in detection and clearance of faults. The goal is having the total operation happen in less than five milliseconds.

iii. From a manufacturing point of view, rolling out a sturdy and simple design, and easy to assemble and maintain, in particular in the harsh environment of offshore wind farms where foot print and weight of equipment are also significant features to be factored in. 
iv. Replacing metal oxide varistors (MOV) with simple non-active elements that have higher life expectancy and higher MTBF and MTTF

v. Verification of the performance of proposed topology using two entirely different simulation scenarios.

\subsection{Thesis Outline}

This thesis consists of six chapters, as follows:

\section{Chapter 1) Introduction.}

This chapter provides a brief review on importance of integrating renewable resources into today's energy production portfolio, and the main motivation for this research. Also, main objectives of the research are clarified.

\section{Chapter 2: Analysis of Existing Circuit Breaker Designs}

A thorough examination of existing HVDC circuit breakers is presented in this chapter, and main advantages and disadvantages of them are analyzed and evaluated.

\section{Chapter 3: Offshore Wind Farms and HVDC Technology}

The reasons for increasing interests in building offshore wind farms and how HVDC technology, and voltage source converters in particular, are related to expansion of offshore wind farms are discussed in this chapter.

\section{Chapter 4: Proposed Circuit Breaker Design}

In this chapter a detailed explanation on proposed novel topology and its key elements and features are presented.

\section{Chapter 5: Simulation Results}


To verify the performance and functionality of the proposed topology, two Simulink models are developed and results are furnished.

Chapter 6: Conclusion

The main conclusions established by this research, its contributions, and also opportunities for further research are maintained. 


\section{Chapter Two: Analysis of Existing Circuit Breaker Designs}

\subsection{Fundamental Concepts}

Circuit breakers are intensively used to interrupt currents in both AC and DC systems. They are the key element in clearing faults, and also disconnecting and removing a faulty apparatus such as a shorted cable or burnt transformer from the grid. Thus circuit breakers allow the electric system continue performing with minimal disturbance and enhance reliability of the grid as a whole. In both switching stations and substations, sectionalizing is achieved by use of disconnecting switches and circuit breakers, which in turn makes fault clearance or maintenance of the system possible without any unnecessary interruption in power delivery. Needless to say, significance of having reliable and durable circuit breakers in the upstream sections of the electric transmission system which operate at higher voltages usually above $69 \mathrm{kV}$, is a key concern. Fig. 2-1 illustrates a typical single line diagram for a small substation. As shown in the figure, numerous circuit breakers are used in this substation to either disconnect, or segregate a part of the system from the rest.

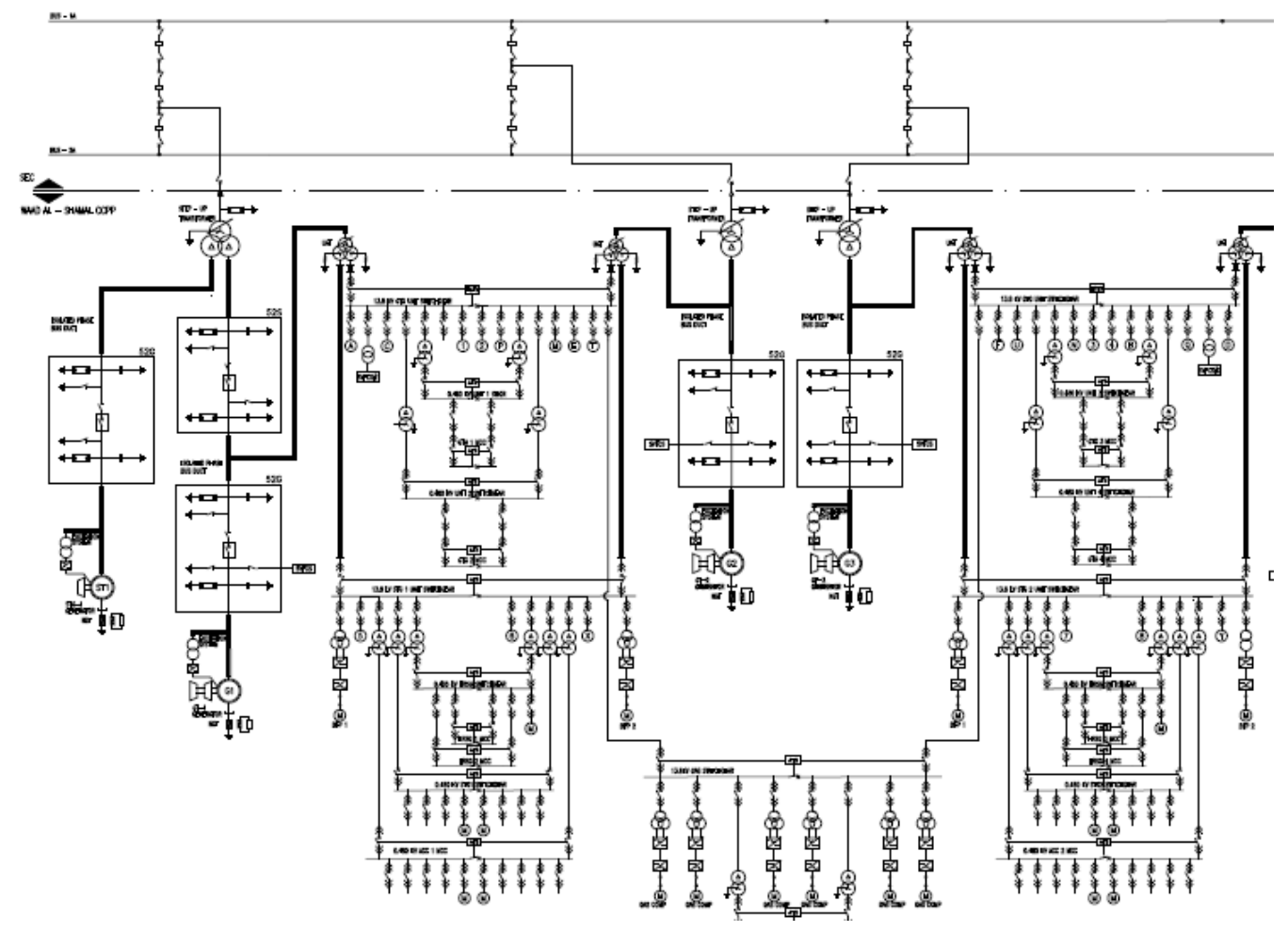

Fig. 2-1 Single line diagram of a typical substation 
Our existing grid is mainly based on production and transmission of alternating current. No wonder that various designs and methodologies have been successfully applied to the development and manufacturing of HVAC circuit breakers, and it is reasonable to conclude that they have delivered a very safe and reliable operation. Unfortunately, this has not been the case for HVDC breakers.

However, as usage of renewable energy sources rises, more HVDC lines are added to the grid. Consequently, traditional approach of controlling the current on the ac side proves quite insufficient and unreliable. HVDC breakers are essential in safeguarding converters which are expensive assets against catastrophic faults and short circuits. Moreover, circuit breakers significantly improve grid reliability by preventing an extensive collapse of the generating stations. Should any fault occurs in any part of the system, the side effects won't propagate to the entire grid. In some cases to improve performance and durability of the system over the long run, a modular hybrid design is used to deliver desired capabilities for both scenarios, full voltage line fault clearance, and lower voltage load breaking. Although what we have discussed is mostly relevant to multi-terminal and interconnected systems, the benefits of having a robust and reliable circuit breaking capabilities are evident in two terminal systems, as they can't either operate safely without implementation of a current interruption device independent from both converter and load.

As larger and more powerful wind farms are envisioned, it will be necessary to harness several converters in parallel to transmit the energy from a single wind farm to the point of contact onshore. Moreover, this will be a valid scenario where future expansions have been considered for a wind farm. Therefore, having parallel converters in both generating stations and substations would be inevitable. In such situations integration of HVDC circuit breakers to ensure system reliability and guaranteeing converter safety is a must. A very fast and responsive breaker is a first line defence against huge fault currents that may bring the system to its knees. If the fault is cleared fast enough, the amplitude of fault current and its damages would be contained, and the ac side of the grid will not experience destructive transients and fluctuations. By the same token, it is necessary to have the circuit breaker as close as possible to the fault location, hence converter's internal protection system wouldn't be an ideal option. 
Finally it is necessary to mention that in case of a converter fault, circuit breaker will protect the transmission line and other parts of the system. In other word, circuit breaker can detect and clear faults regardless of the location, it could be at the load side or even the converter itself. In the latter case, relaying on converter's internal protection to save the system is not an option.

\subsection{Circuit breakers and converters}

It might be argued that converters are always equipped with internal protection systems that keeps them safe against over currents or any fault that occurs outside the converter. Therefore, deploying circuit breakers would be a redundant and superfluous practice, which only adds to the system costs. There are numerous reasons that make utilizing circuit breakers in high voltage transmission lines a necessity. In this section, we shortly review the main rationales.

\subsubsection{Safety and reliability}

Obviously almost all industrial converters are equipped with different protection mechanisms against over current and also short circuit current. So, the reader my wonder why we need additional circuit breakers in the system? There are numerous reasons that relying on circuit breakers and overload relays inside generating stations is not a fail-safe practice. First and foremost is safety. Coming into touch with any energized part or line in high voltage business costs human lives.

Ensuring human safety is a fundamental principle that shall be held paramount in all electrical engineering practices. In high voltage industry, where a simple error could lead to fatal results, making sure that the system is operating safely is much more important. For this reason, while designing high voltage power systems including generating plants, switching stations and substations, numerous safety measures including extensive use of disconnecting switches, breakers, and grounding elements is a common procedure.

In particular, during routine maintenance or replacement of faulty apparatus, it is required to make sure that crew won't be put in danger due to a faulty switch or even operator's error. Therefore, in addition to converter's protection, it is imperative to equip the system with numerous switches and breakers. 


\subsubsection{Fast response}

Once a fault occurs in the transmission system, the faster the fault clearing response the less the amount of fault current and its consequential damages. Therefore, a circuit breaker which is typically closer to the faults in the transmission lines than the converter, would react more quickly. Due to the long connections and cablings between the converter and the main HVDC transmission line in offshore wind farms, it will clearly takes much longer to detect and clear the fault by the converter itself. Moreover, by utilizing sufficient quantity of circuit breakers, the converter's output could be rerouted to other lines. This is specifically important once the fault is of permanent nature which involves time consuming repair operations. In such situations, converter's output will be still available through other connections and transmission lines. As some level of redundancy is taken into account in the design of transmission lines, it would be possible to temporarily evacuate the power of two converters via same line, while the permanently failed element is being replaced or repaired.

\subsubsection{Sectionalizing}

Sectionalizing is the most common practice in power distribution and transmission industry to protect the system from catastrophic fault currents, and also minimizing the time and number of subsystems and consumers who could be affected by the outage resulted from faulty equipment. Moreover, sectionalizing helps manage or completely eliminate the downtime when equipment need repair or replacement. Another common scenario is station expansion, where due to increased demand substation has to be expanded and new equipment installed. This operation shall preferably completed without affecting the system or consumers.

Although a variety of protective equipment and devices are utilized across both transmission and distribution systems, circuit breakers are still the most reliable equipment widely used. Newer designs and improved technologies have enabled state of the art circuit breakers to sense the fault currents at minimum levels when occurring in circuit breaker's protection zone, and interrupt the fault currents very quickly and efficiently. Moreover, benefiting from communication technologies and internet, now circuit breakers can be activated in coordination with both upstream and downstream devices. 
Fig. 2-2 illustrates the typical single line diagram of a single busbar substation which is considered to be a very simple substation designs. Yet, in this basic design, five circuit breakers are included to enhance safety, reliability, and maintainability of the substation.

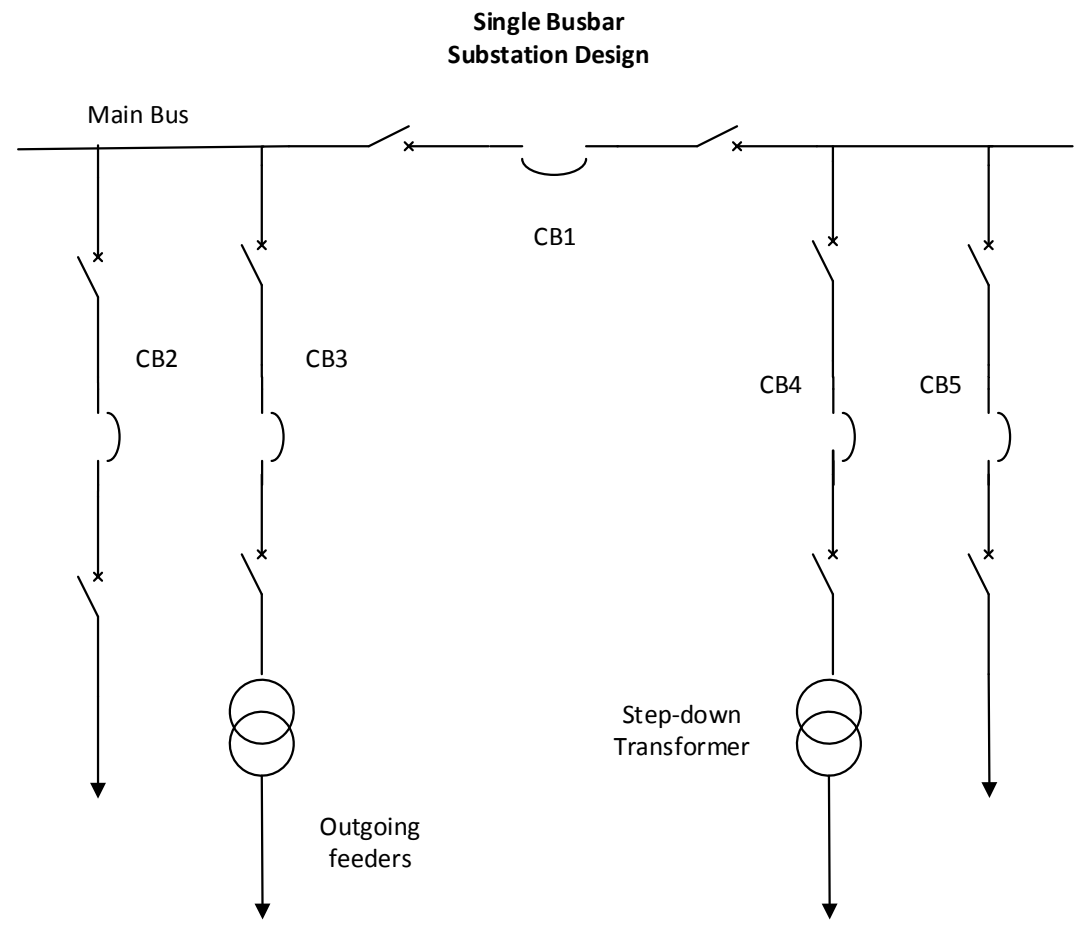

Fig. 2-2 Single busbar substation design

By adding the breakers, it is ensured that

Each and every individual circuit is protected by its own designated circuit breaker. Therefore, occurrence of faults or outages does not necessarily result in a complete system shutdown.

Since substation is equipped with two transformers (a common design) any fault on either of the feeders or their relevant transformers causes the loss of one feeder circuit, which may be restored after isolating and clearing the fault. Therefore, system can be fed via other feeder and its transformer. 
Any repair work or maintenance of a feeder or its relevant equipment such as transformer, disconnect switch, or circuit breaker does not require complete outage of the substation. Meantime, as each feeder or busbar is going through at least one circuit breaker and two disconnect switches, safety and protection of the personnel is guaranteed during maintenance work.

\subsubsection{Reliability in Multi-terminal systems}

In the absence of any circuit breaker to isolate the fault and interrupt the current, the last resort would be relying on converter's control system. Once the converter recognizes a fault resulting in short circuit current, the control system reduces the converter's output current to zero in order to protect the converter and contain any possible damage due to catastrophic fault currents. However, converter's control does so regardless of where the fault happens, therefore, the power flow to the whole system will be interrupted. In a multi terminal configuration, disconnecting the converter because of a segmental or regional fault makes the system very unreliable. However, adding sufficient number of circuit breakers will easily eliminate the problem and increase the reliability. Because a fast breaker would be able to isolate the fault and keep the rest of system functioning with minimum disturbance.

\subsubsection{System Maintenance}

Converters like any other electric device are prone to failure. In the event of converter failure, we cannot count on its integrated overload current to sense and interrupt the current. Therefore, having additional protection equipment, i.e. circuit breaker, is a must. Furthermore, during maintenance period or if the converter needs some repair, there should be other means of disconnecting the converter from the transmission line. Therefore, again, having additional circuit breakers play an inevitable role.

To summarize, there are several reasons proving necessity of utilizing circuit breakers in the transmission system and not solely relying on converter's internal protection. Safety, ensuring rapid response, sectionalizing, enhancing system reliability in multi-terminal systems, and minimizing the downtime during maintenance are among them. 


\subsection{Challenges in HVDC Circuit Breaker Design}

The key issue in dc current is the absence of zero current crossing that occurs twice the line frequency in ac circuits. This fact leads to fundamental differences in the designs and development of dc and ac circuit breakers. Moreover, most HVDC lines and converter systems impart large inductance elements in order to maintain a ripple free and smooth current in the grid. This inductances along with inductance of the transmission line store huge amount of electric energy. Therefore, any sudden abruption in dc current will cause destructive voltage surges that shall be damped in some way. Therefore, almost all HVDC breakers must encompass some means of absorbing significant amount of energy stored in the lump inductance element of the system.

A very fast breaker installed close to the fault point, in this case submarine cables, will significantly reduce the fault current. It also as a buffer protects the ac side from transient shocks. Therefore, it is mandatory to recognize a fault as rapidly as possible and clear it before the converter reacts or in worst case collapses. If VSC is disconnected from the faulty line in a timely manner, it would be able to continue its operation in idling mode, which sometimes is called islanded operation as the converter has to rely on its own reference voltage and frequency. Anyhow, an idling VSC can be reconnected to the grid as soon as the fault is clear.

\begin{tabular}{|l|l|l|}
\hline \multicolumn{2}{||l|}{ Challenges } & Remarks \\
\hline I & $\begin{array}{l}\text { There is no zero crossing point in dc } \\
\text { current. }\end{array}$ & $\begin{array}{l}\text { Current won't reach zero automatically. } \\
\text { Disconnecting the circuit creates huge inductive } \\
\text { current. }\end{array}$ \\
\hline II & $\begin{array}{l}\text { Response time: current interruption in } \\
\text { the event of short circuit shall be very } \\
\text { rapid, in order of few milliseconds. }\end{array}$ & $\begin{array}{l}\text { High } d i / d t \text {, large switching voltage spikes which are } \\
\text { detrimental to valves and other equipment. }\end{array}$ \\
\hline $\begin{array}{l}\text { III } \\
\text { inductance of the system and } \\
\text { transmission line. }\end{array}$ & $\begin{array}{l}\text { Large sure arrestors with capability of absorbing } \\
\text { considerable amount of energy shall be used. Such } \\
\text { ZnO arresters have lower life expectance than } \\
\text { passive element. }\end{array}$ \\
\hline IV & $\begin{array}{l}\text { Solid-state valve are sensitive to } \\
\text { reverse voltages spikes caused by } \\
\text { switching transients. }\end{array}$ & $\begin{array}{l}\text { A subsystem to depress reverse voltage spikes } \\
\text { should be included in the circuit breaker design. }\end{array}$ \\
\hline
\end{tabular}


In the following section, above challenges are analyzed in more details.

\subsubsection{Lack of Zero-crossing Point}

As indicated in contrast with AC systems, DC circuits don't benefit from naturally occurring current zero crossing [11], therefore have to clear the fault under substantially different circumstances. However, one old approach to overcome this problem is to artificially generate a resonant current, hence create a zero current crossing at the time of fault clearance. For instance in some designs a fully charged capacitor bank is discharged in an oscillatory manner at the time of fault occurrence, hence forming a zero crossing. Schematic diagram of such a design is shown in Fig. 2-3 [11].

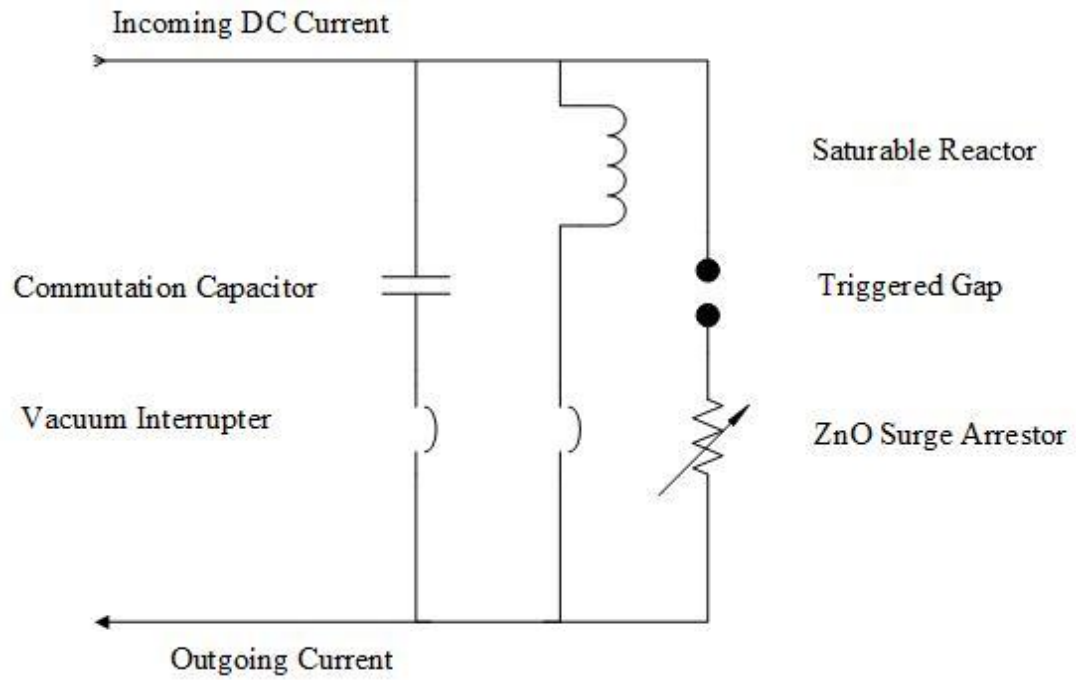

Fig. 2-3 DC circuit breaker with commutation / resonant feature

In this design, the vacuum interrupter functions as the main circuit breaker. In the event of fault occurrence, the breaker opens up and the electric charge stored in the capacitor is discharged to the inductor through the triggered gap. This creates a moment of zero current in the breaker circuit. The inductor helps to maintain the rate of current change $(d i / d t)$ at a controlled level and the R-C circuit regulates the recovery voltage [6]. 
Such breakers and other designs that rely on a resonant circuit for creating a momentarily zero current, mainly utilize $\mathrm{ZnO}$ arresters to absorb the energy stored in the line.

\subsubsection{Response Time and High $d i / d t$}

By the definition, the total response time of a circuit breaker includes the time required for sensing the fault and operating time that clears the fault. Although a fast response time in AC breakers does not impose any substantial structural constraint, the case is entirely different in DC breakers. In most cases, the total response time in the order of few milliseconds is considered fast enough [4]. Higher response times usually reduces the system reliability and also may cause the converter to collapse.

However, the main challenge is that the shorter the response time, the higher the rate of current change, $d i / d t$. In the existing mechanical or hybrid designs, the speed of physical mechanisms of the breaker might be the main limitation. However, in case of solid state breakers, the valves are fast enough to disconnect the current within some tens of microseconds. But the trade-off will be higher voltage spikes to be depressed.

\subsubsection{Energy Absorption}

While clearing the fault at moderate voltages and currents, it might be possible to absorb the whole stored energy by the arc without need for any further parallel circuit or surge arrester [11]. In such cases, the arc must be cooled down and quenched using insulating oil or SF6. Nevertheless, in high voltage and high power circuits it is never sufficient to consider arc as an energy absorbing solution.

The lump inductance of an HVDC system is usually much larger than appears. In addition to current smoothing inductors integrated within the converter, the inductance of the transmission lines, harmonic filters, the circuit breaker itself, commutation reactance (if any), and leakage reactance must be all taken into consideration. Therefore, the circuit breaker must be equipped with some effective means of supressing the line energy. Considering a very simple model, the total energy would be:

$$
\mathrm{E}_{\mathrm{tot}}=1 / 2 \mathrm{~L}_{\text {lump. }} \cdot \mathrm{I}_{\mathrm{sc}}^{2}
$$

Where: 
$\mathrm{E}_{\mathrm{tot}}=$ total energy to be absorbed and suppressed at the time of fault clearance

$\mathrm{L}_{\mathrm{lump}}=$ Lump inductance of the system

$\mathrm{I}_{\mathrm{sc}}=$ Short circuit current

It is important to remember that the faster the response time of the breaker, the smaller the $\mathrm{I}_{\mathrm{sc}}$, as the current can only raise gradually within short-circuit duration $t_{s c}$. On the other hand, the shorter the $t_{s c}$, the higher would be the rate of current change, $d i / d t$, in the course of fault detection and clearance. Therefore some consideration is necessary to optimize the short circuit current duration.

If the total inductance of the system is rather low, the short circuit current raises very quickly which may cause irreversible damages to the converter and transmission system. As indicated existing circuit breaker designs encompass several zinc oxide arresters. In some designs, even three sets of arresters are required to protect the system. Fig. 2-4 illustrates such a design developed by General Electric.

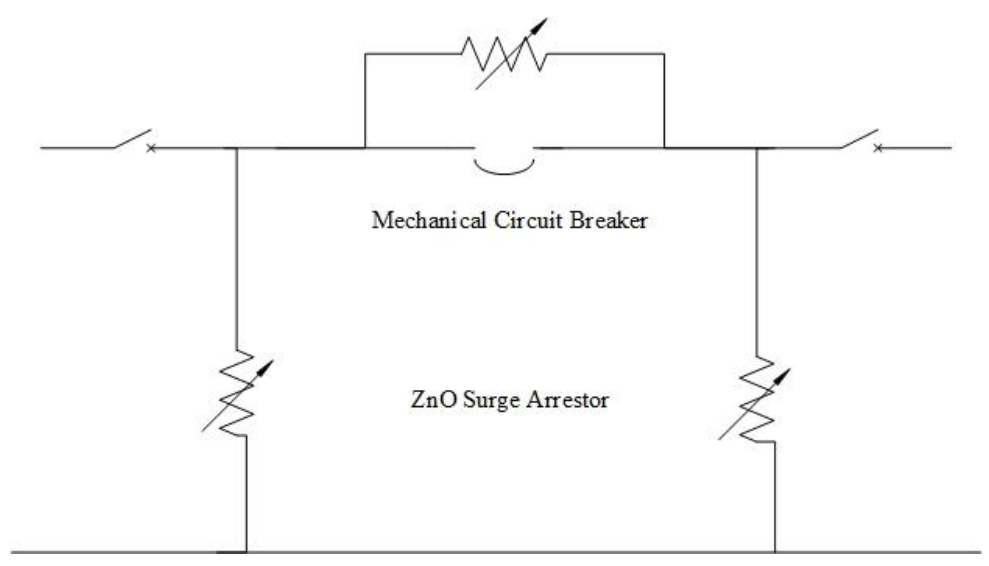

Fig. 2-4 Mechanical circuit breaker with ZnO arresters 


\subsection{Drawbacks of existing circuit breakers}

\subsubsection{Inadequacy of Mechanical Breakers}

Traditional HVDC circuit breakers and newer hybrid breakers both utilize a mechanical breaker to interrupt the main current. Mechanical breakers have been performing quite well in $\mathrm{AC}$ circuits and variety of designs have been developed and presented. In most cases, vacuum, oil, or $\mathrm{SF}_{6}$ is used to control and quench the arc. However, in HVDC technology, the size of mechanical breakers are increased to compensate for not having a naturally occurring zero current. In most designs, the metallic chamber encompassing the breaker weighs several tons. For offshore wind farms, where the footprint, size, and weight of all equipment is a burden, having mechanical beakers is not an ideal option.

In contrast with mechanical breakers, solid-state circuit breakers are much lighter, faster in response, and thanks to modular designs easier to fix and repair.

\subsubsection{Metal Oxide Arresters}

The wide use of zinc oxide arresters in electric transmission system is seems to be inevitable. They are mostly used to suppress and damp voltage surges which may be caused by external phenomena such as lightning, or system related issues such as switching or even faults. Such surges if not controlled and suppressed, travel along the transmission line, generate dangerous dynamic transient over-voltages, hence can damage electrical equipment such as transformers, generators, and even passive elements like bushings and insulators.

In a worst case scenario, such electrical surges may travel a long way and finally encounter a point where the surge impedance of the system or transmission line is intrinsically different. Then, the surge will be refracted and partially reflected backward. This back and forth traveling surge wave continues until eventually total energy of the initial impulse is attenuated over the Ohmic resistance of the distance traveled. Although the whole phenomenon may take a few milliseconds, the voltage stress it imposes on the electrical equipment is considerable. For this reason, most electrical equipment have to undergo an impulse test which is usually defined in standards. For instance power cables designed for a rated voltage of $230 \mathrm{kV}$ shall be able to endure a basic impulse level of $1050 \mathrm{kV}$. 
Although the electrical equipment shall be designed to endure high voltage impulses and transient voltages spikes, the system shall be equipped with some means of suppressing the impulses and surges. And this is why surge arresters, in particular $\mathrm{ZnO}$ arresters, are frequently and generously utilized in transmission system. For instance, in substations arresters are installed at both the entrance of feeders and either side of power transformers.

Due to large lump inductance of HVDC systems, the transient voltage spike generated at the time of fault clearance could be dangerously high. The voltage is basically a result of high rate of current change times the inductance of the system: Ldi/dt. This transient voltage which will be induced across circuit breaker terminals will definitely damages the system components. As mentioned earlier, existing HVDC breakers mainly rely on surge arresters to damp and suppress this inductive transient voltage.
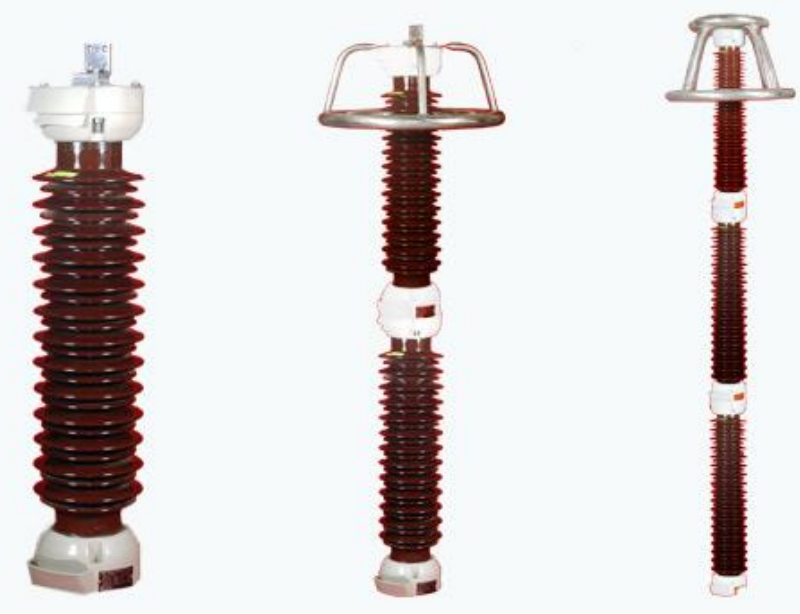

Fig. 2-5 ZnO arresters, porcelain clad, source CG Global website

$\mathrm{A} \mathrm{ZnO}$ arrester is mainly composed of several individual zinc oxide discs. Depending on the operating voltage and the energy to be absorbed, the number of discs and their cross section are calculated. All the discs then are stacked and housed inside a finned cylindrical porcelain or polymer. Since zinc oxide possesses a highly non-uniform current voltage (I - V) characteristics, it acts as a variable resistance whose resistance changes based on the voltage applied across the arrester. At higher voltage levels, the $\mathrm{ZnO}$ becomes less resistive, hence let 
the electrical current pass through it. In electric system, the threshold voltage of arresters is chosen based on the operating voltage. During normal operation, the leakage current is almost negligible, however as soon as the voltage across the surge arrester dramatically increases due to a transient impulse, the zinc oxide turns to conductive and bypasses the surge to the ground.

Yet, zinc oxide arresters have some intrinsic issues, including followings:

- Response time. As the nonlinearity of the material is a response to voltage applied across it, and changes in the micro structure of the material, there is always a time laps between the moment an impulse occurs and the time arrester responds to it.

- Thermal aging problem. The higher the number of surges and impulses, the faster the aging of metal oxide material.

- Sensitivity to ambient environment such as humidity, sun light, salt water (all prevalent in offshore wind farms)

- Possibility of explosion, porcelain housings are prone to explosion, and in case of exploding are very dangerous to adjacent equipment. Fig. 2-7 illustrates a real life photo of a recent incident where a porcelain housing exploded and damaged the adjacent equipment. 
- Discharge residual voltage, after occurrence of each impulse, there is some amount of residual voltage within the zinc oxide material which takes time to fully discharge. Fig. 2-6 illustrates the residual voltage for ABB's EXLIM P surge arresters, which proves that the amount of residual voltage could be quite high for higher current values.

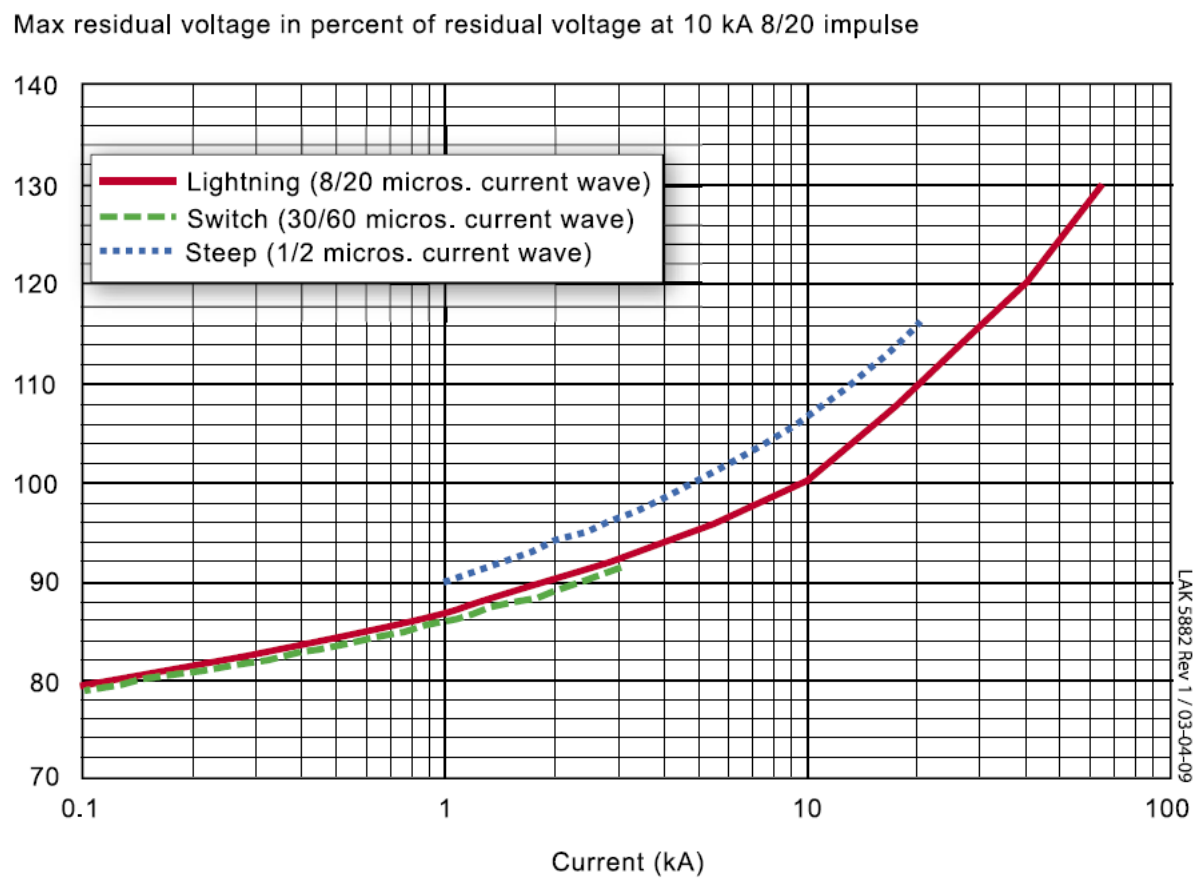

Fig. 2-6 Residual voltage for EXLIM P surge arresters, ABB's product brochure 


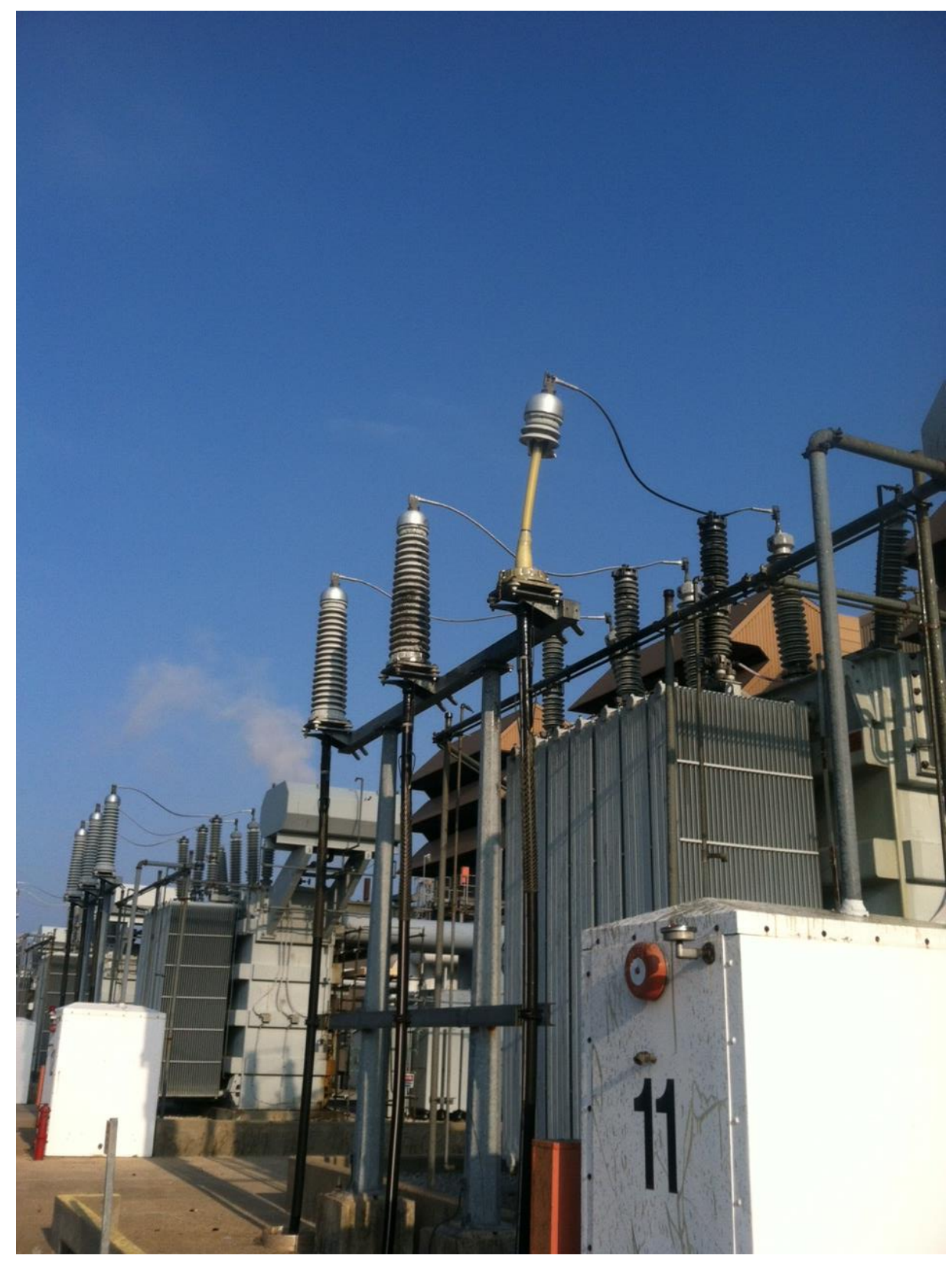

Fig. 2-7 Porcelain housing exploded

Therefore, in our proposed topology we have completely eliminated the need for use of zinc oxide arresters. In our design, we have used passive elements which intrinsically respond instantaneously to any electrical phenomenon. Moreover, passive elements such as resistors, capacitors, and inductors are sturdier and more resistant to harsh environmental conditions. 
It may be argued that instead of absorbing the energy in HVDC circuit breaker or within a $\mathrm{ZnO}$ arrestor, the energy stored in the lump inductance of the system could be fed back to transmission line using a topology similar to buck converters. Fig. 2-8 illustrates such a concept.

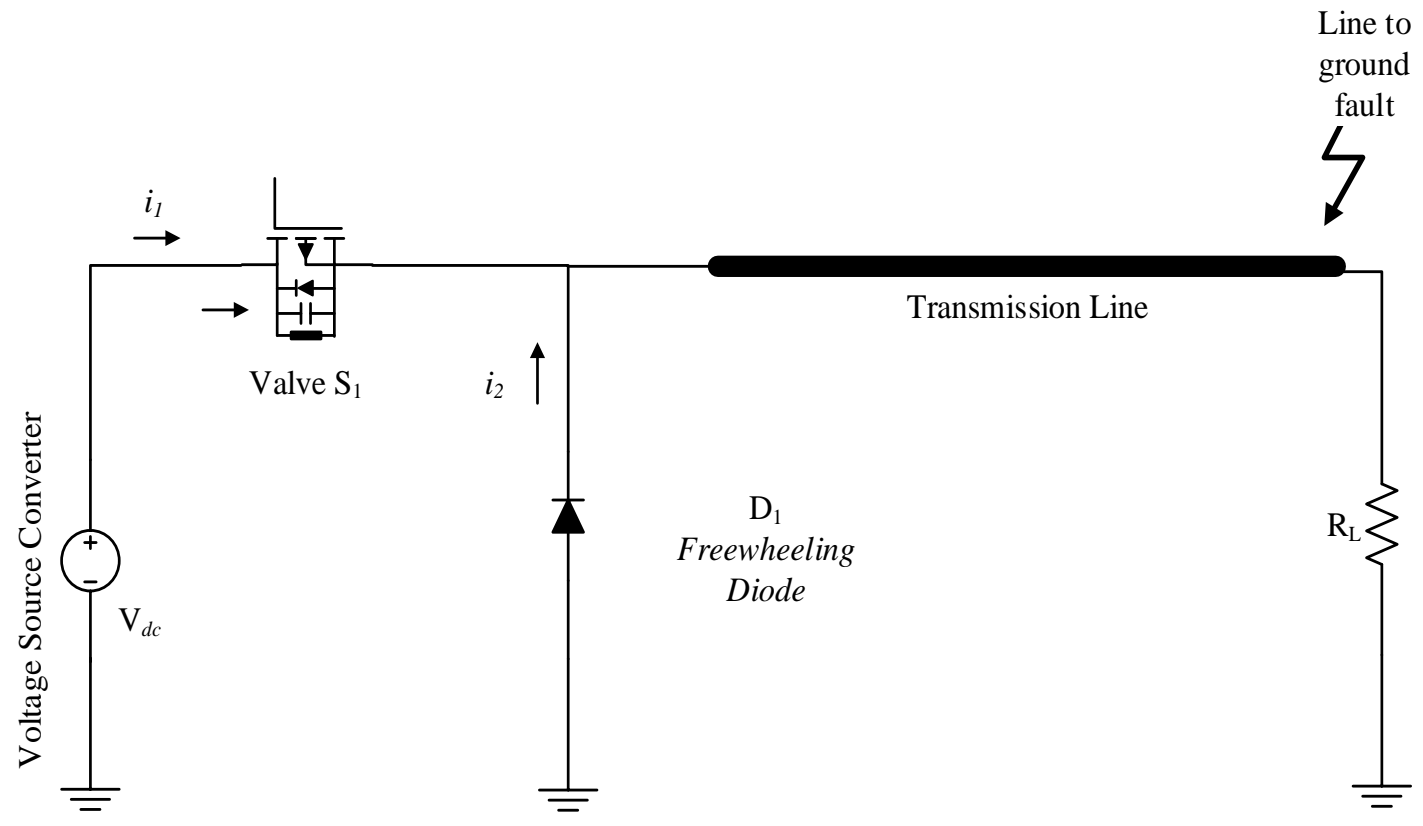

Fig. 2-8 Buck converter concept - delegating fault energy to transmission line

The concept looks deceiving as it utilizes less elements and looks quite simple. As soon as the valve is open, the freewheeling diode $\mathrm{D}_{1}$ starts conducting and the energy stored in the lump inductance of the system is fed into the transmission line. But this topology is not viable for numerous reasons.

First of all, circuit breaker is supposed to isolate and clear the fault on transmission line. Therefore, the fault is supposed to be cleared before the reclosing attempt. Otherwise, the circuit breaker may reconnect the converter to the line, while still some current is flowing in it. A closer examination of the topology reveals that once the valve is open and freewheeling diode is conducting, the system converts to a series LR, inductance-resistance circuit. It is obvious that in the above topology, the energy will continue to flow until it is dissipated by the system resistance. The time will be defined by time constant of system's lump inductance and equivalent resistance of the system which includes transmission line and load. Considering a 
long transmission line, this time constant could be in the order of few tens of millisecond, which is quite unacceptable. It is noteworthy that the goal is to isolate and clear the fault within few milliseconds.

The second issue is that by using a freewheeling diode, we are simply mitigating the risk by forwarding the line energy at the time of short circuit to the system itself, which definitely is not a task expected from a circuit breaker. In this case, the circuit breaker has in fact no control over the duration or the magnitude of the current passing the transmission line.

\subsubsection{MTBF and MTTF}

Mean-Time-Before-Failure and Mean-Time-To-Failure, MTBF and MTTF, are two significant parameters in selecting components and equipment for industrial design. Especially in power industry where the expected design life of power plants or substations is between forty to fifty years, it is of utmost importance to carefully select elements that have a longer performance life.

In offshore wind farms, where the sea rigs are installed far from the mainland, and accessing the equipment for any repair or maintenance would be a great burden, having components which exhibit higher life expectancy is of utmost importance. Both mechanical circuit breakers and zinc oxide surge arresters have much shorter life cycle compared to passive electrical elements and solid state valves, and specifically for $\mathrm{ZnO}$ arresters the higher the varistor current the lower the MTTF [30], as they are dependent.

Therefore, a main goal in our design has been choosing components that lend themselves to high MTBF and MTTF rates. As mentioned in the thesis objectives, we have focused on developing a sturdy yet easy to maintain circuit breaker.

\subsubsection{Opportunity Cost and Repair Downtime}

Yet, another important issue in industry is the concept of opportunity cost. Usually the

opportunity cost due to downtime by far exceeds the cost of repairing or replacing the faulty component. For example, if a wind farm has to be shut down to change a surge arrester, the total 
loss is not the couple of hundred dollars spend on the new arrestor, but the lack of profit as to lost production time.

Furthermore, sea barges and cranes used for installation or repair of offshore wind turbines are very expensive to rent, in the order of couple of hundred thousand dollars per month. Fig. 2-9 illustrates the offshore substation installed for London Array wind farm, and clearly explains the hardship and complicated logistics involved in carrying out any maintenance and repair job at offshore substations. Not surprisingly, the repair cost of any single item on offshore wind farms is heavily affected and influenced by hefty costs of logistics. Therefore, once again in our design we have done our best to utilize components which are proven to be virtually fault and maintenance free.

To summarize, existing topologies fall within three categories: mechanical, hybrid, and solid-state. Mechanical breakers which are basically an extension of their AC counterpart, are quite heavy and massive. The fact that there is no zero-crossing in direct current circuits, makes the manufacturers to utilize larger chamber and contact sizes, and in some cases add additional resonating elements to create an artificial zero-crossing moment at the time of fault isolation. Besides such problems, quenching the electric arc spawned during current interruption and also maintaining the isolation between live and dead parts are other serious issues to be accounted for in the design of mechanical breakers. Common methodologies to solve isolation problem are keeping the live parts in vacuum, or having an insulating medium such as oil or $\mathrm{SF}_{6}$ gas filling the chamber up. In either case, the complexity of breaker increases substantial. Considering what has been said, and wear and tear of parts which is a phenomenon known to all mechanical devices, many designers and manufacturers have welcomed the idea of developing solid-state circuit breaker.

However, solid-state breakers are especially vulnerable to reverse voltage spikes generated at the moment of current disruption. Furthermore, when compared to the mechanical breakers, the total loss of solid-state breakers are much higher during normal operation, that is on state. The reason is that the resistance of the metallic contacts in a traditional circuit breaker is usually in the order of few tens of micro Ohms, whereas the conduction losses of solid-state valves fall 
within the range of tens of milli Ohms. Some manufacturers such as ABB have decided to overcome the loss issue by combining a mechanical breaker with a solid-state valve. Therefore, reducing the conduction losses to negligible amounts by having the mechanical breaker connected in parallel to the solid-state switch. During current interruption, mechanical breaker is actualized before the solid-state valve.

Yet, a common problem that all existing topologies have to overcome is absorption of the energy stored in the lump inductance of the system and transmission line. Particularly, when the HVDC line is fed by a voltage source converter, the problem of energy absorption will be of high importance. Voltage source converters, although are the better choice for connecting the wind farms to the grid, are defenceless against short circuit currents. Anti-parallel diodes integrated with solid-state switches form a shorted pass for DC current that flows back to the converter. Once the huge amount of energy stored in the system flows back to the converter, the consequences could be disastrous and even may cause the converter to burn out.

The most common remedy for absorbing surge of energy at higher voltages, is adding a surge arrester in parallel to the system. Metallic oxide arresters, and specifically $\mathrm{ZnO}$ arresters are commercially available and used liberally in both AC and DC circuits. Nevertheless, ZnO arresters have certain drawbacks including: inherent time delay to respond to any surge as molecular structure of the metal oxide needs time to change in response to high electric field, residual voltage after every surge, aging, being nonresponsive to current surges as its nonlinear resistance reacts to voltage only. Proper functioning of a surge arrester is also dependent on its location and distance from the equipment. Yet, the last flaw, although very rare, could be the most catastrophic one. Regardless of the reason, surge arresters may explode which causes unrepairable damage to adjacent equipment. If the equipment is installed on an offshore deck, then the time and cost of replacing damages items would be colossal.

Therefore, in developing the new design, it was decided that no mechanical breaker or switch should be utilized. When properly designed, a circuit breaker purely based on solid-state valves has a higher MTBT and MTTF rates compared to mechanical breakers. Modularity and ease of controlling, coordination, and signal relaying are also important facets in favor of solid-state breakers. 


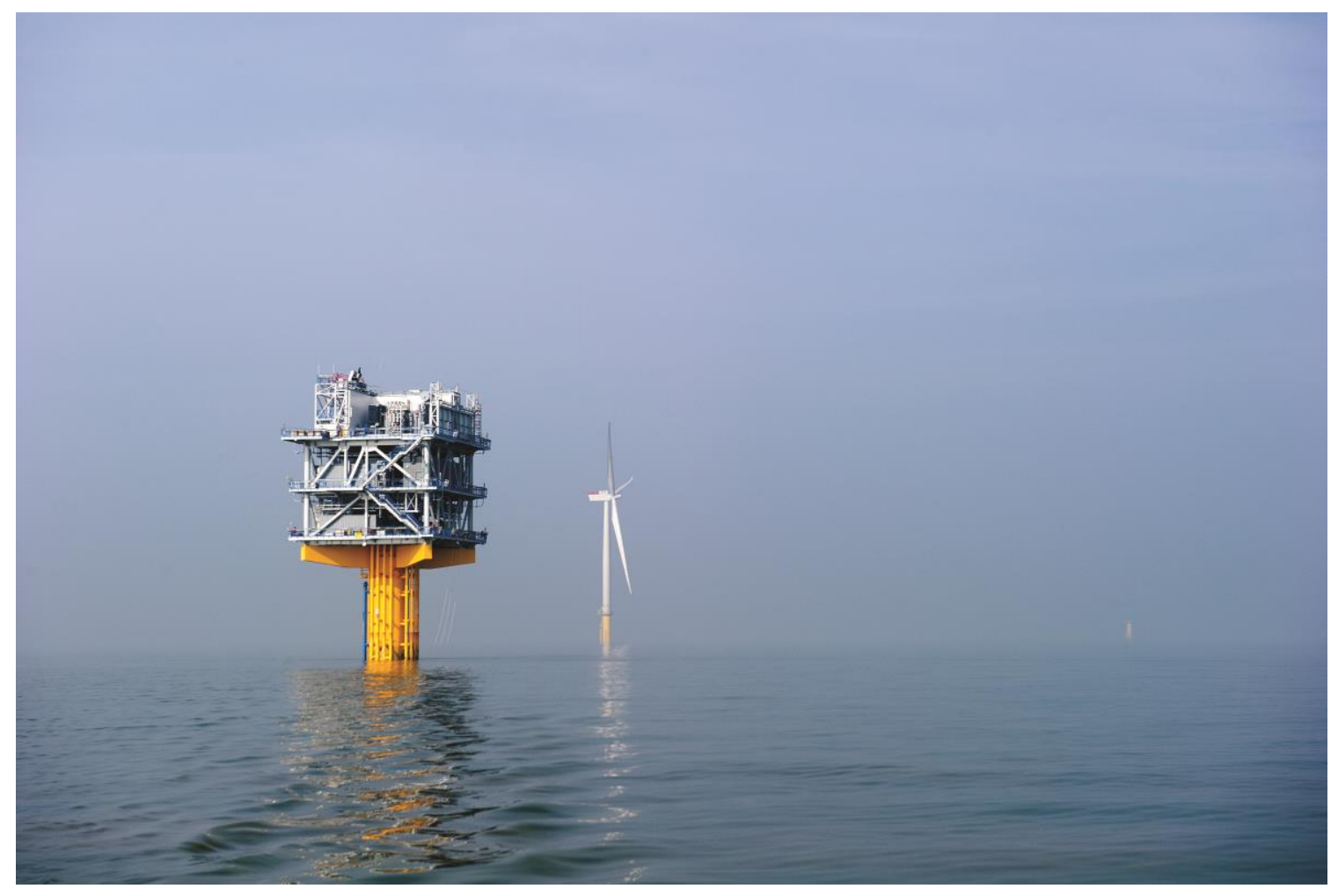

Fig. 2-9 London Array offshore substation (source londonarray.com) 


\section{Chapter Three: Offshore Wind Farms and HVDC Technology}

In this section we will review the underlying motivations to move toward construction of offshore wind farm instead of onshore, and also assess the key reasons for choosing HVDC technology over HVAC for transferring the energy from offshore to the mainland.

As explained in the first chapter, offshore wind farms are gaining more interests due to alleged health concerns associated with onshore farms. Moreover, some social activists and environmentalists oppose to building new wind farms on mainland because they jeopardize the existing ecosystem and wildlife. They argue although building offshore wind farms are more expensive that their onshore counterparts, human should go the extra mile to protect the environment. In fact, they consider a more comprehensive cost-benefit analysis which cannot be not reduced to pure economic parameters.

From this perspective, most valuable benefit of keeping the land intact and instead extracting energy from offshore would be protection of environment and the wildlife. Since offshore technology was pioneered in Europe, environmental concerns and issues have been extensively studied for years and several recommendations and polices are developed. For instance Stockholm Declaration dated September 15, 2008 indicates that generating energy from offshore may have little negative impact on environment, and yet develops some recommendations for successful utilization of the potential offshore energy. Such studies led to developing some regulatory frame works and permitting process in Europe. Although offshore wind farm industry in North America is behind Europe, the outcome of environmental studies would be similar to those of Europe.

In fact U.S. Department of the Interior - Minerals Management Service, disseminated a report by the name of "Programmatic Environmental Impact Statement for Alternative Energy Development and Production and Alternate Use of Facilities on the Outer Continental Shelf' Final Environmental Impact Statement, Volume II, Chapter 5, dated October 2007, which 
confirms that environmental impacts would be negligible to moderate. Therefore, it is expected that more renewable energy projects will swing from onshore to offshore.

Yet, beside the environmental and ecological factors, there are some economic and political motivations to build offshore wind farms. For instance, lower dependence on other sources of energy carriers which are usually of foreign origin, creating jobs, enhancing grid security, ensuring lower energy prices by diversifying the energy sources are among them.

\subsection{Offshore wind farm configuration}

Wind farms usually consist tens of individual wind turbines connected to a collecting substation. The substation then raises the voltage to transmission levels which is typically above $69 \mathrm{kV}$. In case of offshore farms, the distance between the collecting substation and grid connection point could be tens of kilometers. Fig. 3-1 illustrates a schematic diagram of an offshore wind farm. Typically each wind farm consists of several wind turbine generators (WTG) which are connected to a collecting station by medium voltage cables. Voltage is then raised to higher levels by step-up transformer, which feeds the converter. Fig. 3-1 shows London Array's wind farm installed in Kent, UK, and Fig. 3-2 illustrates the schematic diagram connecting offshore wind farms to the grid.

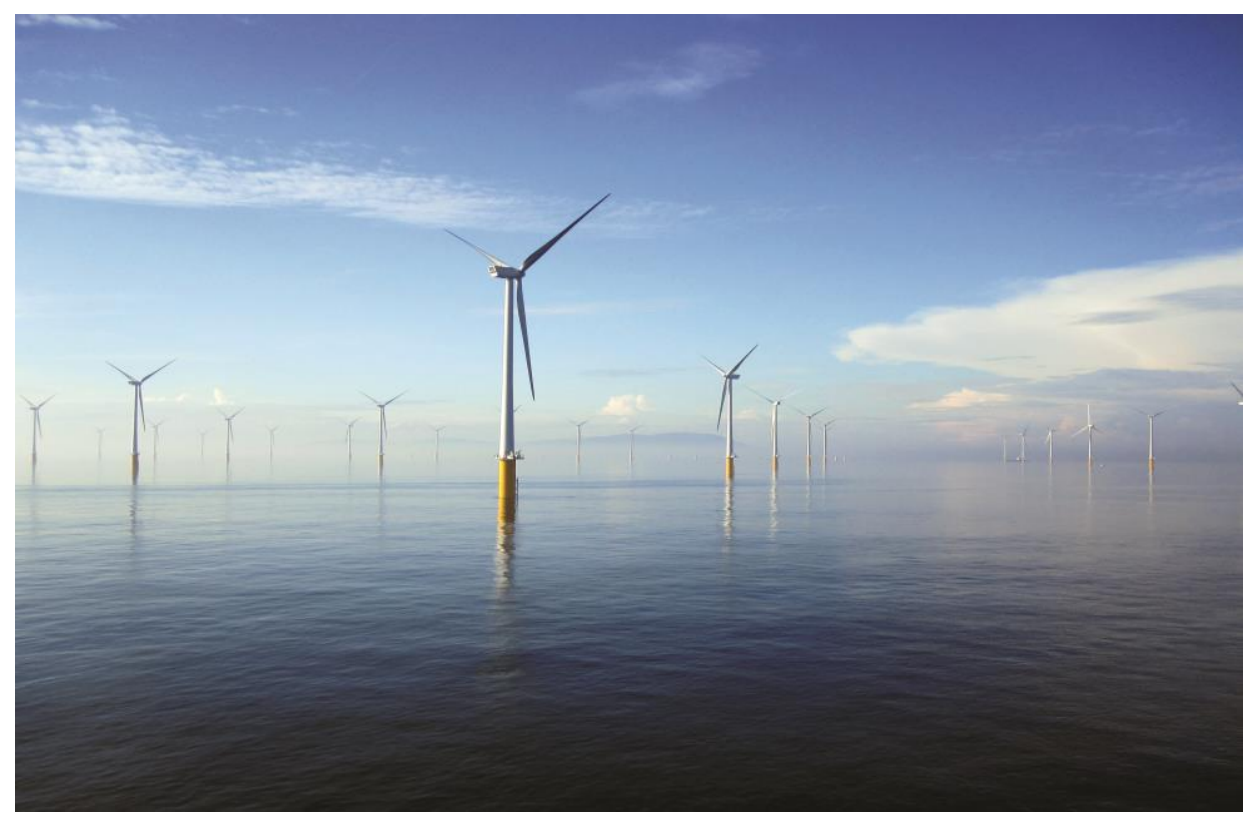

Fig. 3-1 London Array offshore wind farm (source: londonarray.com) 
In A larger scale, several offshore farms can be interconnected together, and then the energy generated by a couple of farms transmitted by one large substation to the main land. In this case the transmission line will perform like a multi-terminal system.

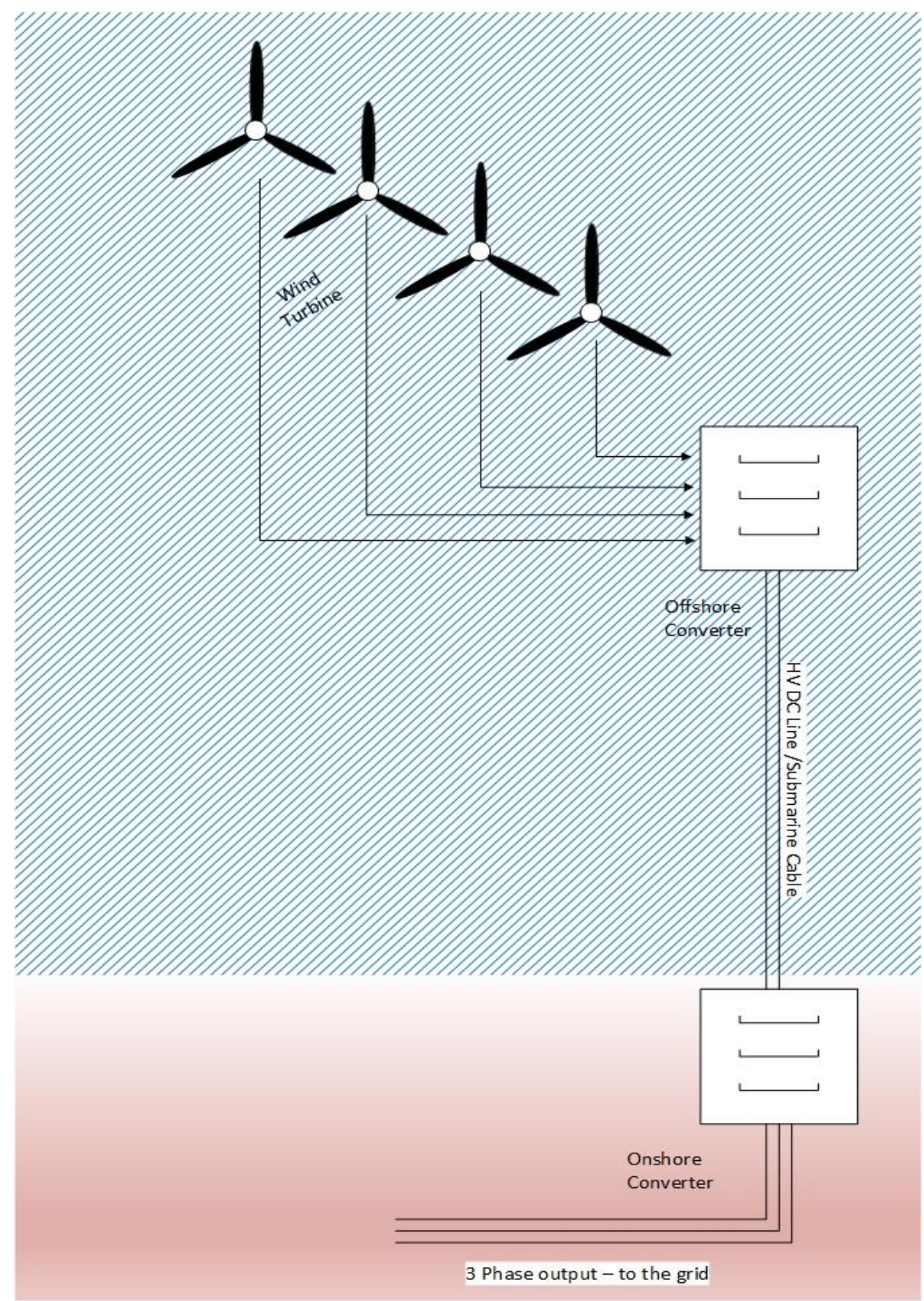

Fig. 3-2 Schematic diagram of an offshore wind farm 


\subsection{Advantages of utilizing HVDC}

Obviously HVAC can be used to evacuate the power from wind farm. However, since the energy transfer is done by submarine cables, HVDC is considered to be the most efficient way as it does not suffer from losses generated due to capacitive charging and discharging of the cable. Power cables inherently constitute a large capacitive element between the voltage carrying conductor and grounded sheath or screen of the cable. Obviously in ac transmission line, the longer the cable the higher its capacitive charging current. As this charging current flows through the cable conductor which possesses some resistance, there will be a sharp increase in total system loss, especially for longer lines. Also the large capacitance of the cable produces huge amounts of reactive power, and leads to instability problems due to very low resonance frequencies.

In addition, there is another limiting factor, which is called critical length, where the charging current of the cable equals its current carrying capacity or "ampacity". Once the line is longer than the critical length, the cable is not capable of transferring any current other than its own charging current. Therefore, long high voltage cables usually require fixed or variable shunt devices to compensate the reactive power [3]. However, in dc transmission there is no continuous charging current, therefore, theoretically no limit to the length of the transmission cable.

Another interesting aspect of using an HVDC link to connect the wind turbine generators (WTG) to the main grid is creating a buffer against detrimental electric transients. Such transients can dramatically increase the level of stress on turbine generators, if connected via conventional HVAC lines. But, the HVDC link eliminates such stresses by isolating the two ac systems at either end from each other. Thus, using high voltage dc current is a superior choice to connect energy harvested from offshore wind farm to the grid.

\subsection{Applications of Voltage Source Converters in Renewable Energy}

To convert ac to dc and vice versa, the self-commutated voltage source converters that generate a stiff dc voltage [12] seem to be the superior choice for remote medium power sources which are connected to weak ac transmission lines with low short circuit ratings. Because, 
performance of a current source converter, which is also called line commutated converter (LCC) relies heavily on the robustness of the ac grid. If the ac grid is not sufficiently strong, valve commutation may not take place, an issue known as commutation failure [13]. On the contrary, in voltage source converters, commutation of switches is not dependent on grid voltage and frequency. Moreover, controlling the flow of energy is much more convenient in voltage source converters as they inherently enjoy the voltage controlling capability that CSCs lack. Furthermore, VSCs require smaller ac filters due to higher switching frequencies.

Voltage Source Converters basically converts a dc voltage to a controlled multi-phase variable frequency source or vice versa. As output frequency of the voltage source converter is independent from the grid, it is an ideal solution for connecting networks with different power frequencies. Hence, the output of a wind farm could be easily converted to HVDC, and then get connected to two separate grids with different voltages. Such a scheme prove beneficial in case a wind farm is constructed as a joint venture by two different countries. Itaipu Hydro Power Plant which is jointly built by Brazil and Paraguay is a nice example of such collective effort.

Furthermore, in some cases adding an HVDC line driven by voltage source converter in parallel to an AC system substantially improves the dynamic stability of the local AC network [19].The main reason lies in the structural differences between current source converters that rely on the network to commute, and voltage source converters that easily control the amount of both active and passive power fed into the grid. Moreover, voltage source converters benefit from wide variety of controlling schemes such as vector control that allows them to regulate active and reactive power independently.

On a different note, it should be borne in mind that the impact of wind farm generation on the grid is also a growing concern. Therefore, many national and international regulatory bodies have set stricter criteria for operation of wind farms [27, 28].For instance ride-through of voltage dips, response time, no contribution to short circuit current levels, and capability of mirroring the grid frequency are common expectations to be met by wind farm generating stations. Voltage source converters can deliver a fully controllable output, whose frequency, amplitude, and phase can be almost instantaneously altered to meet grid requirements. Such flexibility and 
controllability is far beyond reach using conventional current source converters, let alone HVAC systems.

To summarize, voltage source converters are far more efficient and yield much more operational flexibility in connecting remotely located renewable sources of energy such as offshore wind farms or photovoltaic farms to the grid. Their inherent capability to control the voltage, frequency, power flow, active and reactive power regardless of grid robustness makes them the superior choice to evacuate the power from offshore wind farms. Lessening transient disturbances, making restoration of power to a black network easier, and reduction of flickering are also other advantageous characteristics of HVDC systems that utilize voltage source converters. In fact, connecting the wind farm power plants to the grid by HVDC increases the stability of the entire system and even improves the power quality, and availability. Table 3-1 captures the main advantages of employing HVDC over HVAC for offshore wind farms.

\begin{tabular}{|c|c|c|}
\hline \multicolumn{3}{|c|}{ Advantages of Using HVDC over HVAC } \\
\hline 1 & Controllability & $\begin{array}{l}\text { Voltage, frequency, and phase, hence both active and reactive power } \\
\text { flow can be controlled independently. }\end{array}$ \\
\hline 2 & $\begin{array}{l}\text { Long distance } \\
\text { connections }\end{array}$ & $\begin{array}{l}\text { Submarine cables have large capacitive characteristics, hence not } \\
\text { suitable for HVAC due to large reactive power, reduced ampacity, } \\
\text { and destabilizing the network due to low resonances. HVDC } \\
\text { eliminates all these problems. }\end{array}$ \\
\hline 3 & $\begin{array}{l}\text { Connecting } \\
\text { asynchronous grids }\end{array}$ & $\begin{array}{l}\text { To connect two AC systems, they should be synchronized; requiring } \\
\text { same voltage levels and frequencies. HVDC is capable to connect } \\
\text { AC systems that are not synchronous. }\end{array}$ \\
\hline 4 & $\begin{array}{l}\text { Low short circuit } \\
\text { currents }\end{array}$ & $\begin{array}{l}\text { An HVDC system does not contribute to the short circuit current of } \\
\text { the AC system. Therefore, no need for upsizing or replacing } \\
\text { existing equipment such as circuit breakers. }\end{array}$ \\
\hline 5 & Stabilizing AC grid & An HVDC system improves the stability of the AC grid. \\
\hline 6 & $\begin{array}{l}\text { Improving power } \\
\text { quality }\end{array}$ & $\begin{array}{l}\text { Inherent controllability of VSC based HVDC system improves the } \\
\text { power quality and performance of AC grid. Reduced flickering, } \\
\text { compensating reactive power, damping of power swings in the grid, } \\
\text { are among the key benefits of HVDC. }\end{array}$ \\
\hline 7 & Reducing losses & $\begin{array}{l}\text { HVDC generates no reactive power in submarine cables, hence } \\
\text { copper losses of the long transmission line reduces substantially. }\end{array}$ \\
\hline
\end{tabular}




\subsection{Vulnerability of Voltage Source Converters against External Faults}

Voltage source converters (VCC) regardless of their design and control scheme are usually built modular based upon simple leg constructions. Output frequency and voltage of the converter is determined by modulation frequency and index. Basically by employing pulse width modulation, the amplitude and phase of the output voltage can be controlled independently from the grid, hence allowing to control the flow of both active and reactive power. Voltage source converters with pulse width modulation can be considered as zero-inertia motor or generator, as they are almost capable to instantaneously control both active and reactive power [30].

Although the basic modulation method for voltage source converters is PWM, several modulation schemes such as space vector modulation (SVM), alternative phase opposition disposition (APOD), phase-shifted carrier (PSC), etc. have been developed for better control of VSCs. Many of these new techniques, led to significant reduction of total harmonic distortion (THD) of the output current. In addition to modulation scheme, number of voltage levels that the converter deploys has a great impact on the quality of output current and voltage. Nevertheless, a two-level, three-level, or four-level converter could be analyzed using the simple schematic Fig. 3-3 which illustrate a basic two-level voltage source inverter that is only consisted of three legs. As shown, converter comprises two groups of active switches or valves whose gate signals are complementary. However, the key issue is that all the switches are equipped with an anti-parallel diode, which conducts the current in the reverse direction.

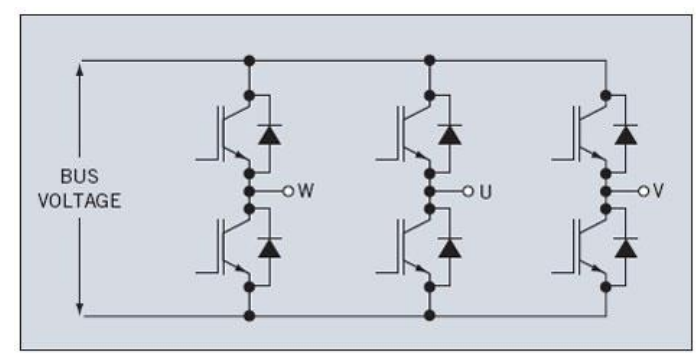

Fig. 3-3 Solid-state valves and anti-parallel diodes - three phase system 
In high power applications, such as transferring the energy from offshore wind farms or solar farms, multilevel VSCs are preferred to two level converters. The main advantage of multilevel converter is delivering staircase waveform quality which significantly reduces output voltage distortion, as shown in Fig. 3-4. Moreover, multilevel converters allow the solid-valves to operate at substantially lowers $d v / d t$ rates, and have lower common-mode (CM) voltages compared to traditional two level topology. Consequently output current of such converters impart less THD and readily meet both national and international standards such as IEEE 519 and IEC 61000 with regard to harmonic levels fed into the grid.

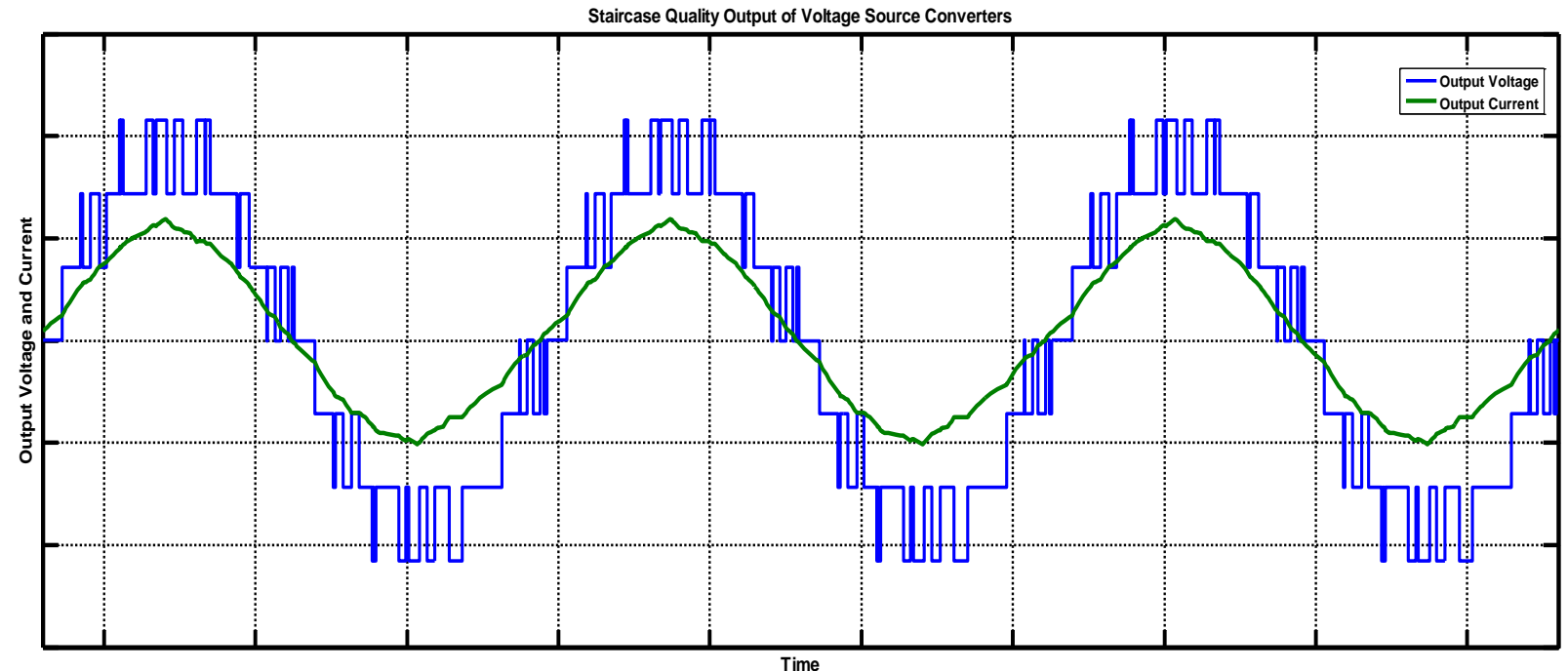

Fig. 3-4 Staircase quality output of voltage source converters 
Nevertheless, as mentioned, the construction of voltage source converters and their working principle requires integration of anti-parallel diodes with switches. This diodes create a pass for reverse current when the corresponding switch is off, yet the phase current is still flowing. Ironically, existence of anti-parallel diodes makes the voltage source converters very vulnerable against external fault currents.

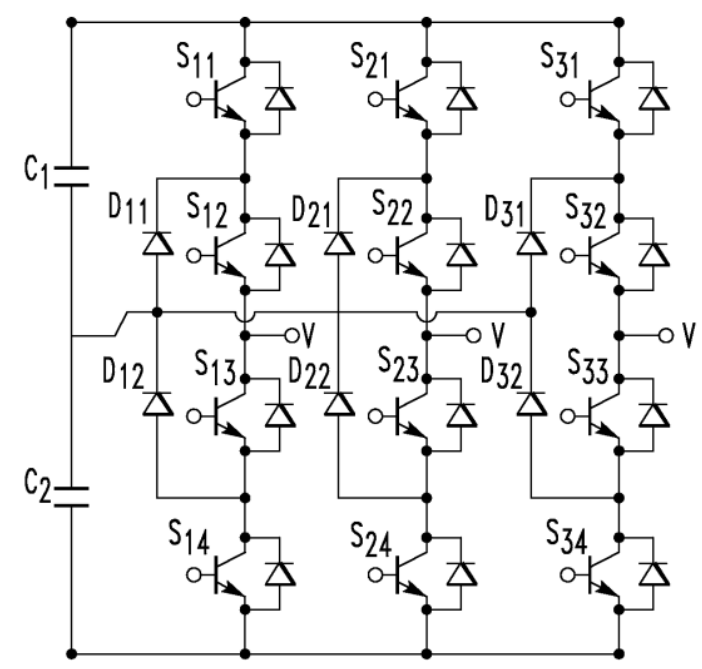

Fig. 3-5 Multilevel converter and anti-parallel diodes

In practice, when a short circuit current happens, the energy stored in the lump inductance of the system can flow back toward the converter which in turn leads to serious damages. This is way in contrast with current source converters, voltage source converters are very vulnerable against short circuit currents. Considering this inherent drawback of voltage source converters, and other criteria making use of circuit breakers necessary in the grid, the motivation for this research is once again obvious. 


\section{Chapter Four: Proposed Circuit Breaker Design}

As there is no zero-crossing point in dc current, the functioning of a dc circuit breaker is substantially different from ac breaker [4]. Various topologies have been developed which are mainly based on either utilizing solid-state devices or a combination of solid-state switches and mechanical switches, the latter a topology called hybrid. Utilizing a mechanical switch lowers the total losses of the circuit breaker in normal operation to a negligible amount. Yet, there are some important drawbacks including total cost of the circuit breaker, needing a much bigger foot print, and quite higher maintenance costs. Nevertheless, the main task of a reliable circuit breaker would still be fast handling of the fault, in order to protect the converter.

Reaction time of the breaker is a very important feature. If the breaker is capable of disconnecting the system in a very short period of time, i.e. few millisecond, converter would be able to continue its operation and remain ready to energize the line as soon as the fault is cleared [8]. Therefore, in developing a solid-state circuit breaker fast reaction along with some other features would be quite essential. To summarize, the design goals are recognizing and isolating faults within few milliseconds; fast enough to keep the converter running and restore the connection after fault clearance. A response time less than 5 milliseconds sounds to be sufficient [4]. having very low loss, compared to total converter losses, hence eliminating the mechanical switch capability to tolerate short circuit currents in the order of few kilo amperes, i.e. $5 \mathrm{kA}$. And finally proving high reliability, compactness and economical

As already explained in pervious chapter, a main challenge in HVDC circuit breaker is absorption of the energy stored in transmission line. As soon as a short circuit occurs in the system, the current rises rapidly until the breaker disconnects the line from the converter. However, to avoid generation of large values of $d i / d t$ that could be disastrous to the system, a trade-off between the switching time and acceptable values of voltage surge would be necessary.

Many topologies have relied on a resonance circuit to create a counter current forcing the main dc current to cross zero, and also using a sure arrester as the energy absorption element. In the proposed topology shown in Fig. 4-1, we have used a mutual inductance to steer the energy surge away from the semiconductor switch and dissipating the energy in a resistive 
element. A diode is also added to the circuit to bypass any reverse voltage impulse, hence keeping the switching IGBT safe from voltages spikes.

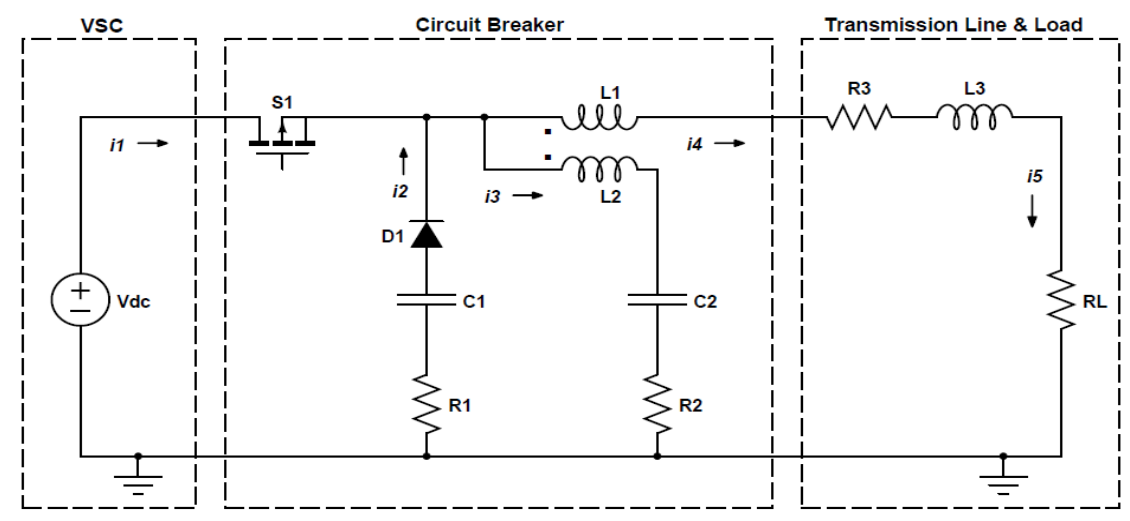

Fig. 4-1 Schematic diagram of the proposed circuit breaker design

Fig. 4-1 depicts the basic topology of the circuit breaker. $V_{\mathrm{dc}}$ represents the voltage source converter that transfers the energy to the load via submarine high voltage dc cables. The breaker contains $S_{1}, D_{1}$, mutual inductance $L_{1}-L_{2}, R_{1}, R_{2}$, and finally $C_{1}$ and $C_{2}$. On the right hand side, $\mathrm{L}_{3}$ is the total inductance value consisting both line and load inductances. $\mathrm{R}_{3}$ represents the dc resistance of the power cable connecting the VSC to the load, and RL is the load resistance at steady state.

In the following section we review the building blocks of the proposed topology and analyze its performance. First we will look into construction and key elements of the circuit breaker.

\subsection{Structural Analysis of the Circuit Breaker}

First we look into the key elements used in the proposed topology and their functions. As the circuit breaker is a solid-state equipment, no mechanical breaker or interrupter exists in its construction, which is a big advantage due to ensuring much smaller foot print, sturdier design, faster response, and easier to replace and maintain. In this topology, we have deployed a high power IGBT as the main switching valve. Depending on the rated voltage and current of the circuit breaker several IGBT banks may be used in series or parallel. 


\subsubsection{Switching Valve}

An IGBT, $\mathrm{S}_{1}$, is used to control the converter's outgoing dc current to the load. As already explained the main difference between mechanical, hybrid, and solid-state circuit breaker designs lies in the choice of switch technology. In topology, no mechanical switch is included as the main or parallel current path, hence it is solely the responsibility of a solid-state valve to make or break the current. Consequently selection of the right valve for safe and reliable operation of the circuit breaker would be crucial.

As illustrated in Fig. 4-2, during normal operation IGBT is on and except for conduction losses of $\mathrm{S}_{1}$ and resistive losses of $\mathrm{L}_{1}$, circuit breaker has no effect on the flow of energy. However, the basic assumption is that $\mathrm{V}_{\mathrm{dc}}$ is an ideal source without any voltage ripple, otherwise, the mutual inductance $\mathrm{L}_{1}-\mathrm{L}_{2}$ and the branch $\mathrm{C}_{2}-\mathrm{R}_{2}$ will perform as a ripple steering configuration. To minimize the losses during normal opétation and increase overall efficiency of the system, several IGBT packs can be used in parallel, and also a higher conductor cross section could be selected for $L_{1}$ winding. Although $L_{2}$ has the same number of turns as $L_{1}$, since no current passes through $\mathrm{L}_{2}$ when the circuit breaker is on, the conductor cross section of $\mathrm{L}_{2}$ could be much smaller than $\mathrm{L}_{1}$.

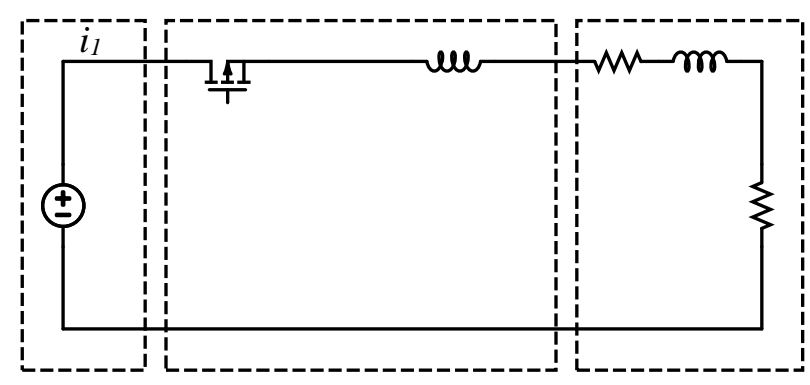

Fig. 4-2 Circuit breaker during normal operation

After detection of the fault, the switch is turned off and removes the load and transmission line from the converter output. However, disconnecting the load over a short period of time means a very high $d i / d t$ ratio, which in turn creates a destructive reverse voltage spike. Moreover, we need to suppress the energy stored in the lump inductance of the line and load, $\mathrm{L}_{3}$, in a method that keeps the IGBT safe and unaffected. 
The total energy that is stored in the inductances of the system and should be absorbed at the time of switching, depends on the level of short-circuit current that trips the circuit breaker. In the very moment before opening the switch, the energy would be:

$$
\mathrm{W}=\frac{L \cdot i s c^{2}}{2}
$$

Where $\mathrm{L}$ is the sum of $\mathrm{L}_{1}$ and $\mathrm{L}_{3}$, and isc is the short circuit current at the time of switching the IGBT off. Considering a short circuit current of $5 \mathrm{kA}, 2 \mathrm{mH}$ for $\mathrm{L}_{1}$ and $20 \mathrm{mH}$ for $\mathrm{L}_{3}$, the total energy stored in the system would be $275 \mathrm{~kJ}$. This amount of energy can easily destroy the IGBTs that constitute $\mathrm{S}_{1}$. In most topologies, $\mathrm{ZnO}$ surge arresters that exhibit very nonlinear voltage-resistance characteristics are used to absorb the overvoltage surges and spikes caused by switching. However, surge arresters are expensive devices that require some regular maintenance. Conversely, simpler elements like resistors and capacitors are less expensive and demand less maintenance.

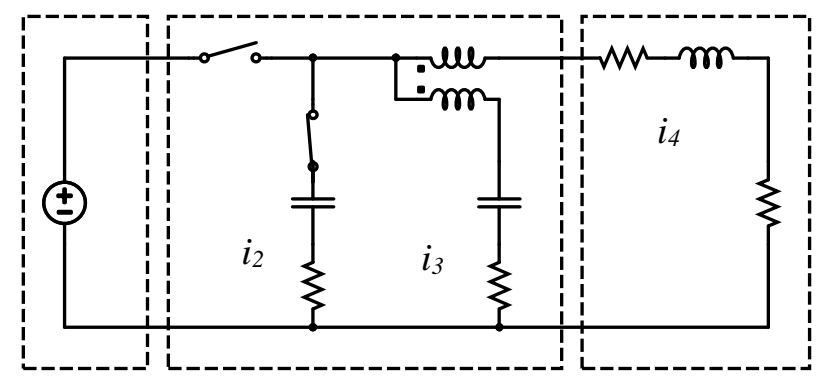

Fig. 4-3 Circuit breaker after fault detection and isolation

Therefore, a main advantage of suggested topology is eliminating the need for $\mathrm{ZnO}$ surge arrester to suppress the overvoltage.

\subsubsection{Mutual Inductance}

The most differentiating aspect of our topology is embedding a mutual inductance as the fundamental means of diverting line energy to a dump resistor, hence keeping the valve and converter safe from the back flowing energy. Furthermore, utilizing this mutual inductance, eliminates the need for use of regular metallic surge arresters, as any sudden impulse in either current or voltage will be suppressed by high pass filter connected to the secondary winding of 
the mutual inductance. This high pass filter consisting $\mathrm{C}_{2}$ and $\mathrm{R}_{2}$, provide a safe and reliable means to convert electrical energy to heat. Details of the mechanism is explained further.

The mutual inductance consisting of $\mathrm{L}_{1}$ and $\mathrm{L}_{2}$ plus capacitor $\mathrm{C}_{1}$ provide a mean for steering the voltage surge created at the time of switching away from the switching IGBT. The idea has been known in dc converters as a ripple steering method for many years. However, in the proposed circuit, we have used it to eliminate the flow of energy backward to the circuit breaker. Following formula explain the basic principle of the mutual inductance:

$$
\begin{aligned}
& v_{1}=L_{1} \frac{d i_{1}}{d t}+M \frac{d i_{2}}{d t} \\
& v_{2}=L_{2} \frac{d i_{2}}{d t}+M \frac{d i_{1}}{d t}
\end{aligned}
$$

Whereas, mutual inductance, $\mathrm{M}$, is defined as:

$$
\mathrm{M}=\sqrt{L_{1} \cdot L_{2}}
$$

Considering ideal elements, the mutual inductance has no effect on the outgoing dc current of the circuit breaker. However, assuming a perfect magnetic coupling between $\mathrm{L}_{1}$ and $\mathrm{L}_{2}$, any surge in current passing through $\mathrm{L}_{1}\left(d i_{1} / d t\right)$ induces a current in $\mathrm{L}_{2}$ in almost same order of magnitude. The induced current in $\mathrm{L}_{2}$ is shorted to the ground through $\mathrm{C}_{2}$ and $\mathrm{R}_{2}$. However, this current opposes its initiating current that flows through $\mathrm{L}_{1}$. In other word, the two currents flowing $L_{1}$ and $L_{2}$ cancel each other out and the current surge does not propagate into the switching valve.

During normal operation, the current passing through $\mathrm{R}_{2}$ is negligible, and the resistor comes into play only once a short circuit - a sudden rise in the outgoing current - is detected. Therefore, it is not necessary to consider a high wattage resistance for this branch, as the duty cycle is very short and intermittent. As previously discussed, the total energy that is suppressed by $\mathrm{R}_{2}$ depends on short circuit current and total inductance of the system.

Fig. 4-3 depicts the system after detection of a fault and turning the IGBT $\mathrm{S}_{1}$ off which in turn disconnects VSC from the load. 


\subsubsection{RCD Passive Dissipative Snubber}

It is necessary to protect the solid-state valve against voltage transients and spikes that may damage or destroy it. In this topology we have used a passive voltage snubber consisting of a resistor, capacitor, and diode, hence called RCD snubber. Since the energy is dissipated in the resistor, the snubber can be classified as a passive dissipative one, which clamps the transient voltage spikes.

In the proposed topology, branch consisting of $\mathrm{D}_{1}$ and $\mathrm{C}_{1}$ and $\mathrm{R}_{1}$ are devised as the protective snubber to safeguard switching valve against potential reverse voltage spikes. During normal operation, $\mathrm{D}_{1}$ is reverse biased and no current passes through the branch. However, shall any reverse voltage spike generated at the time of disconnecting the load, $\mathrm{D}_{1}$ conducts and suppresses the transient voltage through bypass capacitor $\mathrm{C}_{1}$ and resistor $\mathrm{R}_{1}$. It is obvious that the RC time constant must be quite small, so after each reclosing attempt by the HVDC circuit breaker, the snubber is ready for clamping transient voltages.

While selecting the diode for this part of the circuit breaker, it shall be into consideration that the operating voltage and maximum break-down voltage of the device must be a few times higher than the rated voltage of HVDC line. Moreover, as the diode is supposed to protect the valve, it shall be a fast turn-on type diode. However, on the other hand, there is virtually no current passing through the diode in normal operation. Moreover, the current at the instant of line interruption by the main valve, is almost negligible and lasts for less than few microseconds. Therefore, power rating of the diode would be quite low. In selection of $\mathrm{C}_{1}$ and $\mathrm{R}_{1}$, it is crucial to use low ESR capacitor, and select a resistor with low parasitic inductance.

To summarize, in the proposed topology, by benefiting from a mutual inductance and an RCD passive dissipative snubber, the circuit breaker steers the energy stored in line and load inductances away from the switching device and dumps them through a resistive element. The switching IGBT is also protected against reverse voltage spikes by a diode. This topology does not require any $\mathrm{ZnO}$ arresters, hence alleviates all technical problems relevant to such arresters. 


\subsection{Operational Analysis of the Circuit Breaker}

The performance of the system can be analyzed in three stages: normal operation, occurrence of fault and raise of line current, detection of fault and disconnecting the load.

\subsubsection{Normal Operation}

During normal operation IGBT is switched on, connecting the converter to the load. Output current of voltage source converter, $i_{1}$, equals the load current, because:

$$
i_{1}=i_{2}+i_{3}+i_{4}
$$

However, considering ideal elements both $i_{2}$ and $i_{3}$ are zero, as $j \omega c$ approaches infinity at dc, and no current passes through either $\mathrm{D}_{1}-\mathrm{C}_{1}-\mathrm{R}_{1}$ or $\mathrm{L}_{2}-\mathrm{C}_{2}-\mathrm{R}_{2}$ branches.

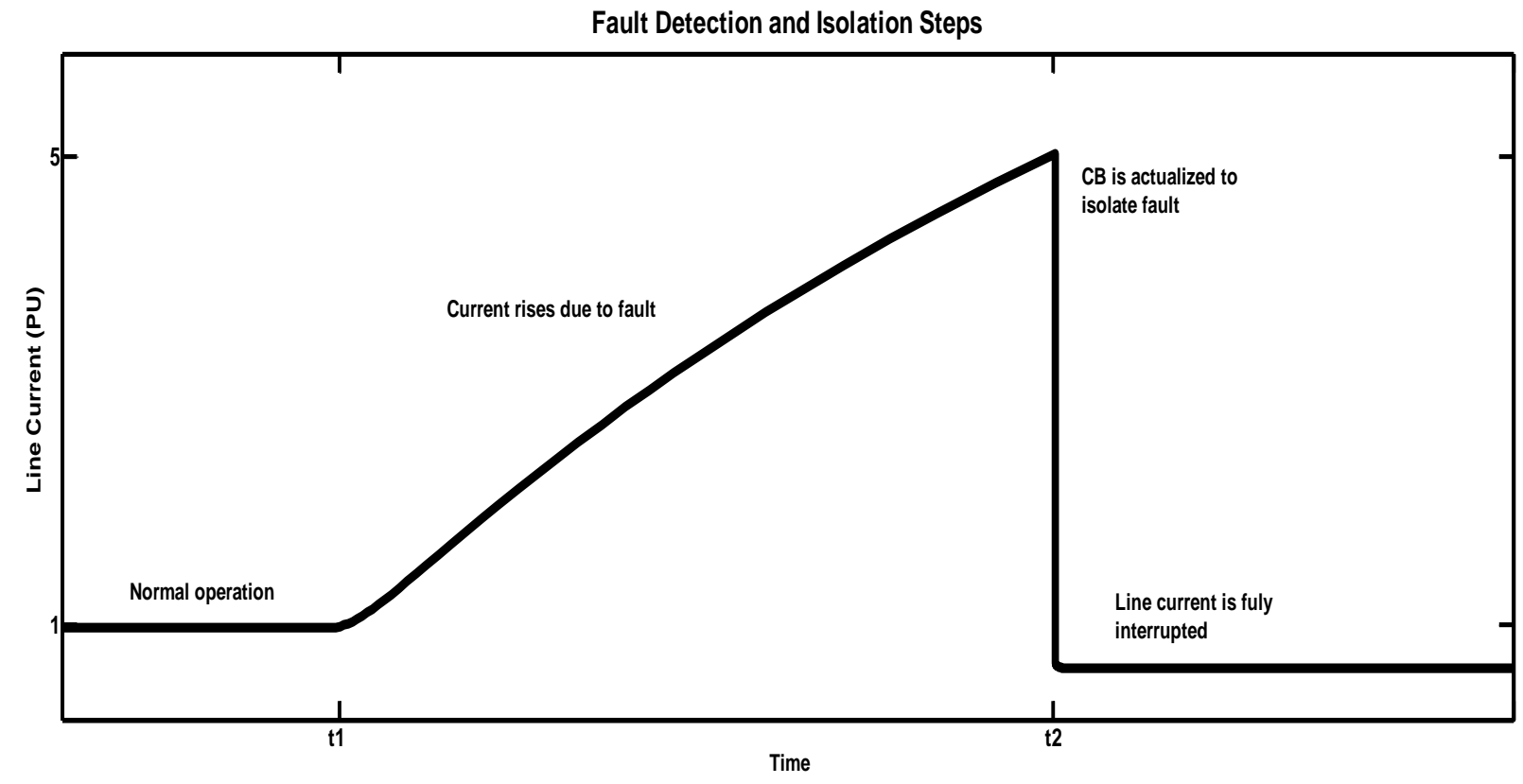

Fig. 4-4 Operational Analysis of Circuit breaker 
Thus except for conduction losses of the semiconductor devices constituting S1 and the resistive loss of $L_{1}$, circuit breaker has no other impact on flow of energy.

During the normal operation, the basic assumption is that $\mathrm{V}_{\mathrm{dc}}$ is an ideal source without any ripple, otherwise, the mutual inductance $\mathrm{L}_{1}-\mathrm{L}_{2}$ and the branch $\mathrm{C}_{2}-\mathrm{R}_{2}$ will perform as a ripple steering configuration. To minimize the losses during normal operation and increase overall efficiency of the system, several IGBT packs can be used in parallel, and additionally a higher conductor cross section could be selected for $L_{1}$ winding. Although in our design $L_{2}$ has the same number of turns as $L_{1}$, no current passes through $\mathrm{L}_{2}$ when the circuit breaker is closed, thus the conductor cross section of $\mathrm{L}_{2}$ can be selected to be much smaller than $\mathrm{L}_{1}$. This helps to reduce the total size and weight of mutual inductance.

\subsubsection{Fault Occurrence}

After occurrence of a fault at load side at time $t=t_{1}$, the current $i_{1}$ starts to rise. However, both line inductance $\mathrm{L}_{3}$ and circuit breakers inductance $\mathrm{L}_{1}$ prevent any abrupt change in the current; hence the current steadily increases untill reaches the tripping threshold of the system at $t=t_{2}$. Assuming that VSC would be able to sustain a constant output voltage over the time period of $t_{1}$ to $t_{2}$, rate of current rise depends on $\mathrm{V}_{\mathrm{dc}}$ and sum of $\mathrm{L}_{2}$ and $\mathrm{L}_{3}$, and can be calculated as:

$$
\frac{\Delta i_{1}}{\left(t_{2}-t_{1}\right)}=\frac{V_{\mathrm{dc}}}{\left(\mathrm{L}_{2}+\mathrm{L}_{3}\right)}
$$

Since $\mathrm{V}_{\mathrm{dc}}$ is constant, $i_{2}$ would still be zero. However, the rising current $i_{1}$ that passes through $\mathrm{L}_{2}$ generates a flux in the mutual inductance, which in turn induces a current in $\mathrm{L}_{3}$, namely $i_{3}$, which opposes the change in its initiating current $i_{4}$. However, $i_{3}$ is not sufficient to annul the impact of short circuit current on the current supplied by the converter $i_{1}$. Subsequently, $i_{1}$ steadily increases till the circuit is disconnected.

\subsubsection{Fault Isolation}

When $i_{2}$ reaches the value defined as maximum fault current at $t_{2}$, switch $S_{1}$ is turned off and CB detaches the load and transmission line from the converter output. However, sudden disconnection of the load will translate into an extremely steep rise of $d i / d t$, which creates a 
destructive reverse voltage spikes across the system inductances. Therefore, we not only need to suppress the energy stored in the lump inductance of the line and load, $\mathrm{L}_{3}$, but also have to make sure that semiconductor switch $S_{1}$ remains safe and unaffected by the reverse voltage.

The total energy that is stored in the inductances of the system at $t_{2}$, and consequently should be absorbed at the time of switching, depends on the level of short-circuit current and the inductances in the system. In the very moment before opening the switch, the energy would be defined by Eq. 4-1. However it can be shown that this energy is also dependent on the duration of short circuit current and the line voltage at the time of current interruption:

$$
\mathrm{W}=\frac{L \cdot i_{S C}^{2}}{2}=\frac{V_{S C}{ }^{2} \cdot t_{S C}{ }^{2}}{2 \mathrm{~L}}
$$

Because using an approximate simple model and assuming the line voltage remains constant during short circuit, it can be shown that the current raises linearly according to Eq. 4-8:

$$
i_{S C}=\frac{V}{\mathrm{~L}} \cdot \Delta t
$$

Where $\mathrm{L}$ is the sum of $\mathrm{L}_{1}$ and $\mathrm{L}_{3}$, and $i_{s c}$ is the short circuit current at $t_{2}, V s c$ is the voltage, and finally $t_{s c}$ is the duration of short circuit current. Considering some typical values, for example a short circuit current of $5 \mathrm{kA}, 2 \mathrm{mH}$ for $\mathrm{L}_{1}$ and $20 \mathrm{mH}$ for $\mathrm{L}_{3}$, the total energy stored in the system would be $275 \mathrm{~kJ}$. This amount of energy, if remains uncontrolled, can easily destroy IGBTs or other types of semiconductor devices that constitute $\mathrm{S}_{1}$. As indicated, in most topologies, $\mathrm{ZnO}$ surge arresters that exhibit very nonlinear voltage-resistance characteristics are used to absorb the energy and bypass the transient overvoltage surges and caused by switching. However, surge arresters are not solid devices and require some regular maintenance. Conversely, simpler elements like resistors and capacitors are less expensive and demand far less maintenance. Therefore, a main advantage of suggested topology is eliminating the need for any $\mathrm{ZnO}$ varistor to suppress the overvoltage.

In the proposed topology, the task of absorbing energy is performed by a mutual inductance consisting of $L_{1}$ and $L_{2}$, plus capacitor $C_{2}$ and $R_{2}$. This system provides an effective means to steer the energy surge created at the time of switching away from the semiconductor valve. The idea has been known in dc converters as a ripple steering method for many years [12]. However, 
in this circuit, it has been used it to eliminate the flow of energy backward through the circuit breaker to the converter. As stated in the previous section, Eq. 4-2 and Eq. 4-3 explain the basic principle of how a mutual inductance works.

During normal operation, mutual inductance has no effect on the outgoing dc current. However, assuming equal values for both $\mathrm{L}_{1}$ and $\mathrm{L}_{2}$, and also a perfect magnetic coupling between the two, any change in current passing through $\mathrm{L}_{1}$ induces a current in $\mathrm{L}_{2}$ in the same order of magnitude. The induced current in $\mathrm{L}_{2}$ is bypassed to the ground through $\mathrm{C}_{2}$ and $\mathrm{R}_{2}$. However, this induced current $i_{3}$ opposes its initiating current $i_{4}$ that flows through $\mathrm{L}_{1}$. In other word, the two currents flowing through $\mathrm{L}_{1}$ and $\mathrm{L}_{2}$ cancel each other out and the current variation does not propagate back into the switching IGBT.

Although the current passing through $\mathrm{C}_{2}-\mathrm{R}_{2}$ is almost negligible before $t_{2}$, this high-pass filter comes into play once a short circuit - a sudden rise in the outgoing current - happens. Nevertheless, it is not necessary to consider a high wattage resistor for this branch, as the duty cycle is very short and quite intermittent. As previously discussed, the total energy that is dissipated by $R_{2}$ depends on short circuit current and total inductance of the system.

The branch consisting of $\mathrm{D}_{1}, \mathrm{C}_{1}$, and $\mathrm{R}_{1}$ is devised as a protection to safeguard switching IGBT against potential reverse voltage spikes. During normal operation, $\mathrm{D}_{1}$ is reverse biased and no current passes through the branch. However, shall any reverse voltage generated across $\mathrm{L}_{1}$ and $\mathrm{L}_{3}$ at the time of fault isolation, $\mathrm{D}_{1}$ conducts and suppresses the transient voltage through bypass capacitor $\mathrm{C}_{1}$ and resistor $\mathrm{R}_{1}$. 


\section{Chapter Five: Simulation Results}

\subsection{Simple Model}

To simulate and verify the functionality of the proposed circuit breaker design, a simple model has been used at the first step. In this model, a dc source has replaced the voltage source converter for simplicity of analysis. Following figure illustrates the Simulink model used to test the performance of the circuit breaker.

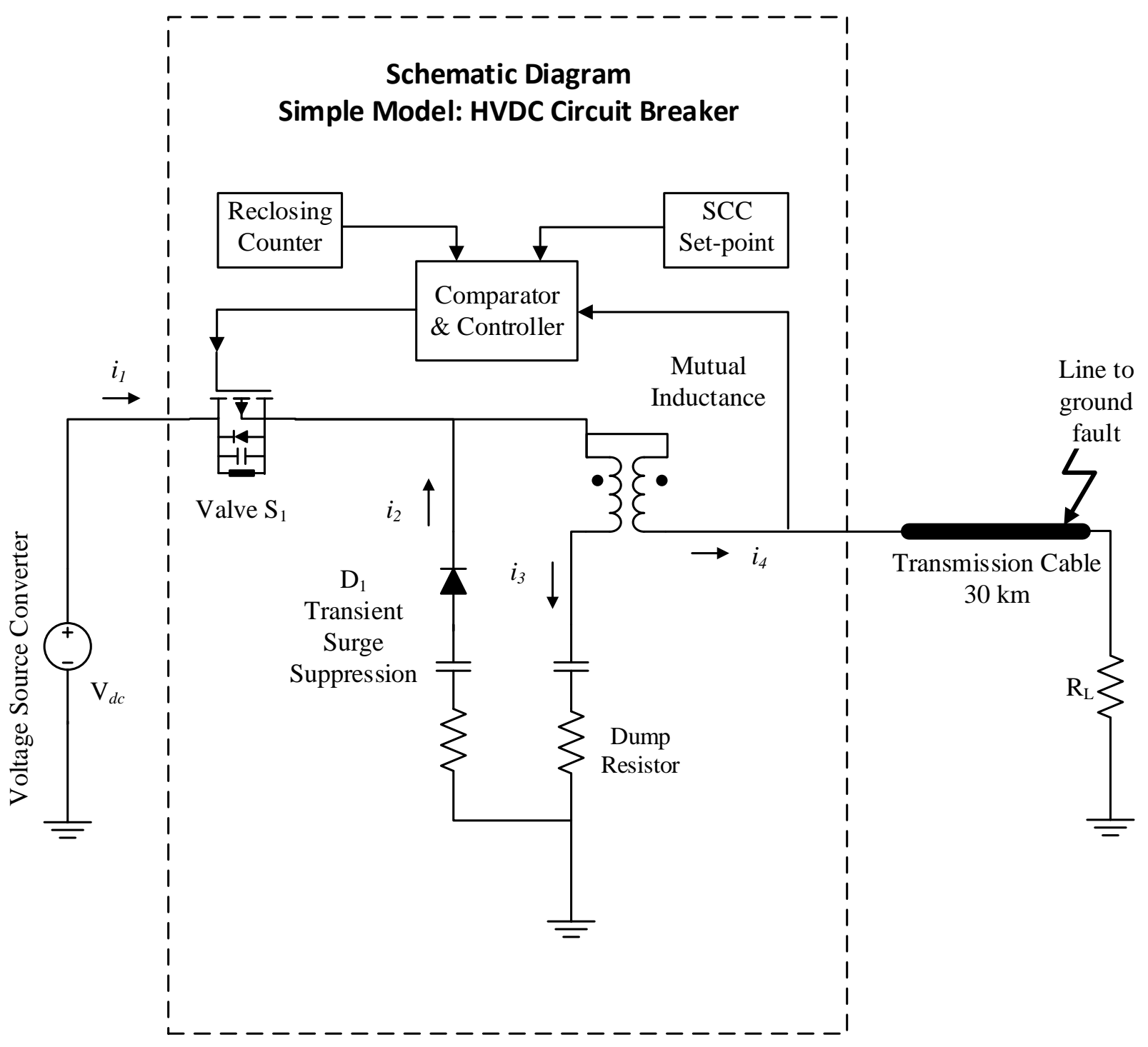

Fig. 5-1 Schematic diagram of circuit breaker in a simple simulation scheme 
To put the proposed topology to test, we have considered a typical $250 \mathrm{MW}$ wind farm [14] connected to the grid by a $40 \mathrm{~km}$ long transmission line. A bipolar HVDC scheme operating at $+300 \mathrm{kV}$ is assumed for the system as well. Therefore, taking into account an overall efficiency of $95 \%$, transmission line $\mathrm{T}_{1}$ while operating at $+300 \mathrm{kV}$ must carry a current of approximately 438.6 A. A submarine transmission cable with a cross section of 150 square mm, a standard sized defined in IEC60228, will be sufficient to carry the current. Furthermore, a threshold of 5 $\mathrm{kA}$ - approximately 10 times the normal operating current - is considered as the tripping level for the circuit breaker to activate and isolate the fault. For the switching IGBTs, Mitsubishi's CM750HG-130R which exhibits the following characteristics could be selected:

$$
\mathrm{I}_{\mathrm{C}}=750 \mathrm{~A}
$$

$$
\mathrm{V}_{\mathrm{CES}}=6500 \mathrm{~V}
$$

However, taking into account the safe operating area and a safety margin of $50 \%$, a pack of 100 switching IGBTs in series will be required to disconnect $300 \mathrm{kV}$. Moreover, in order to reduce the conduction losses and improve current handling performance of the valve, two IGBT series in parallel are utilized to handle the rated operating current of $438.6 \mathrm{~A}$. 


\begin{tabular}{|c|c|c|}
\hline \multicolumn{3}{|c|}{$\begin{array}{c}\text { International Standard Conductor Sizes according to IEC } 60228 \\
\text { High Voltage Power Cables }\end{array}$} \\
\hline SI system & $\begin{array}{l}\text { kcmil equivalent } \\
\text { (soft conversion) }\end{array}$ & Resistance Ohm/1000 m \\
\hline $120 \mathrm{~mm}^{2}$ & 250 & \\
\hline $150 \mathrm{~mm}^{2}$ & 300 & \\
\hline $185 \mathrm{~mm}^{2}$ & 350 & \\
\hline $240 \mathrm{~mm}^{2}$ & 500 & \\
\hline $300 \mathrm{~mm}^{2}$ & 600 & \\
\hline $400 \mathrm{~mm}^{2}$ & 750 & \\
\hline $500 \mathrm{~mm}^{2}$ & 1000 & \\
\hline $630 \mathrm{~mm}^{2}$ & 1250 & \\
\hline $800 \mathrm{~mm}^{2}$ & 1600 & \\
\hline $1000 \mathrm{~mm}^{2}$ & 2000 & \\
\hline $1200 \mathrm{~mm}^{2}$ & 2400 & \\
\hline $1400 \mathrm{~mm}^{2}$ & 2750 & \\
\hline $1600 \mathrm{~mm}^{2}$ & 3200 & \\
\hline $2000 \mathrm{~mm}^{2}$ & 4000 & \\
\hline $2500 \mathrm{~mm}^{2}$ & 5000 & \\
\hline
\end{tabular}

Table 5-1 International Standard Conductor Sizes 
To simulate the transmission line, a simple model as shown in Fig. 5-4 has been used. Assuming a transmission length of $40 \mathrm{~km}$ and a value of $0.5 \mathrm{mH} / \mathrm{km}$, the total cable inductance will be around $20 \mathrm{mH}$. A dc resistance of $0.7667 \Omega / \mathrm{km}$ is considered for the 150 square millimeter cable; consequently total resistance of the line would be $30.668 \mathrm{Ohm}$. Also assuming a capacitance of $0.13 \mu \mathrm{F}$ per 1000 meters, $\mathrm{C}_{\mathrm{x}}$ would be equal to $5.2 \mu \mathrm{F}$.

Although increasing the inductance of $\mathrm{L}_{1}$ would be beneficial in reducing the $d i / d t$, it will negatively affect the control system [15]. Furthermore, the higher the value of $\mathrm{L}_{1}$ and $\mathrm{L}_{2}$, the bigger would be the size of the inductor, so do its cost and footprint. Considering the pros and cons, $\mathrm{L}_{1}$ is set to be equal to $10 \%$ of the line inductance.

Fig. 5-2 shows the simulation results. In this scenario, a short circuit occurs at time $t=0.15$ $\mathrm{ms}$, and consequently the current rises till it hits the trigger point of $5 \mathrm{kA}$. Then the circuit breaker trips off and disconnects the load from the converter. As soon as the load is disconnected, the mutual inductance pushes the current surge to the branch containing $\mathrm{L}_{2}, \mathrm{C}_{2}$, and $\mathrm{R}_{2}$. In less than 3 milliseconds more than $95 \%$ of the energy stored in line and load inductances is dissipated in $\mathrm{R}_{2}$ and the system will be ready reclose, provided that the fault is cleared. Diode $\mathrm{D}_{1}$ and the high pass filter $\mathrm{C}_{1}$ and $\mathrm{R}_{1}$, bypass the reverse voltage spike that lasts a few microseconds only, thus keeping the switching IGBTs of $S_{1}$ safeguarded against reverse overvoltage impulses. The time period just before occurrence of the fault and after isolating the fault is more closely examined in Fig. 5-3. As it can be seen the total duration since the moment of having a short circuit until disconnecting the converter from the line takes less than one millisecond. 


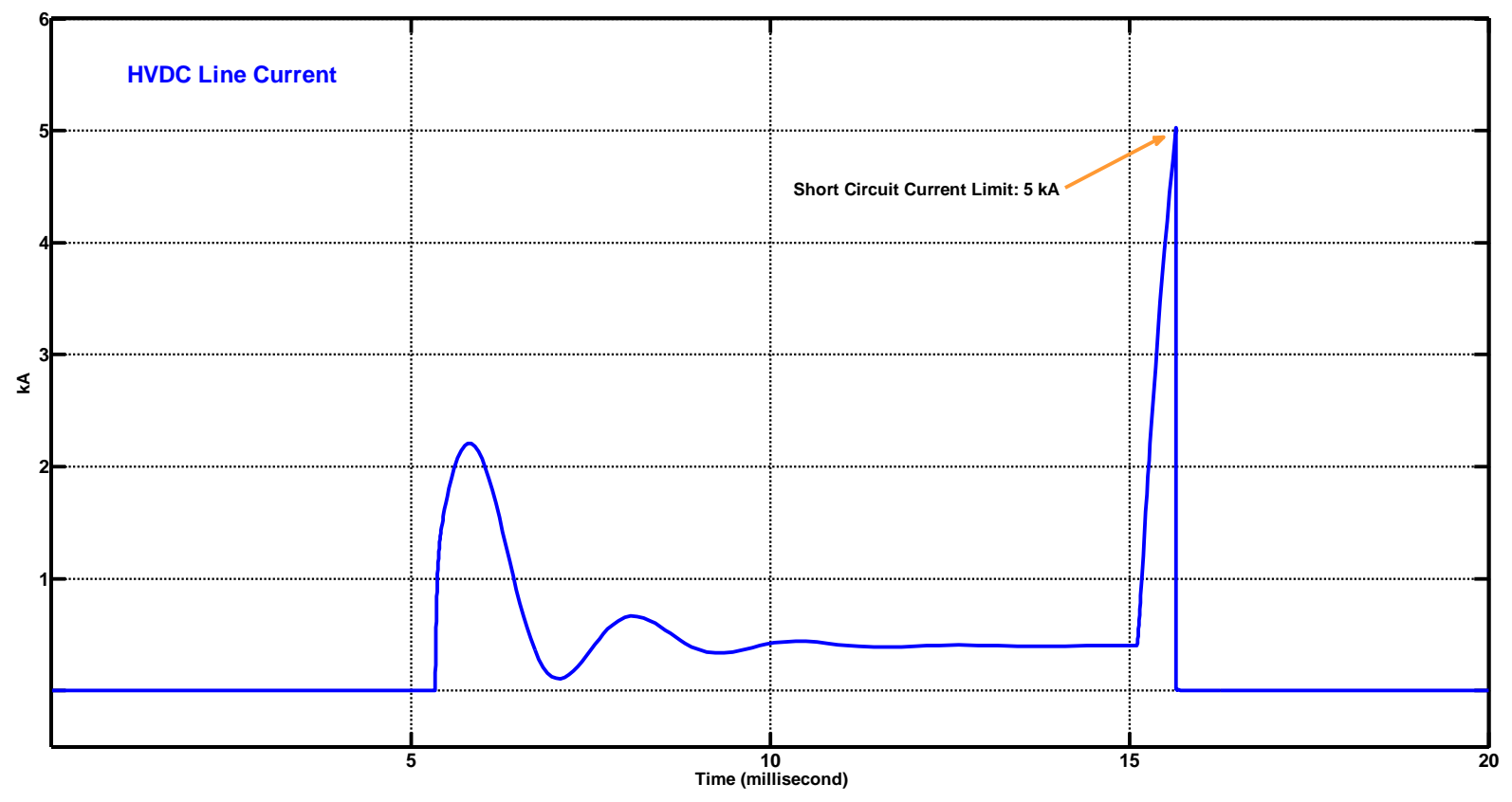

Fig. 5-2 HVDC line current - simple simulation

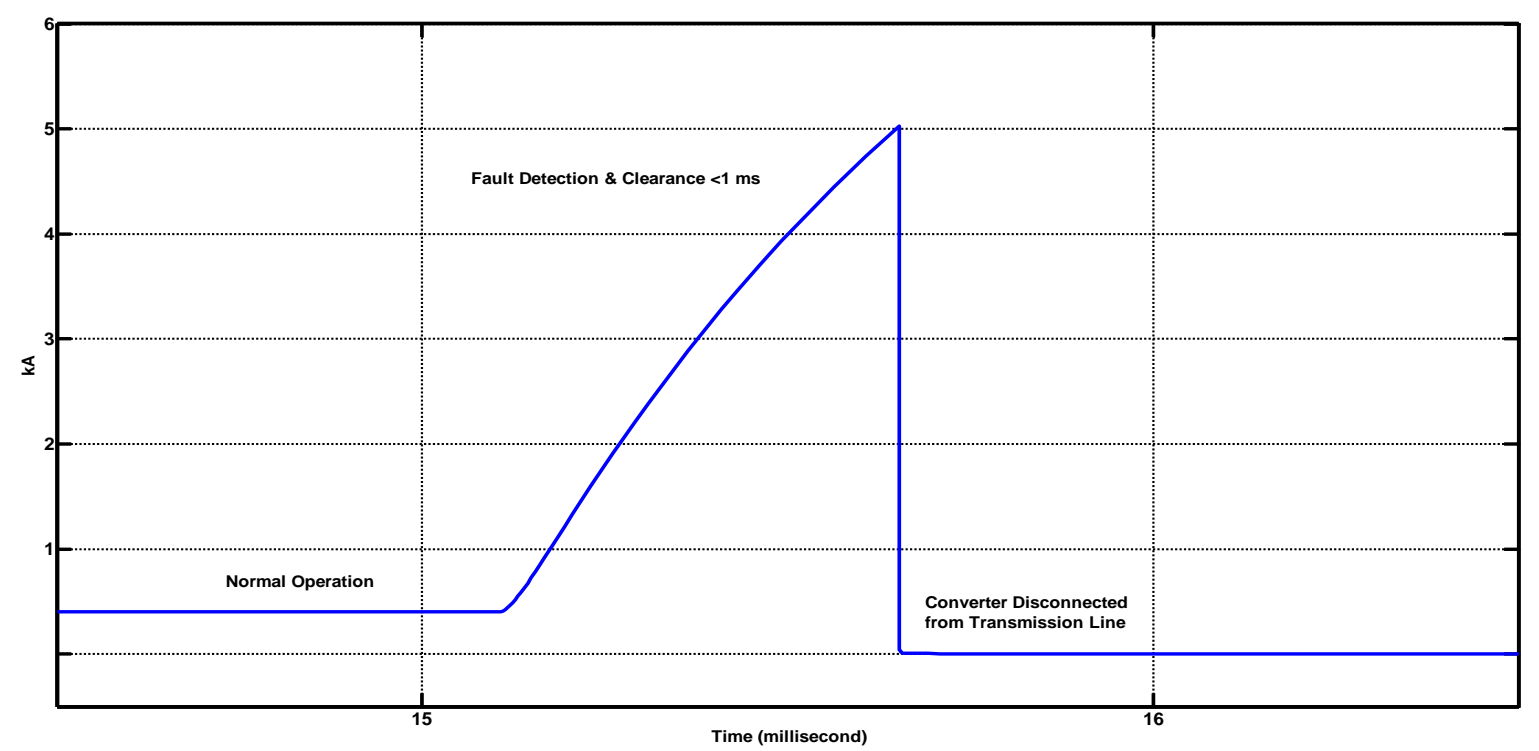

Fig. 5-3 Fault detection and isolation, simple simulation 
Yet, another important task after deploying the solid-state valve to disconnect the current, is to absorb the energy stored in the line and other inductive elements of the system. We expect that this energy is steered away by the mutual inductance and absorbed in the resistor provided for this purpose. Following figure shows the current that passes through the mutual inductance and the branch $\mathrm{C}_{2}-\mathrm{R}_{2}$. The main portion of the back-flowing energy is coming from the lump inductance element of the system and transmission line as shown in Fig. 5-4.

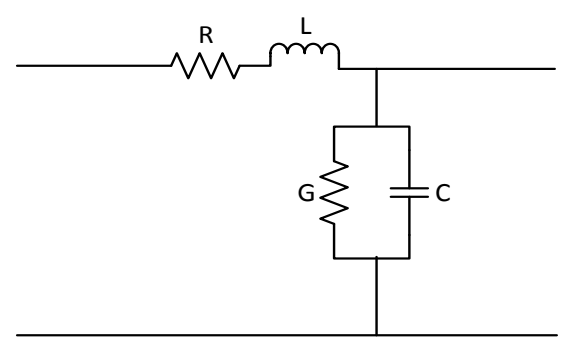

Fig. 5-4 Circuit equivalent for HVDC submarine cable line

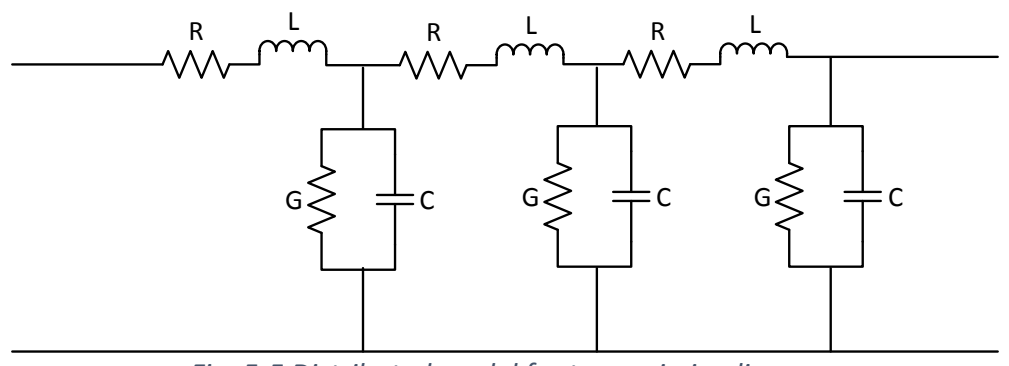

Fig. 5-5 Distributed model for transmission line

Please note that although there are other equivalents circuits for transmission lines, such as distributed model depicted in Fig. 5-5, which is somehow similar to distributed pi used in Simulink. However, using that models does not yield to any radical change in the outcome of the simulation results. Therefore, we have only used the model as shown in Fig. 5-4. 


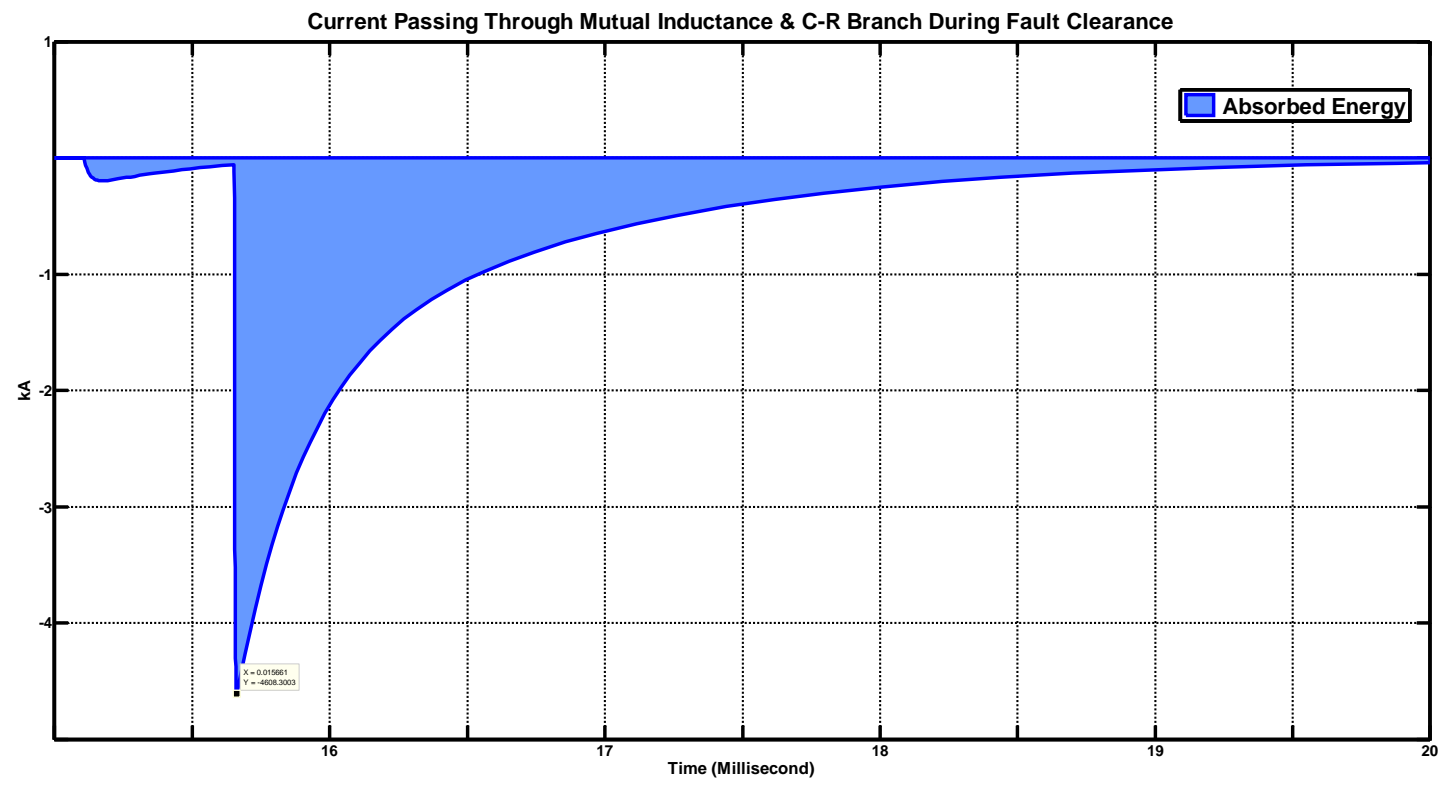

Fig. 5-6 Line energy steered toward and absorbed by resistor

The colored area under the curve is an indication of the total energy steered away and absorbed by the branch $\mathrm{L}_{2}-\mathrm{C}_{2}-\mathrm{R}_{2}$. Comparing this area with the needle shaped overvoltage spike passing through snubber branch $\mathrm{D}_{1}-\mathrm{C}_{1}-\mathrm{R}_{1}$ proves the efficiency of the steering mechanism employed to protect the converter from back flowing current at the time of fault occurrence. It can be verified that the total energy absorbed by the resistive element, is approximately equal to the calculated energy stored in the system inductances.

The results of simple model verifies the functionality of the proposed circuit breaker topology. The breaker can efficiently sense the over current fault, and isolate it while keeping the valve safe and prohibiting any backflow of current towards the converter. However, real life scenario would be more complex and there are many other parameters interfering with 
performance of the breaker. Therefore, in order to corroborate the results, a complex model has been also developed and functionality of the circuit breaker tested at that environment.

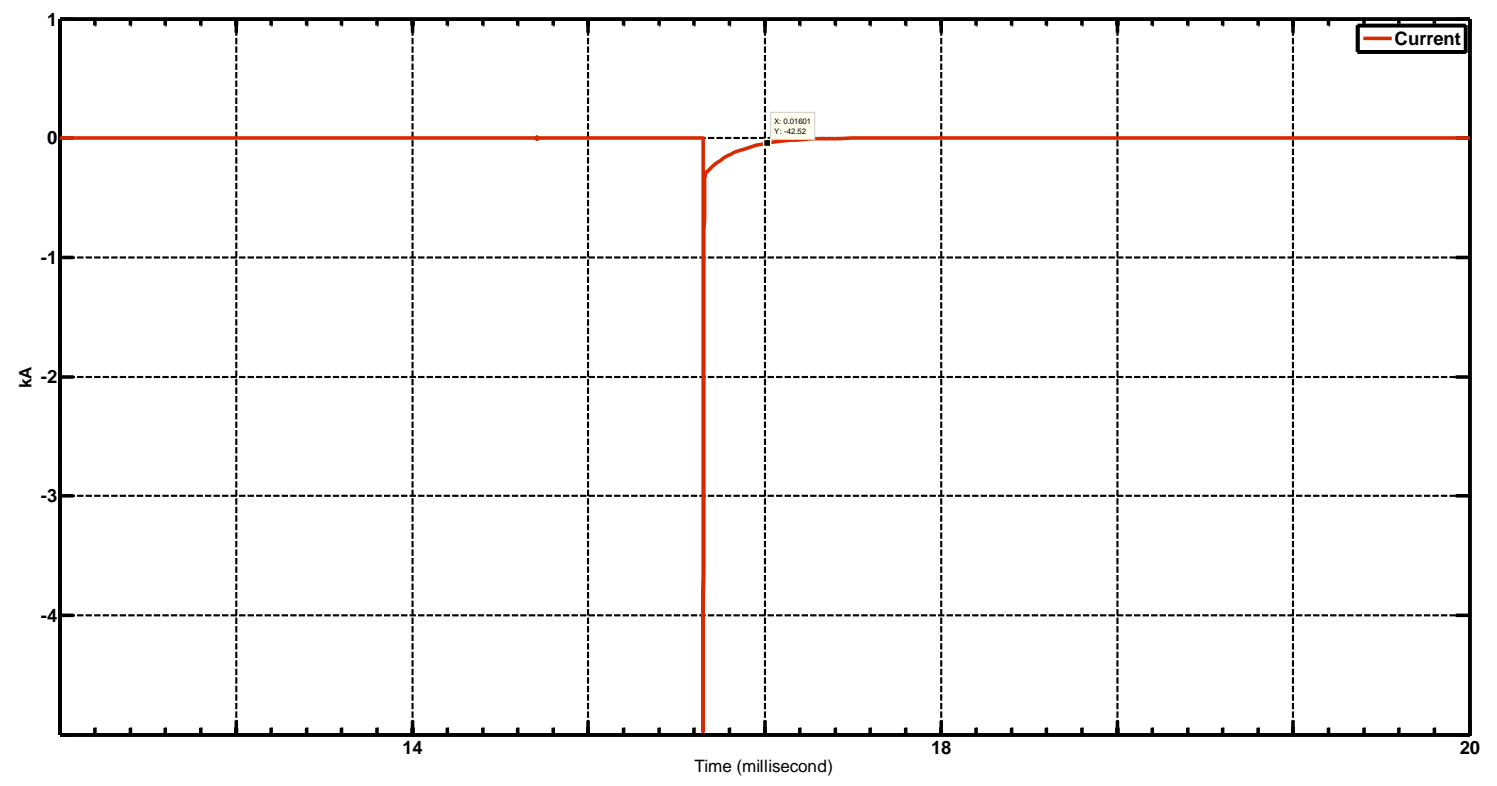

Fig. 5-7 Current passing through protective RCD snubber

\subsection{Complex Model}

In the complex model, we have borrowed a Simulink model which has been developed for a bi-polar HVDC voltage source converter connected to the AC grid, then our model for circuit breaker has been incorporated into the system. In this model, the short circuit occurs at the end of the transmission line, where the huge inductance of HVDC cable comes into play. In other word, the worst case scenario has been modeled and tested. The model provided a simulation environment to analyze and verify circuit breaker's fault detection speed, functionality of reclosing attempts, detrimental effects of short circuit current on AC/DC converter located at 
the end of the transmission line which connects the wind farm output to the AC grid, and finally the disturbance caused by the fault at HVDC system on the AC grid bus.

The model simulates a 200 MVA wind farm connected via a +/- $100 \mathrm{kV}$ bipolar HVDC line to the AC grid. The capacity of AC grid is considered to be 2000 MVA, which is ten times higher than that of the wind farm. The output voltage of the collecting station is increased by a step-up transformer, rectified to DC, and fed to a voltage source converter. The converter is connected to the transmission lines which are terminated to another converter. The onshore converter generates three-phase $\mathrm{AC}$ which is then connected via step-up transformer to the $\mathrm{AC}$ grid. And finally a load is added to the AC bus.

Although it has been shown that step-up transformers could be eliminated while connecting an array of wind farms to the converter and grid [20], in this simulation we have included stepup transformers on both side as they affect the dynamic behaviour of the system, and make it more complicated. Therefore, testing the performance of the circuit breaker in this arrangement that encompasses transformers, will ensure that the performance of the breaker in a less complicated network will be guaranteed.

The transmission lines between the two converters are 75 kilometers long, and are simulated accordingly. The proposed circuit breaker is connected to the positive pole of HVDC transmission line, and a fault point is considered right after end of transmission line. Total simulation time is three seconds, and once the system is stabilized, fault occurs at time $t=1.5 \mathrm{~s}$. After running the simulation, we expect the circuit breaker to detect and isolate the fault before the converter on the generating side does so. 


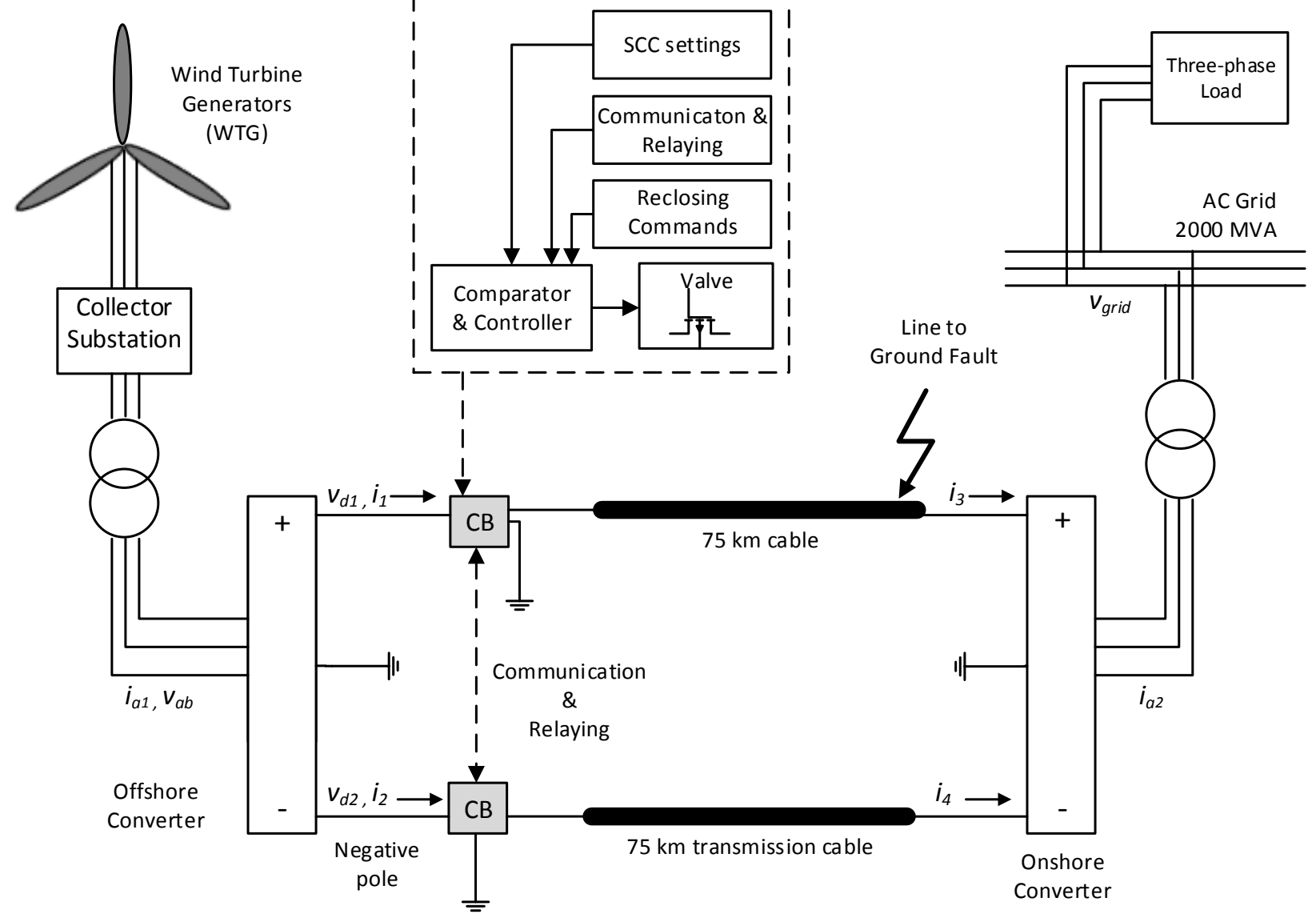

Fig. 5-8 Schematic diagram of circuit breaker in a complex model simulation

As mentioned, in this scenario, fault occurs after the system is stabilized to make sure that system start-up disturbances are cleared up, and the circuit breaker is tested during normal operation. Moreover, quite similar to real life situations and industry practices, the circuit breaker tries to reclose the system for three times. However, in the simulation the fault is cleared just before the third attempt, therefore, system is supposed to re-stabilize and continue functioning normally. However, the control system utilized in either converter or in the wind farm are not on interest in this study. It is obvious that the wind farm like any other power plant requires employing a method for active power control mode such as frequency control, power 
rate limiter, delta control or other schemes [21], however we haven't taken them into consideration as in real life the manufacturer of circuit breaker cannot either.

Fig. 5-9 depicts the effect of the fault on the HVDC line current. It can clearly be seen that the circuit breaker disconnects the system after the current exceeds the threshold value of 5 PU. Once the current reaches zero, and after a very short time laps, circuit breaker recloses the system. However, since the fault is not cleared yet, the current rises again rapidly which causes the circuit breaker to actuate again and disconnect the converter from the line. Right before the third reclosing attempt, the fault is cleared up. Therefore, the pick short circuit current remains slightly shy of $5 \mathrm{PU}$, consequently circuit breaker keeps the system in normal condition.

However, it is noticeable that due to high value of the total lump inductance of the system, it takes a few milliseconds for the current to settle and reach the normal operating value.

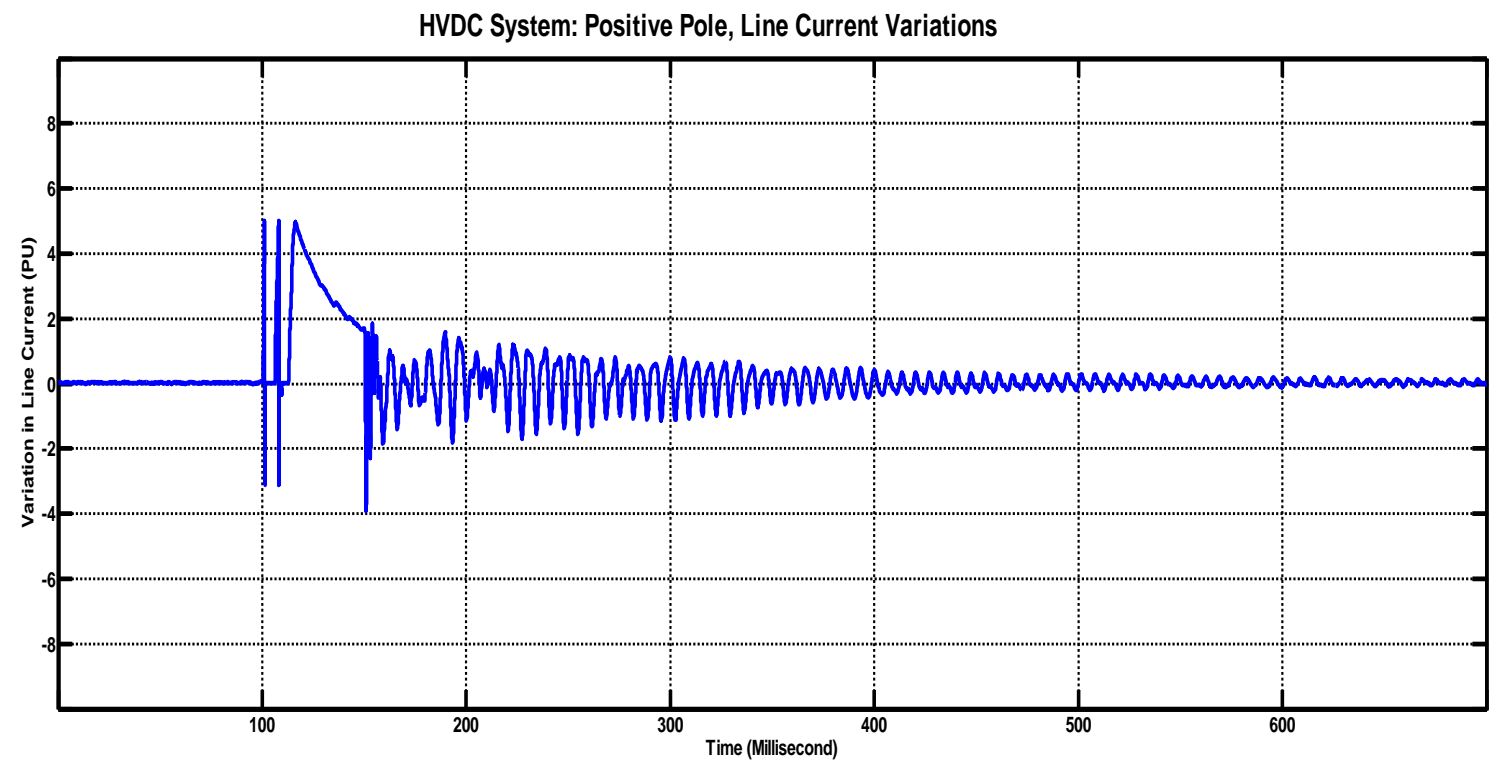

Fig. 5-9 HVDC line current during fault and clearance

Following figure analyzes the fault occurrence and reclosing attempts in a closer way. It is obvious that the fault detection and three reclosing attempts all happen within less than ten 
milliseconds with reflects one of the objectives defined for the circuit breaker. Closer examination of the picture reveals that each incident of fault detection and fault isolation has taken less than three milliseconds; in line with our goal.

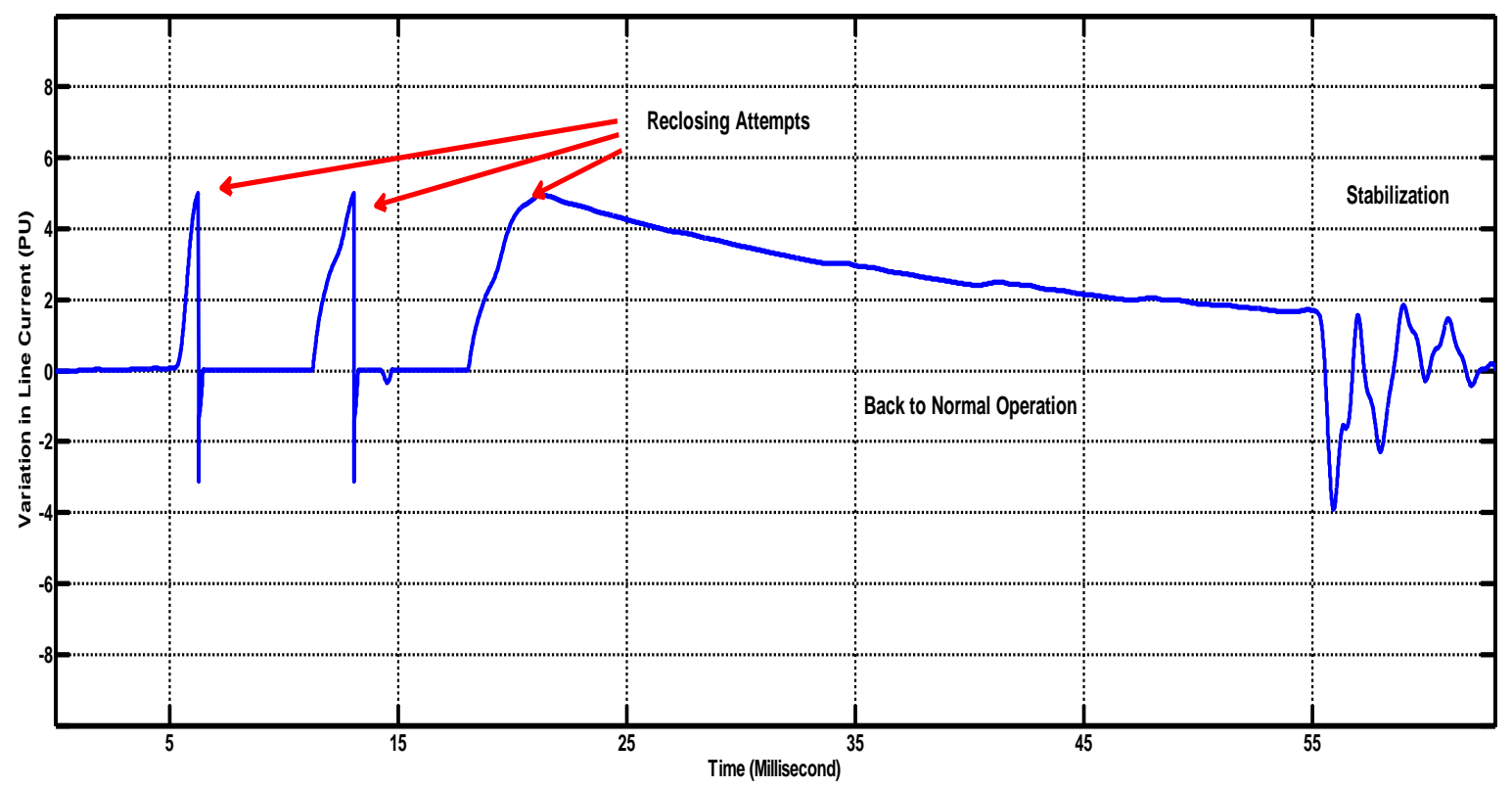

Fig. 5-10 HVDC line current, fault, and reclosing attempts

A main function defined for circuit breaker is to sense the fault and isolate it much faster than converter, and make sure that the system does not collapse. Therefore, system down time will be minimized and converter can resume its normal operation as soon as the fault is eliminated. To test the responsiveness of the circuit breaker, simulation results for two scenarios are compared. In scenario A, voltage source converter is first connected to the circuit breaker and then to the HVDC transmission line. In scenario B, the converter is directly connected to the HVDC transmission line. Fig. 5-11 and Fig. 5-12 present the line voltages as measured on the other end of the HVDC system, which is onshore voltage source converters. It is quite obvious that circuit breaker has detected and isolated the fault much faster than VSC. 


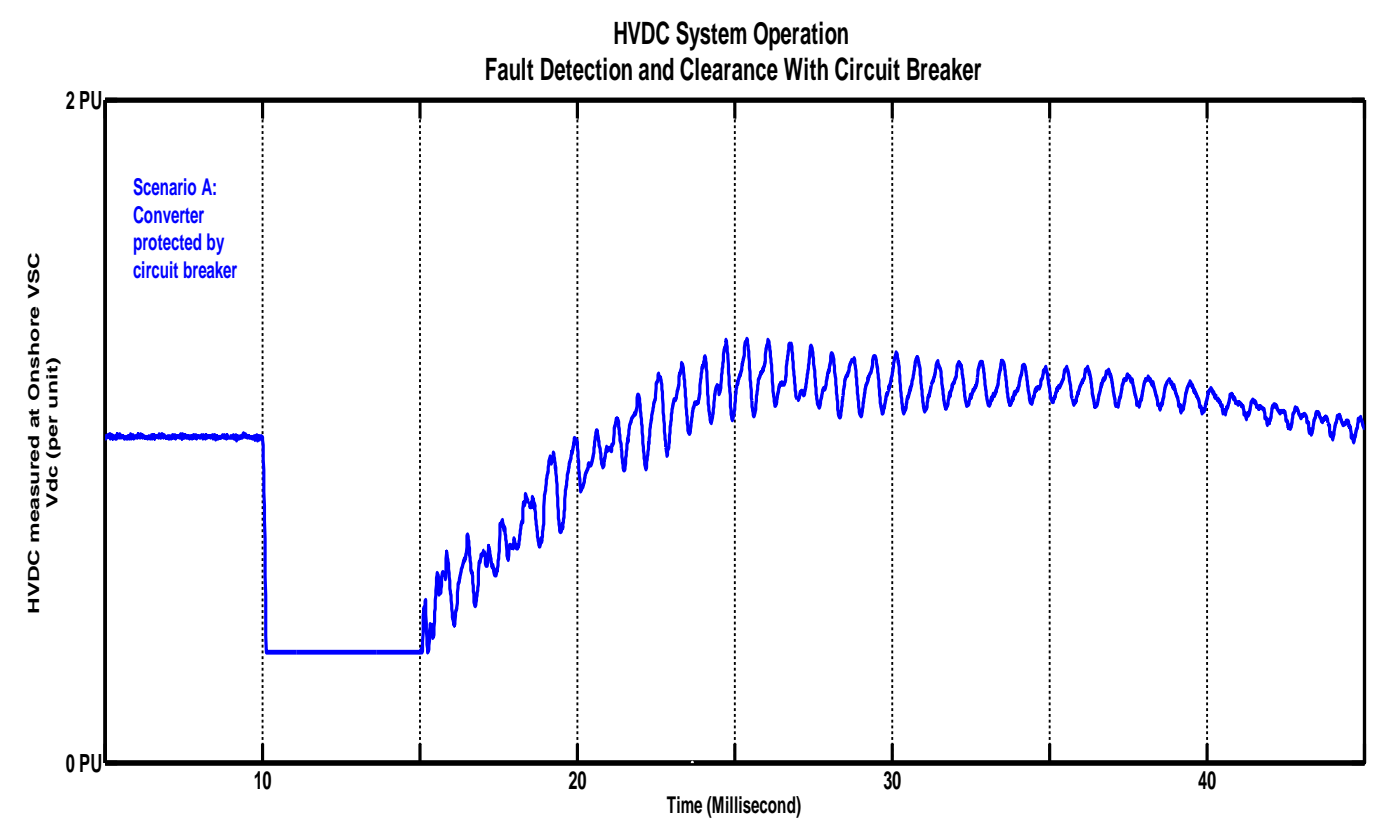

Fig. 5-11 Scenario A, system is protected by circuit breaker

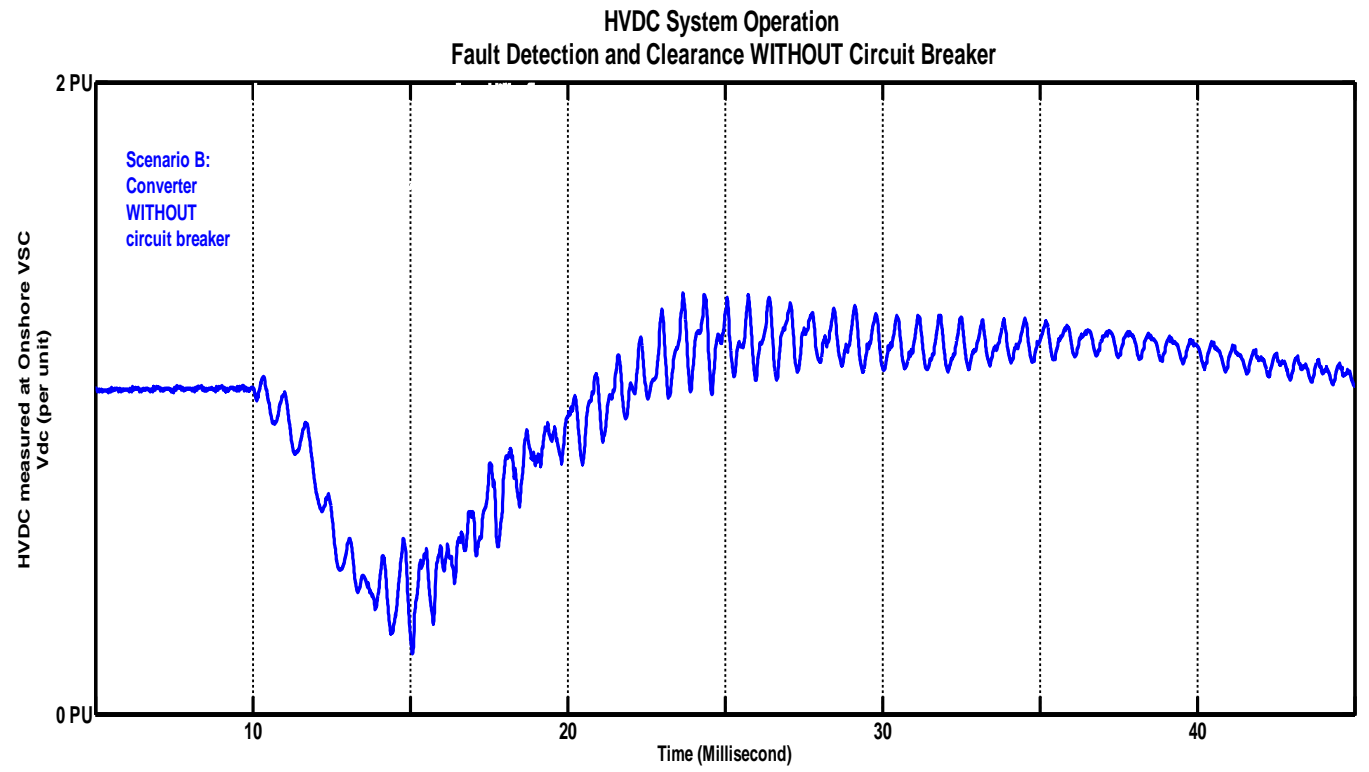

Fig. 5-12 Scenario B, system NOT protected by circuit breaker

Fig. 5-11 represents the results of first arrangement, where the circuit breaker rapidly detects the fault and isolates the converter from the shorted transmission line. Therefore, as soon as the breaker disconnects the offshore converter from the line, the $\mathrm{V}_{\mathrm{dc}}$ as measured at onshore 
converter drops to zero. Fig. 5-12 illustrates the result of the second experimental arrangement, where the offshore voltage source converter has to detect the line to ground fault and reduce the voltage to zero in order to minimize the risks and damages. It can be seen that converters responds much slower to the fault, and tries to adjust the current in a number of consecutive trials, which fails and finally hits zero after about five milliseconds. The overcurrent that rushes into the converter over this period could be quite detrimental. On the other hand, keeping the energy flow during the fault period, could seriously increase the total system damages and even make it impossible for some equipment to recover. Because typically the converter depends on grid voltage measurement and tries to maximize the transferable active power. Then, after a fault incident, a command to reduce the active power factor is sent to the wind turbine generator through communication link [22]. However, due to large inductance of the cables connecting generators to the substation and converter, there is usually a delay in sensing any fault on the transmission line side. Moreover, another disadvantage is that the controller entirely relies on communication link, which might not be necessarily a wise and dependable choice to control the active power transmission [23].

Now we can analyze how fault on the HVDC transmission line is affecting the onshore converter which uses the DC energy to produce three-phase AC and feed it to the grid. Fig. 5-13 shows the output voltage of the converter. It is necessary to remind the reader that the HVDC system utilized in this model is a bipolar system, and the phase to ground fault occurs on the positive line. This is why, the converter connected to the negative pole tries to increase the output voltage to compensate the inadequacy of incoming power. Thus, to make the operation safer, it would be better to have another circuit breaker connected to the negative pole, and both breakers are mutually relayed, so they would trip simultaneously in case of fault on either of the lines. 


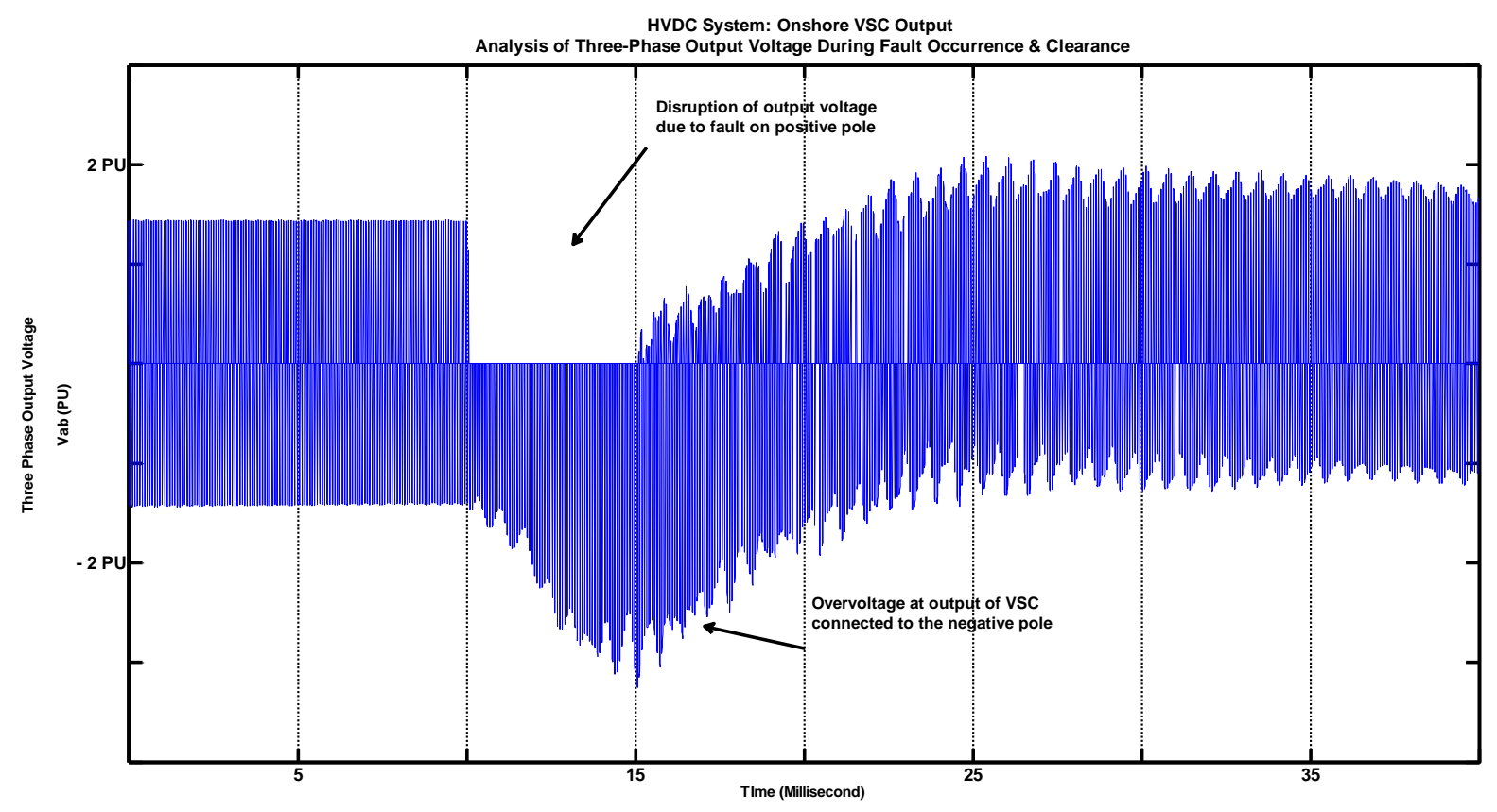

Fig. 5-13 Onshore VSC output during fault and clearance

As shown on the figure, after fault is eliminated, the converter on the positve pole resumes, and within less than 20 milliseconds after the first fault system regains control and maintains the flow of energy. Once again, we emphasize on necessity of having the circuit breaker installed on the negative pole to be coordinated and actualized mutually and simultanously with the circuit breaker on the positive line. This measure, will ensure that no overvoltage will happen due to a fault occuring on the other transmission pole.

Now let's verify the effects whether or not the circuit breaker has minimized the effect of fault occurrence on the AC grid. Fig. 5-14 illustrates the negative impact of the fault on the AC side. The bus voltage on the AC grid has been analyzed for thirty milliseconds, which is subdivided to followings periods:

- Normal operation

- Fault on HVDC line

- Transitory period 


\section{- Back to normal operation}

The fault on HVDC creates a voltage dip on the AC grid which lasts for five milliseconds, and then after reconnecting the positive pole, it takes the system approximately ten milliseconds to pass the transitory period and stabilize. However, even during the fault period, the AC network has not collapsed, hence service to the customers is not disrupted, which is again a major design goal for any circuit breaker design.

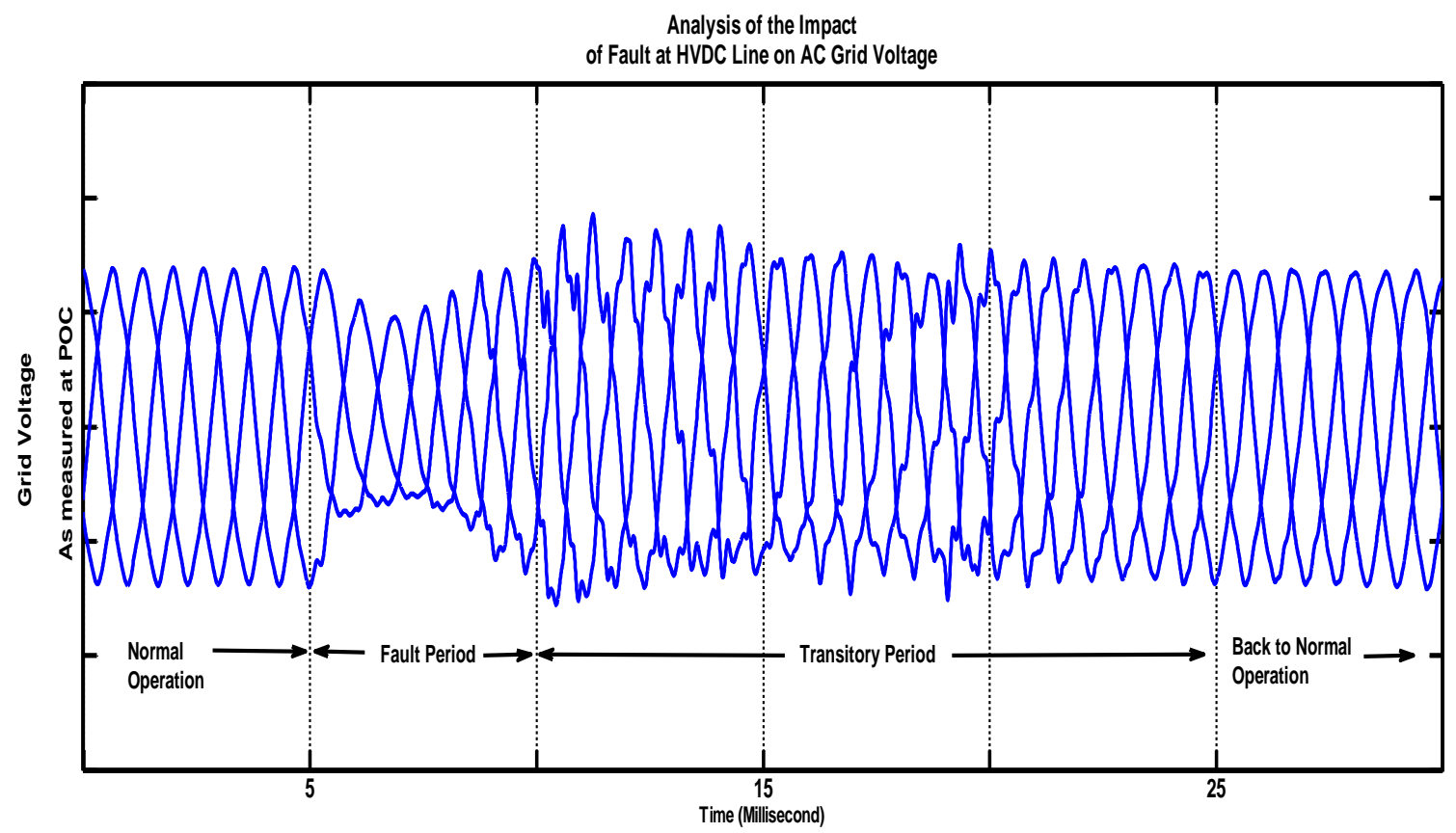

Fig. 5-14 Three-phase voltage on AC grid bus

It is obvious that after any fault or short circuit incident, it takes some time for the converter to regulate the voltage and maintain it at a constant level. All the figures presented in this section shows that after fault clearance, the VSC's controller makes attempt to increase the voltage to rated value. However, typically an overshoot occurs within a few milliseconds, and then reduces the voltage and successfully keeps it constant. Duration of transitory period depends on the control system integrated into the HVDC system and other grid parameters, which requires an analysis and discussion beyond the scope of this thesis. 
However, the focus of our model is to verify the functionality of the circuit breaker and while attaining the design goals enlisted for the breaker, which have been successfully achieved. Once again, it is of high importance to realize that the circuit breaker has reacted to the fault occurrence much faster than the converter, hence safeguarded the system against fault and minimized the service disruption, which all constitute the main purpose of utilizing circuit breakers in the electrical system.

\subsection{Simulation Results}

As verified in both simple and complex models, the proposed circuit breaker topology has successfully detected, and isolated the fault within a few milliseconds. Our primary goal was to keep the detection and clearance period under 5 milliseconds recommended by ABB [4] which is achieved in both scenarios. Furthermore, we expected the circuit breaker to protect the voltage source converter by blocking any backflow of energy which is stored in the line, and provide an alternative means to absorb and dump that energy. As illustrated, instead of relying on a surge voltage arrester, mutual inductance diverts the line energy to the branch consisting a capacitor and resistance. One of our objectives, has been replacing a $\mathrm{ZnO}$ arrester with simple elements which possess higher ruggedness and life expectancy.

The complex model, incorporates all the complexities of a fully integrated HVDC / HVAC system and pertinent parameters. The comparison of the currents of both HVAC and HVDC

lines, clearly demonstrates that circuit breaker has been able to detect the fault, and clear it within a few milliseconds, hence keeping both converter and line safe from further damages. The rapid reaction of the circuit breaker is quite important as it prevents the collapse of converter, and keeps it functional until the short circuit is eliminated.

To maintain the generation, industrial circuit breakers are designed to reclose the system after a few milliseconds, and therefore minimize the negative effect of fault, which could be a blackout. The proposed circuit breaker also recloses the system over a predetermined number of times, until the fault is cleared. 


\subsection{Pros and Cons of Proposed Topology}

Engineering design is a process through which our endeavors are targeted at solving a problem, while considering all practical constraints. In many cases, the outcome would be a trade-off between different interplaying parameters. Depending on priorities, the design addresses some of the concerns while making a compromise on others. Our proposed design is not an exception.

We have already established that other designs, regardless of the type of switch, utilize surge arresters to dump the energy stored in line inductance. Metallic surge arresters, especially $\mathrm{ZnO}$ arresters, are commercially produced in large volumes, hence are reasonably priced. Moreover, they are much lighter than the proposed mutual inductance in our design. For instance a $230 \mathrm{kV}$ station class surge arrestor, depending on the maximum discharge voltage and protection class, is typically around a few thousands of US dollars. However, an air-core dry type mutual inductance would cost in the order of few tens of thousands US dollars. However, mass production of such mutual inductances will lead to substantial reduction in production costs.

Therefore, it might be argued that the proposed topology would be more expensive than existing solution. However, as explained, safety of both humans and electrical equipment are of outmost importance. In particular, on offshore substations, where all apparatus are assembled in closest possible vicinity to save space, safety concern and having a higher safety design margin would be a higher priority.

Moreover, to present the cost comparison in a more accurate way, it is necessary to consider the total cost of the system over its useful life, which is sometimes referred to as life-cycle cost analysis. In such an analysis, following factors are accounted for:

- Initial expenditure (capital investement)

- Operational costs

- Maintenance costs including preventive replacements and unforeseen repairs

- End of life (decommissioning and salvage) costs 
- $\quad$ Risks and values

Although the proposed topology entails higher capital investment, the repair and maintenance costs over the long run would be much less than other topologies that utilize $\mathrm{ZnO}$ arresters. A mutual inductance, is virtually a maintenance free element that exhibits very long MTBT and MTTF rates. No scheduled maintenance or replacement is required to keep the mutual inductance functioning. On the other hand, after each short circuit current, the absorbed energy is easily dissipated by the winding into the surrounding air, hence aging or accelerated aging due to thermal stress will not be an issue. However, the aging is a concern in metal oxide varistors, and they should be replaced whenever the voltage-current characteristic is deteriorated or not corresponding the initial values.

It is worth mentioning that the repair and maintenance cost of any industrial equipment is much higher than the initial cost of spare parts or replacement parts, as mobilization of tools and crew could be much higher than the parts used. In remote generating stations, like offshore wind farms where accessing the station requires deploying barges and cranes, mobilization costs could be hefty. To summarize, taking the total operational costs of the HVDC circuit breaker over its expected life into account, the topology which uses the mutual inductance will prove to be more appealing.

On a different note, it shall be reminded that mechanical circuit breakers, and their hybrid offspring, have almost negligible losses as the Ohmic resistance of the metallic contacts are typically quite low. On the other hand, all solid-state designs, including our proposed topology, suffer from higher losses due to conduction losses of valves utilized. Currently the conduction resistance of most power switches is around tens of milli-Ohms. For high power high current HVDC transmission lines it could be a huge disadvantage. However, from a holistic point of view, the total losses of the circuit breaker compared to the losses caused by Ohmic resistance of power cables would be very small. Yet, new advancements in production of newer and more efficient semi-conductive materials and switches, constantly push the frontiers forward and make them more attractive choices.

And finally to the advantage of solid-state breakers, it shall be added that having no mechanical actuator or any moving part, directly translates to less mechanical wear and tear. 
An outcome that is long proved in any battle between a mechanical device and its solid-state counterpart.

Following table summarizes the pros and cons of different type of breakers.

\begin{tabular}{|l|c|c|c|}
\hline Characteristics & Mechanical & Hybrid & $\begin{array}{c}\text { Proposed } \\
\text { Solid-State }\end{array}$ \\
\hline Weight \& Footprint & - & - & + \\
\hline Wear \& Tear & - & - & + \\
\hline Price & + & - & + \\
\hline Modularity & - & - & + \\
\hline Integration with System's Control Scheme & - & + & + \\
\hline Detection Speed & - & + & + \\
\hline Fault Clearance Speed & - & + & + \\
\hline Efficiency & + & + & + \\
\hline Not utilizing ZnO Arrester & + & + & + \\
\hline
\end{tabular}




\subsection{Practical Considerations}

\subsubsection{Selection of Switches}

The key role of power electronics in new circuit breaker designs in undeniable. Most companies are now trying to replace traditional mechanical devices with their electronic counterparts. A thought through and experimentally verified design, along with adopting a proper selection procedure for the parts ensure safe and long lasting operation of the apparatus in wind farm industry [26]. Not surprisingly, rreliability and performance of the circuit breaker over the long run depends on the selection of suitable solid-state valves which will be utilized to pass through or block the current. Typically following criteria are important in selection of the switches:

Rated operating voltage, collector-emitter voltage $V_{\text {CES }}$

Rated operating current, DC collector current $\mathrm{I}_{\mathrm{C}}$

Maximum short duration current, peak collector current $\mathrm{I}_{\mathrm{CM}}$

Isolation voltage, $\mathrm{V}_{\text {isol }}$

Breakdown voltage, collector-emitter breakdown voltage $\mathrm{V}_{(\mathrm{BR}) \text { CES }}$

Total power dissipation, $\mathrm{P}_{\text {tot }}$

Switching frequency, $\mathrm{f}_{\mathrm{s}}$

Switching characteristics

Losses and cooling method (water-cooled, air-cooled, etc.)

Safe Operating Area, and Short Circuit SOA t $\mathrm{psc}$ 
It is necessary to bear in mind that for high voltage applications, a solid-state valve constitutes a number of switches connected in series and parallel to be able to handle both operating voltage and current.

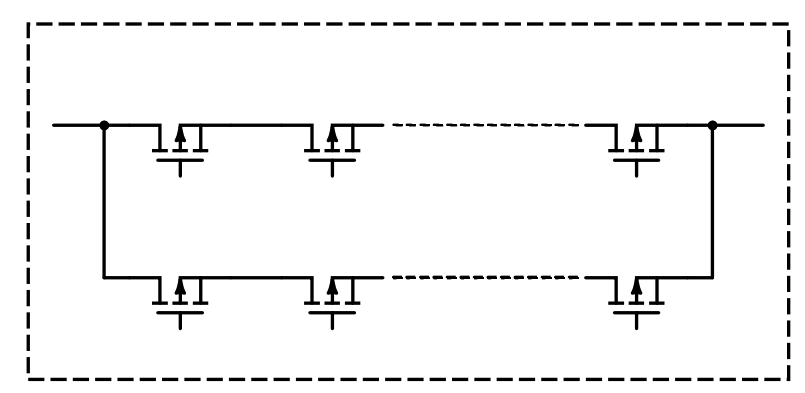

Fig. 5-15 Typical solid-state valve comprising of both series and parallel switches

Therefore, considering appropriate means for voltage equalization among the switches will be mandatory. Moreover, a liberal safety margin during the design process is highly recommended [24].

In the complex simulation, we examined connection of a $200 \mathrm{MW}$ wind farm to the grid. Since a bipolar HVDC operating at $+100 \mathrm{kV}$ and $-100 \mathrm{kV}$ deployed to transfer the power, each pole carries $100 \mathrm{MW}$ which equals to $1000 \mathrm{~A}$ per line. Therefore, we have to select solid-state valves that can safely and reliably function at $100 \mathrm{kV}$ and pass $1000 \mathrm{~A}$.

There are several well-known manufacturers for solid-state switches such as Semikron, Mitsubishi-Powerex, Microsemi, Hitachi, CNR, Danfoss, Fuji, IXYS, and ABB. However, in this example we have considered ABB's 5SNA 2000K450300 StakPak IGBT Module. Based on the datasheet, following characteristics are confirmed:

$$
\begin{aligned}
& \mathrm{V}_{\mathrm{CES}}=4500 \mathrm{~V} \max (\text { collector }- \text { emitter voltage }) \\
& \mathrm{I}_{\mathrm{C}}=2000 \mathrm{~A} \max (\text { DC collector current }) \\
& \mathrm{I}_{\mathrm{CM}}=4000 \mathrm{~A} \max \left(\text { peak collector current, } \mathrm{t}_{\mathrm{p}}=1 \mathrm{~ms}\right) \\
& \left.\mathrm{I}_{\mathrm{SC}}=9000 \mathrm{~A} \text { (short circuit current }\right)
\end{aligned}
$$




$$
\begin{aligned}
& \left.\mathrm{I}_{\mathrm{FSM}}=32000 \mathrm{~A} \text { (surge current }\right) \\
& \mathrm{P}_{\mathrm{tot}}=25000 \mathrm{~W} \text { (total power dissipation) } \\
& \mathrm{T}_{\mathrm{psc}}=10 \mu \mathrm{s}\left(\mathrm{IGBT} \text { short circuit SOA, } \mathrm{V}_{\mathrm{CC}}=3400 \mathrm{~V}, \mathrm{~V}_{\mathrm{CEM} \mathrm{CHIP}}<4500 \mathrm{~V}\right) .
\end{aligned}
$$

Considering the total power that this pack can deliver while remaining in the safe operating area, i.e. $25 \mathrm{~kW}$, and in order to eliminate need for any parallel pack, each valve would be able to handle $2500 \mathrm{~V}$ when passing a current of $1000 \mathrm{~A}$ through. Therefore, for a $100 \mathrm{kV}$ line, we need forty packs of 5SNA 2000K450300 to be installed in series.

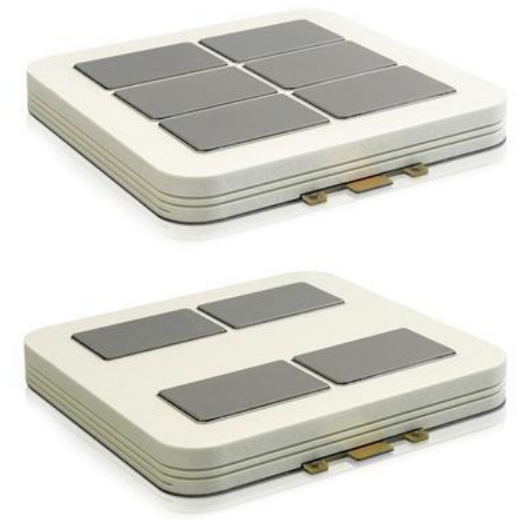

Fig. 5-16 IGBT pack type 5SNA 2000K450300, source ABB's website

Both maximum collector current of $4 \mathrm{kA}$ and surge current of $32 \mathrm{kA}$ make the selected IGBT pack a suitable choice for the HVDC system we simulated. The turn-on delay time in worst case is $800 \mathrm{~ns}$ which is much faster than the response time of the circuit breaker which is in the order of few milliseconds.

Fig. 5-18 illustrates the relationship between the collector current and voltage drop between collector and emitter. As shown on the graph, at $1000 \mathrm{~A}$ and elevated temperature $\mathrm{t}=125^{\circ} \mathrm{C}$, the forward voltage drop would be less than $2.5 \mathrm{~V}$. Therefore, total losses of the solid-state valve considered for the circuit breaker would be:

$$
P_{\text {loss.tot }}=\mathrm{N} \mathrm{I}_{\mathrm{C}} \mathrm{V}_{\mathrm{CE}}
$$


Where:

$\mathrm{P}_{\text {loss.tot }}=$ total conduction loss attributable to circuit breaker valve

$\mathrm{N}=$ number of IGBT packs in the valve, 40 in this case

$\mathrm{I}_{\mathrm{C}}=$ collector current at rated transmission line power, i.e. $1000 \mathrm{~A}$

$\mathrm{V}_{\mathrm{CE}}=$ voltage drop across collector-emitter junction, $2.5 \mathrm{~V}$

Putting the numbers in the equation, the total loss will be $100 \mathrm{~kW}$. Although this is a considerable loss compared to that of a mechanical breaker, the loss of the breaker is still less than the loss of $75 \mathrm{~km}$ of power cables that is used to connect the off shore wind farm to the grid in our example.

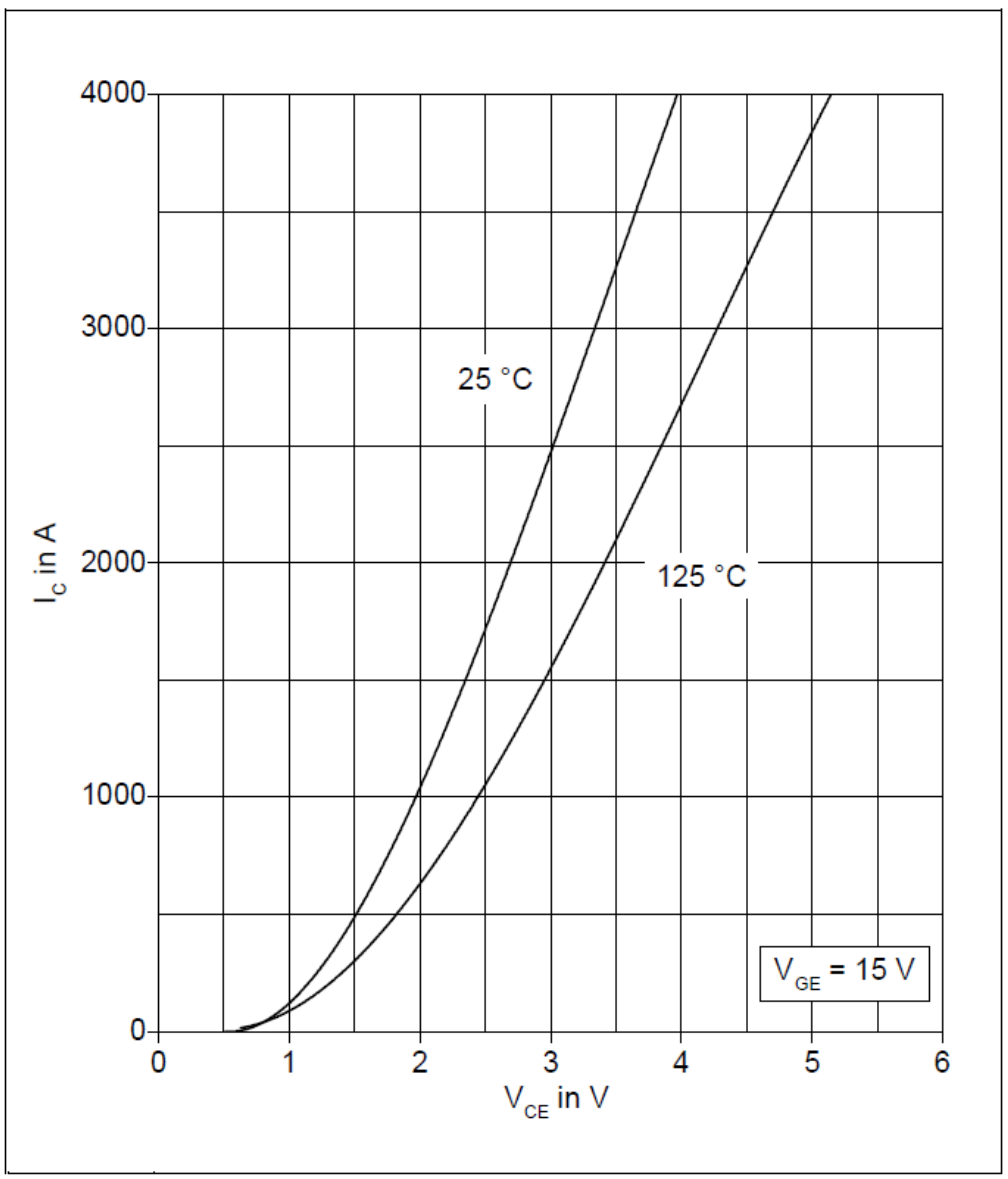

Fig. 5-17 Typical on-state characteristics for 5SNA 2000K450300, source ABB's product catalog 
There are several companies like Semikron, Amantys, Concept (IGBT-Driver), and Powerex who produce gate drivers for various IGBT manufacturers. Fig. 5-19 shows a typical gate driver for IGBT packs. Many such drivers send and receive commands using fibre optics, hence providing a full isolation between the circuit level voltage and gating signals.

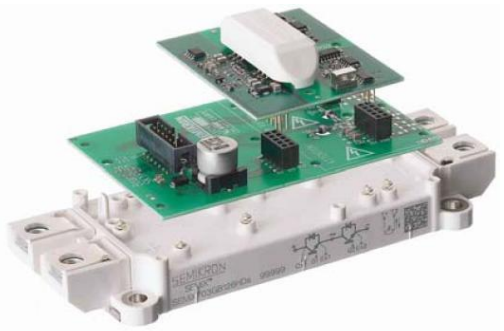

Fig. 5-18 Gate driver module for IGBT, source Semikron's website

Most existing gate drivers for IGBT packs used in high voltage, are equipped with communication capabilities which provide the required basis for relaying and coordination activities. In our simulation, both circuit breakers installed on positive transmission line and negative line must actuate simultaneously, otherwise the voltage source converter on the uninterrupted line will create an overvoltage in order to compensate for the loss of the other pole.

\subsubsection{Combining Mutual Inductance and Dumping Resistor}

Effective commercialization of any new product or innovation requires careful examination of both the market and product. Regardless of the market demand and economic factors, the equipment design shall be reviewed in order to ensure its reliability and performance. Moreover, before starting any manufacturing process, it is necessary to analyze each element, make decision on necessary trade-offs, and finally develop a buildable, efficient, and economically optimized prototype.

While working on the proposed topology, we realized that the second winding of mutual inductance and the resistor in series with it could be combined together. In other words, if the secondary winding could be wound by using conductor materials other than pure electrical copper. Such alloys are commercially available, hence the second winding inherently yields a 
higher Ohmic resistance. If designed correctly, the Ohmic resistance of the winding can precisely match the required value for the dump resistor, hence one element would be eliminated. This in turn leads to a system that is more robust and requires one less number of elements to manufacture.

In addition, in order to avoid saturation, mutual inductance must be built without any iron or ferrite core. Having air freely flowing through the windings of mutual inductance, the heat produced during the fault clearance and absorption of line energy will be easily dissipated.

In simulating the performance of the proposed topology, we used a mutual inductance of approximately $2 \mathrm{mH}$. Using the following formula, we can calculate the number of turn necessary for building such inductance:

$$
\mathrm{L}=l^{-1} \mu_{0} \mathrm{KN}^{2} \mathrm{~A}
$$

Where:

$\mathrm{L}=$ inductance in Henries

$l=$ length of coil in meters $(\mathrm{m})$

$\mu_{0}=$ permeability of free space, $4 \pi \times 10^{-7} \mathrm{H} / \mathrm{m}$

$\mathrm{K}=$ Nagaoka coefficient (approximately unity, for a coil that are longer than its diameter)

$\mathrm{N}=$ number of turns

$\mathrm{A}=$ cross sectional area of the coil in square meters $\left(\mathrm{m}^{2}\right)$

Based on the above formula, a coil with a diameter of 0.25 meter, height of 2 meters, and having 190-200 turns yields an inductance of approximately $2 \mathrm{mH}$. As Nagaoka coefficient is practically less than unity, the best practice will be building the inductor and adjusting its inductance by adding or removing one or two turns.

The total length of the wire required to wind the inductor would be 150 meters. Therefore, selecting the right wire of Nickel Chrome alloy will easily yield the required resistance. 


\section{Chapter Six: Conclusion}

\subsection{Conclusions}

In this thesis, a new topology for HVDC circuit breaker is proposed. As more offshore wind farm generating stations are going to be realized in the course of the next decades, their integration with existing grid in a safe and controllable manner is of high importance [29]. The topology we have developed deploys solid state valves for current interruption, and utilizes a mutual inductance to divert the energy stored in the line to a resistor. In other words, transient voltage and backward current generated at the time of circuit disruption are controlled in a manner that safeguards the valves and converter.

The new topology was developed such that no surge arrester would be necessary to protect the system against energy surges. Instead, a mutual inductance is embedded in the design, which diverts any current surge into a peripheral branch consisting a resistor. Mutual inductance and resistor are both robust elements (compared to metal oxide arresters), which respond to surges without any delay. At the time of breaking the circuit, resistor converts the energy stored in the line to heat. There is no residual voltage, no necessary time delay between consecutive surges, thus a very robust and practical solution. It is noteworthy that this design will be applicable to direct current systems only, as mutual inductance's behaviour is completely different in AC systems. As a result, the new design can be utilized in HVDC applications.

A scaled-down low voltage prototype would be of no empirical significance, because the amount of transient energy and impulse levels generated in low voltage systems are tolerable by most conventional solid-state valves. In addition, practical issues such as balancing the voltage among switches connected in series, producing synchronized gating signals, controlling

partial discharge, insulation level coordination, and many other factors that are important in high voltage systems, are absent or ignorable at lower voltages.

Since performance verification of the proposed breaker design has been done by simulation, it is important to corroborate the results. Therefore, two separate models that emulate two entirely different scenarios are developed. In a simple model, the performance of the circuit 
breaker has been tested in fault detection and fault isolation of a $40 \mathrm{~km}$ long transmission line operating at $+300 \mathrm{kV}$. In a second simulation, the circuit breaker embedded as the protecting device after the voltage source converter which feeds the energy extracted from a $200 \mathrm{MW}$ wind farm over a bipolar HVDC transmission line to the grid. The line operates at $+/-100 \mathrm{kV}$. In the latter simulation, wind turbines are connected to a collecting station, which transmits the energy via step-up transformer to voltage source converter. At the end of the line, another converter transforms the high voltage DC to alternating current which is connected to a $2000 \mathrm{MVA}$ grid. Various cases has been modeled and the best results were achieved with a mutual inductance which equals ten percent of total line inductance. Higher inductances interferes with system control, and lower inductance revealed to be insufficient. Outcomes of both simulations are consistent, and validate effectiveness of the proposed breaker design. Contrary to other solidstate topologies that have been developed by other researchers, this novel topology is not dependent on zinc oxide arresters for absorbing the energy, but efficiently diverts and dumps the energy in a resistor.

Therefore, it has been shown and proven that the proposed novel topology can detect and isolate faults in the order of several kilo amperes in less than few milliseconds. The new circuit breaker design utilizes solid-state valves and incorporates a mutual inductance and $\mathrm{R}-\mathrm{C}$ branch for absorption of line energy at the time of current interruption. Therefore, in contrast with existing topologies, no surge arrester is required to suppress and dump surges. This topology is specifically applicable to and valid for HVDC technology, and cannot be utilized in HVAC. Remarkably, while existing designs have tried to overcome difficulties of disrupting current in DC applications, the proposed topology takes advantage of direct current characteristics by using a mutual inductance to divert line energy to a dumping resistor; the energy that could inflict irreversible damages to voltage source converters.

\subsection{Main Contribution}

This thesis further on pervious researches done on developing a reliable, yet sturdy and simple circuit breaker for high voltage direct current transmission lines. While most circuit breakers which are industrially available are using a mechanical interrupter, as the only current 
interrupting device or in combination with solid state valves (hybrid designs), this research shows the possibility of manufacturing a simple solid state circuit breaker without any need for zinc oxide arresters. Such a circuit breaker when commercially available, will substantially enhance the performance and reliability of HVDC transmission grid, and multi-terminal systems in particular.

Based on the research work, following contributions can be stated:

- A new topology for HVDC circuit breaker has been developed. This topology allows the circuit breaker to detect and isolate the faults within few milliseconds, before the relevant side effects propagate through the system and damages the voltage source converter or other equipment installed on the faulty line. To maintain the functionality of the system as a whole, and minimize the negative effects, the circuit breaker detects and isolates the faults in less than 5 milliseconds. Minimizing the risks and negative impacts of faults occurring at wind farm generating stations and lines is among the strict requirements that is set force by regulatory bodies in many countries including US and Canada [27, 28].

- A new method to suppress and dissipate the energy stored in long transmission lines and other lump inductances of the system is developed. This method utilizes a mutual inductance and an $\mathrm{R}-\mathrm{C}$ branch which all are robust in structure and have long life expectancy compared to metallic oxide arrestors.

- The novel topology developed in this research is proved to be quite fast in both detecting and isolating the fault, and also absorbing line energy. The traditional methods which utilize mechanical switches cannot be as fast as solid-state switches due to high mass of the actuator and momentum of the mechanical system.

- $\mathrm{ZnO}$ arresters rely on changes in the molecular structure of the material to drop the resistivity of the element during voltage surges. Therefore, there is always a delay between the onset of detection of high voltage surge, and subsequent reduction in material resistance. In addition to this, the surge arrestor needs some time to eliminate the residual voltage across its terminals. In this research, the energy is consumed and dissipated by a resistor which inherently has no time lag to response to the system. 
Furthermore, the mutual inductance responds to current irregularities. Therefore, even if the back flow of energy from line to converter does not constitute a high voltage surge, the mutual inductance will divert the energy away from converter; a huge advantage over surge arrestor that functions based on the voltage applied across its terminals.

- Two simulation models are put forth to test the applicability and performance of the HVDC circuit breaker. Both models corroborate the results and verify the expected outcome of the proposed circuit breaker topology.

\subsection{Future Works}

Based on the research outcomes, followings are suggested for further research:

- Building a prototype operating at high voltage, in order to identify any problematic aspect and enhance the performance of the proposed topology.

- Developing a design based on variable mutual inductance in order to fine tune the performance of the breaker according to specific line requirements.

- Designing a novel control method for the proposed circuit breaker topology.

- Studying the possibility of integrating a similar circuit breaker topology inside converters, in order to increase their internal safety against likely faults on transmission lines, and preventing the inrush current toward the converter.

- Conducting further studies on developing a combination of mutual inductance and high pass filter as a replacement to $\mathrm{ZnO}$ zing oxide surge arresters in transmission industry. 


\section{References}

[1] J. Charles and C. Clark," A Fresh Look At Wind, reflections on where we are going," IEEE PES: Power and Energy Magazine, vol. 11, no. 6, pp. 16-19, Nov/Dec 2013.

[2] J. P. Harrison, "Wind Turbine Noise". Bulletin of Science, Technology \& Society, vol. 31, no. 4, pp. 256-261, Sage Publications, 2011.

[3] L. Colla, F. M. Gatta, A. Geri, S. Lauria and M. Maccioni, "Steady-state operation of very long EHV AC cable lines," PowerTech, pp. 1-8, IEEE Bucharest, Jun. - Jul., 2009.

[4] C. M. Franck, "HVDC Circuit Breakers: A Review Identifying Future Research Needs," IEEE Trans. Power Delivery, vol. 26, pp. 998-1007, 2011.

[5] Peng Chang, Wen Jia-liang, Wang Xiu-huan, Liu Zhi-Gang and Yu Kun-shan, "Application research and prototype development of $\pm 800 \mathrm{kV}$ UHVDC breaker" Sec. Int'l Conf. Intelligent System Design and Engineering Application (ISDEA), pp. 1387-1391, Sanya, Hainan, China, Jan. 2012.

[6] B.L. Damsky, P. Barkan, I. Imam, W. Premerlani, “A New HVDC Circuit Breaker Design System for $\pm 400 \mathrm{kV}, " 7^{\text {th }}$ IEE/PE Transmission and Distribution Conf. and Exp., CH11395/0000-0230500, 75, Apr. 1979

[7] Yeqi Wang and R. Marquardt, "Future HVDC-grids employing modular multilevel converters and hybrid DC-breakers," $15^{\text {th }}$ European Conf. on Power Electronics and Applications (EPE), pp. 1-8, Lille, France, Sep. 2013.

[8] Kenichiro Sano and Masahiro Takasaki, "A Surge-Less Solid-State DC Circuit Breaker for Voltage Source Converter Based HVDC Transmission Systems," IEEE Trans. Industry Applications, Vol. 50, no. 4, pp. 2690-2699, Dec. 2013.

[9] C. Meyer, M. Kowal, and R. W. De Doncker, "Circuit Breaker Concepts for Future Highpower DC Applications," 40 th IAS Annual Meeting Conf., Oct. 2005, vol. 2, pp. 860-866, Oct. 2005. 
[10] Taylor James, "Short Circuit Behaviour, Surge Arresters and Counters," ABB Power Products, Ludvika Sweden. [online]. available:

http://www05.abb.com/global/scot/scot245.nsf/veritydisplay/57c525bdc7615021c12572d5 0040a56a/\$File/Short\%20circuit\%20behaviour\%20$\% 20$ Surge\%20arresters\%20and\%20counters.pdf.

[11] John J. Vithayathil, "HVDC Breaker and Its Applications," presented at Int'l Symp. HVDC Technology, Rio de Janeiro, Brazil, 1983.

[12] M. Jafar and M. Molinas, "Effects and mitigation of post-fault commutation failures in linecommutated HVDC transmission system," IEEE Int'l Symp. Industrial Electronics ISIE, pp. 81-85, Seoul, Korea, Jul. 2009.

[13] D. Jovcic, M. Hajian and L. Zhang, "DC transmission grids with fault tolerant LCL VSC converters and mechanical DC circuit breakers," presented at $10^{\text {th }}$ IET Int' 1 Conf. AC and DC Power Transmission (ACDC 2012), pp. 1-6, Birmingham, UK, Dec. 2012.

[14] Lianxiang Tang and Boon-Teck Ooi, "Locating and Isolating DC Faults in Multi-Terminal DC Systems," IEEE Trans. Power Delivery, vol. 22, no. 3, pp. 1877-1884, Jul. 2007.

[15] J. Yang, J. E. Fletcher, J. O'Reilly, G. P. Adam and S. Fan, "Protection scheme design for meshed VSC-HVDC transmission systems of large-scale wind farms," $9^{\text {th }}$ IET Inte'l Conf. AC and DC Power Transmission, pp. 1-5, London, UK, Oct. 2010.

[16] M. Hajian, D. Jovcic and Bin Wu, "Evaluation of Semiconductor Based Methods for Fault Isolation on High Voltage DC Grids," IEEE Trans. Smart Grid, vol. 4, no. 2, pp. 1171-1179, Mar. 2013.

[17] F. Musavi, M. Edington, W. Eberle and W. G. Dunford, "The effect of ripple steering on control loop stability for a CCM PFC boost converter," Energy Conversion Cong. and Exp. (ECCE) 2011, pp. 3193-3199, Phoenix, AZ, Sep., 2011

[18] Natural Resources Defense Council, "Renewable energy for America, Harvesting the benefits of homegrown renewable energy", available: http://www.nrdc.org/energy/renewables/wind.asp 
[19] U. Axelsson, A. Holm, C. Liljegren, M. Aberg, K. Eriksson and O. Tollerz, "The gotland HVDC Light Project Experience from Trail and Commerical Operation," in Electricity Distribution, 2001. Part 1: Contributions. CIRED. 16 ${ }^{\text {th }}$ Inte'l Conf. and Ex., Electricity Distribution, Part 1: Cobributions, CIRED, IEE Conf. Publ. no. 482, vol. 1, Amesterdam, Netherlands, Jun. 2001.

[20] A. Prasai, Jung-Sik Yim, D. Divan, A Bendre and Seung-Ki Sul, "A New Architechture for Offshore Wind Farms," IEEE Trans. Power Electronics, vol. 23, no. 3, pp. 1198-1204, May 2008.

[21] A. D. Hansen, P. Sorensen, F. Iov and F. Blaabjerg, "Centralised Power Control of Wind Farm with Doubly Fed Induction Generators," Renewable Energy, vol. 31, no. 7, pp. 935951, Jun. 2006.

[22] L. Xu and B. R. Andersen, "Grid Connection of Large Offshore Wind Farms Using HVDC," Wind Energy, vol. 9, no. 4, pp. 371-382, Jul. - Aug. 2006.

[23] G. Ramtharan, A. Arulampalam, J. Ekanayake, F. Hughes and N. Jenkins, "Fault Ride Through of Fully Rated Converter Wind Turbines with AC and DC Transmission," IET Renewable Power Generation, vol. 3, no. 4, pp. 426-438, Dec. 2009.

[24] Application Note 5SYA 2031-04, "Applying IGCT Gate Units," ABB Switzerland, Aug. 2013, [online]. Available:

http://www05.abb.com/global/scot/scot256.nsf/veritydisplay/a22646d1cf5f4a31c12578620 02863e8/\$file/Applying\%20IGCT\%20gate\%20units_5SYA\%202031.pdf

[25] M. P. Bahrman and B. K. Johnson, "The ABCs of HVDC Transmission Technologies," IEEE Power and Energy Magazine, vol. 5, no. 2, pp. 32-44, Mar. / Apr. 2007.

[26] Z. Chen, J. M. Guerrero and F. Blaabjerg, "A Review of the State-of-the-art Power Electronics for Wind Turbines," IEEE Trans. Power Electronics, vol. 24, no. 8, pp. 18591875, Aug. 2009. 
[27] S. Heier and R. Waddington, "The Transfer of Electrical Energy to the Supply Grid," in Grid Integration of Wind Energy Conversion Systems, $3^{\text {rd }}$ ed., West Sussex, UK: J. Wiley \& Sons, 2014, pp. 210-346.

[28] “Grid Code, High and Extra High Voltage, “ E. ON Nez GmbH, Bayreuth, Germany, Apr. 2006.

[29] Lie Xu, Liangzhoung Yao and C. Sasse, "Grid Integration of Large DFIG-Based Wind Farms Using VSC Transmission,” IEEE Trans. Power Systems, vol. 22, no. 3, pp. 976-984, Aug. 2007.

[30] K. G. Ringler, P. Kirkby,C. C. Erven, M. V. Lat, T. A. "The Energy Absorption Capability and Time-to-failure of Varistors Used in Station-class Metal-oxide Surge Arresters," IEEE Trans. Power Delivery, vol. 12, no. 1, pp. 203-212, Jan. 1997

[31] B. Wu, "Multilevel Voltage Source Converters" in High Power Converters and AC Drives, $1^{\text {st }}$ ed., Hoboken, NJ: J. Wiley \& Sons - IEEE Press, 2006, pp. 93-186.

[32] A. Yazdani and R. Iravani, "Back-to-Back HVDC Converstion Systems, in Voltage Sourced Converters in Power Systems, Modeling, Control, and Applications, $1^{\text {st }}$ ed., Hoboken, NJ: J. Wiley \& Sons - IEEE Press, 2010, pp. 334-384.

[33] C. Kim, V. K. Sood, G. Jang, S. Lim and S. Lee, "Fault Behaviour and Protection of HVDC System," in HVDC Transmission, Power Conversion Applications in Power Systems, $1^{\text {st }}$ ed., Sigapore: J. Wiley and Sons, 2009, pp. 257-278. 


\section{Appendix}

\section{A) Simulink Model - Simple Simulation}

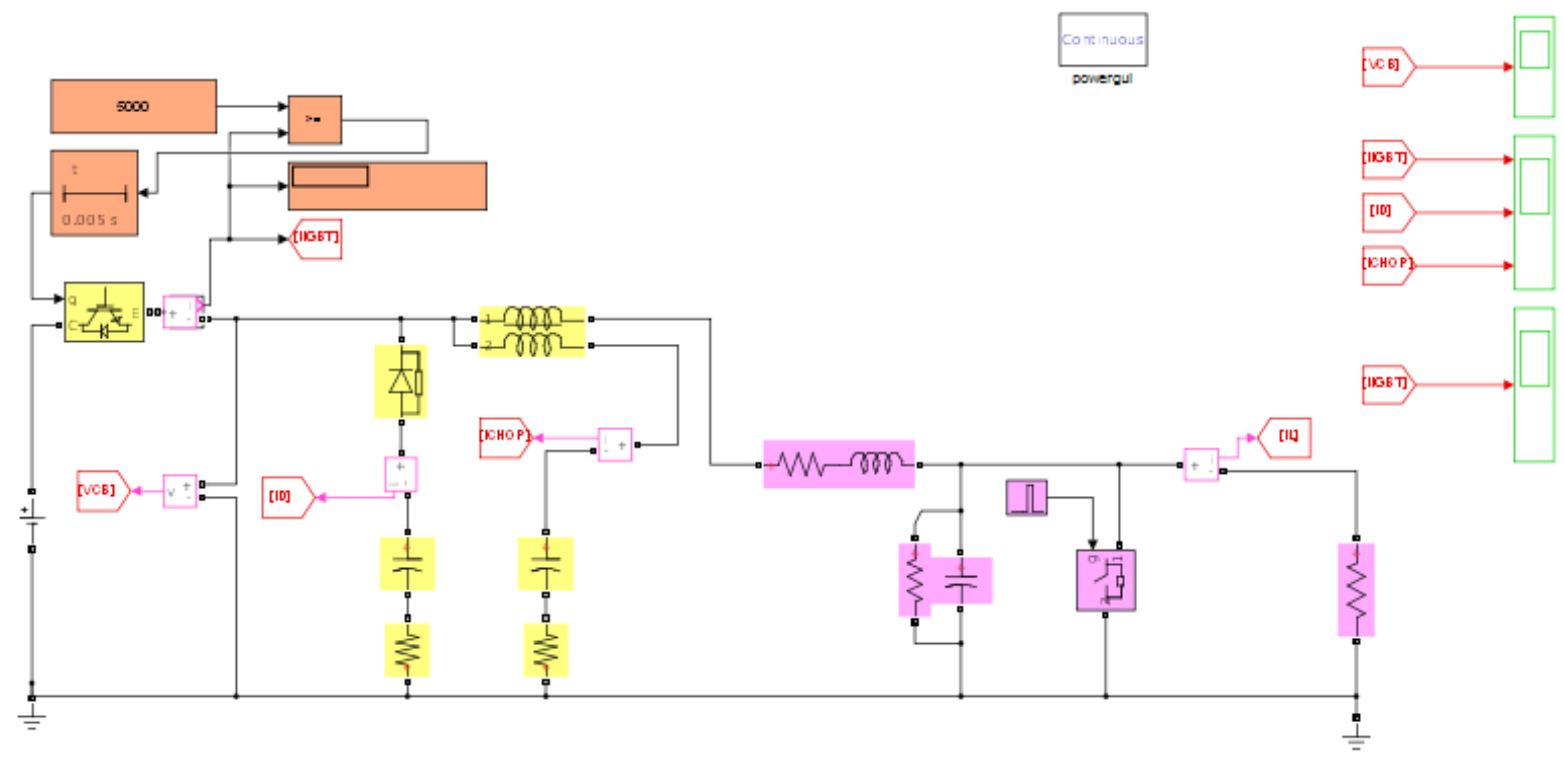

Table 1. Constant Block Properties

\begin{tabular}{|l|l|l|l|l|l|l|}
\hline Name & Value & Sampling Mode & Out Data Type Str & Lock Scale & Sample Time & Frame Period \\
\hline Constant & 5000 & Sample based & Inherit: Inherit from 'Constant value' & off & inf \\
\hline
\end{tabular}

Table 2. DC Voltage Source Block Properties

\begin{tabular}{|l|l|l|}
\hline Name & Amplitude & Measurements \\
\hline DC Voltage Source & $3.0 \mathrm{e} 5$ & None \\
\hline
\end{tabular}

Table 3. Diode Block Properties

\begin{tabular}{|l|l|l|l|l|l|l|l|}
\hline Name & Ron & Lon & Vf & IC & Rs & Cs & Measurements \\
\hline Diode2 & 0.001 & 0 & 0.8 & 0 & 500 & $250 \mathrm{e}-9$ & off \\
\hline
\end{tabular}

Table 4. IGBT/Diode Block Properties 


\begin{tabular}{|l|l|l|l|l|}
\hline Name & Ron & Rs & Cs & Measurements \\
\hline IGBT/Diode & $1 \mathrm{e}-3$ & $1 \mathrm{e} 5$ & inf & off \\
\hline
\end{tabular}

Table 5. Mutual Inductance Block Properties

\begin{tabular}{|l|l|l|l|l|l|l|}
\hline Name & Type Of Mutual & $\begin{array}{l}\text { Self Impedance } \\
\mathbf{1}\end{array}$ & $\begin{array}{l}\text { Self Impedance } \\
\mathbf{2}\end{array}$ & $\begin{array}{l}\text { Three } \\
\text { Windings }\end{array}$ & $\begin{array}{l}\text { Mutual } \\
\text { Impedance }\end{array}$ & Measurements \\
\hline $\begin{array}{l}\text { Mutual } \\
\text { Inductance }\end{array}$ & $\begin{array}{l}\text { Two or three windings with equal } \\
\text { mutual terms }\end{array}$ & {$[0.12 .20 \mathrm{e}-03]$} & {$[0.12 .20 \mathrm{e}-03]$} & off & {$[0.21 .9 \mathrm{e}-03]$} & None \\
\hline
\end{tabular}

Table 6. PSB option menu block Block Properties

\begin{tabular}{|l|l|l|l|l|l|l|l|l|l|l|l|l|}
\hline Name & $\begin{array}{l}\text { Simulation } \\
\text { Mode }\end{array}$ & SPID & Frequencyindice & Pbase & $\begin{array}{l}\text { Err } \\
\text { Max }\end{array}$ & Iterations & $\begin{array}{l}\text { Units } \\
\text { V }\end{array}$ & $\begin{array}{l}\text { Units } \\
\text { W }\end{array}$ & $\begin{array}{l}\text { Function } \\
\text { Messages }\end{array}$ & Echomessages & $\begin{array}{l}\text { Enable Use } \\
\text { Of TLC }\end{array}$ & X0status \\
\hline powergui & Continuous & off & 0 & $100 \mathrm{e} 6$ & $1 \mathrm{e}-4$ & 50 & $\mathrm{kV}$ & $\mathrm{MW}$ & off & off & off & blocks \\
\hline
\end{tabular}

Table 7. Series RLC Branch Block Properties

\begin{tabular}{|l|l|l|l|}
\hline Name & Branch Type & Resistance & Measurements \\
\hline Series RLC Branch1 & R & 720 & None \\
\hline Series RLC Branch2 & RL & 30.667 & None \\
\hline Series RLC Branch3 & R & $1 \mathrm{e} 8$ & None \\
\hline Series RLC Branch4 & R & 100 & None \\
\hline Series RLC Branch5 & R & $1 \mathrm{e}$ & None \\
\hline Series RLC Brnch1 & C & 1 & None \\
\hline Series RLC Brnch2 & C & 1 & None \\
\hline Series RLC Brnch3 & C & 1 & \\
\hline
\end{tabular}




\section{B) Simulink Model - Complex Model}

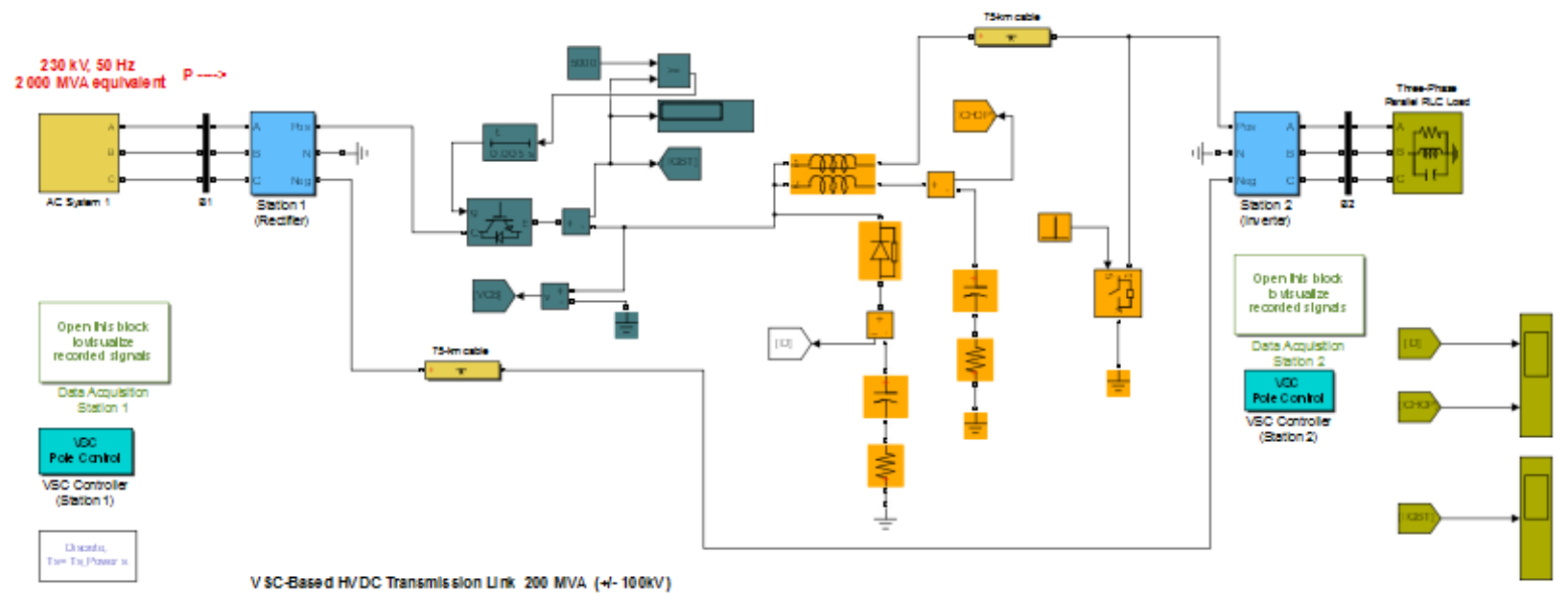

\begin{tabular}{|l|l|l|}
\hline Simulation Parameter & Value \\
\hline Solver & ode45 \\
\hline RelTol & $1 \mathrm{e}-3$ \\
\hline AbsTol & $1 \mathrm{e}-2$ \\
\hline Refine & 1 \\
\hline MaxOrder & 5 \\
\hline FixedStep & Ts_Power \\
\hline ZeroCross & on \\
\hline
\end{tabular}

Table 1. PSB option menu block Block Properties

\begin{tabular}{|c|c|c|c|c|c|c|c|c|c|c|c|c|}
\hline Name & $\begin{array}{l}\text { Simulation } \\
\text { Mode }\end{array}$ & SPID & Frequencyindice & Pbase & $\begin{array}{l}\text { Err } \\
\text { Max }\end{array}$ & Iterations & $\begin{array}{l}\text { Units } \\
\text { V }\end{array}$ & $\begin{array}{l}\text { Units } \\
\text { W }\end{array}$ & $\begin{array}{l}\text { Function } \\
\text { Messages }\end{array}$ & Echomessages & $\begin{array}{l}\text { Enable Use } \\
\text { Of TLC }\end{array}$ & XOstatus \\
\hline powergui & Discrete & off & 0 & $100 \mathrm{e} 6$ & $1 e-4$ & 50 & kV & MW & off & off & off & blocks \\
\hline
\end{tabular}

Table 2. Pi Section Line Block Properties

\begin{tabular}{|c|c|c|c|c|c|c|c|}
\hline Name & Frequency & Resistance & Inductance & Capacitance & Length & Pi Sections & Measurements \\
\hline 75-km cable & Fnom & $1.3900 \mathrm{e}-002$ & $1.5900 \mathrm{e}-004$ & $2.3100 \mathrm{e}-007$ & 75 & 2 & None \\
\hline 75-km cable & Fnom & $1.3900 \mathrm{e}-002$ & 1.5900e-004 & $2.3100 \mathrm{e}-007$ & 75 & 2 & None \\
\hline
\end{tabular}

System - CBComplex_Final_Oct2014/AC System 1

Sy stem 1

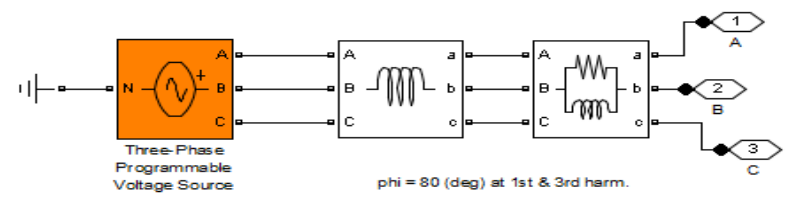




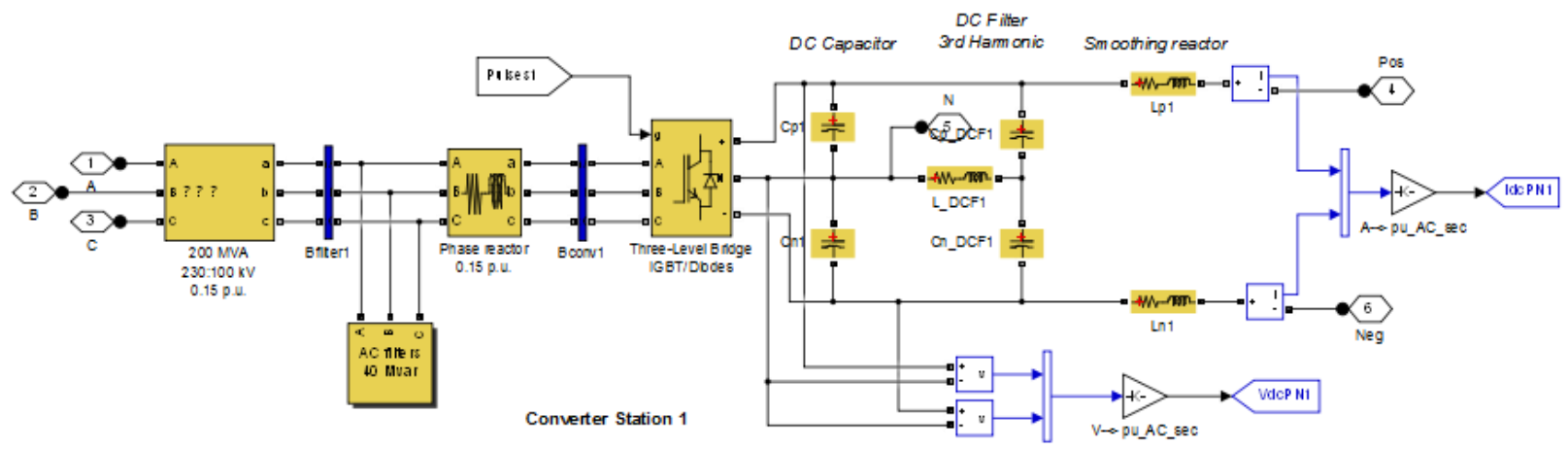

Table 3. Three-Level Bridge Block Properties

\begin{tabular}{|l|l|l|l|l|l|l|l|}
\hline Name & Arms & Snubber Resistance & Sbubber Capacitance & Device & Ron & Forward Voltages & Measurements \\
\hline Three-Level Bridge IGBT/Diodes & 3 & 5000 & $1 \mathrm{e}-6$ & IGBT / Diodes & $1 \mathrm{e}-3$ & {$[00$ ] } & None \\
\hline
\end{tabular}

Table 4. Three-Phase Series RLC Branch Block Properties

\begin{tabular}{|l|l|l|l|l|l|}
\hline Name & Branch Type & Resistance & Inductance & Capacitance & Measurements \\
\hline Phase reactor 0.15 p.u. & RL & $0.0015^{*}\left(100^{\wedge} 2 / 200\right)$ & $0.15^{*}\left(100^{\wedge} 2 / 200\right) /\left(2^{*}\right.$ pi*fnom $)$ & 1.0 & None \\
\hline
\end{tabular}

Table 5. Three-Phase Transformer (Two Windings) Block Properties

\begin{tabular}{|c|c|c|c|c|c|c|c|c|c|c|c|c|c|c|}
\hline Name & $\begin{array}{l}\text { Winding } \\
\text { 1Connectio } \\
n\end{array}$ & $\begin{array}{l}\text { UNIT } \\
S\end{array}$ & $\begin{array}{l}\text { Nomin } \\
\text { al } \\
\text { Power }\end{array}$ & $\begin{array}{l}\text { Windin } \\
\text { g } 1\end{array}$ & $\begin{array}{l}\text { Winding } \\
\text { 2Connectio } \\
n\end{array}$ & $\begin{array}{l}\text { Windin } \\
\text { g } 2\end{array}$ & $\begin{array}{l}\text { Set } \\
\text { Saturatio } \\
n\end{array}$ & $\mathbf{R m}$ & Lm & $\begin{array}{l}\text { Saturatio } \\
n\end{array}$ & Initial Fluxes & $\begin{array}{l}\text { Measuremen } \\
\text { ts }\end{array}$ & $\begin{array}{l}\text { Brea } \\
k \\
\text { Loop }\end{array}$ & $\begin{array}{l}\text { Dat } \\
\text { a } \\
\text { Typ } \\
\text { e }\end{array}$ \\
\hline $\begin{array}{l}200 \\
\text { MVA } \\
230: 10 \\
0 \mathrm{kV} \\
0.15 \\
\text { p.u. }\end{array}$ & Yg & pu & $\begin{array}{l}{[200 \mathrm{e} 6} \\
\text {, Fnom] }\end{array}$ & $\begin{array}{l}{[230 \mathrm{e} 3} \\
* 0.915 \\
0.0025 \\
0.075]\end{array}$ & Delta (D1) & $\begin{array}{l}{[100 \mathrm{e} 3} \\
0.0025 \\
0.075]\end{array}$ & off & $\begin{array}{l}50 \\
0\end{array}$ & $\begin{array}{l}50 \\
0\end{array}$ & $\begin{array}{l}{[0,0 ;} \\
0.012,1.2 \\
5 ; \\
1.012,1.6 \\
]\end{array}$ & $\begin{array}{l}{[-} \\
1.03850588171453 \\
0.52723323367613 \\
2 \\
0.51127264804170 \\
3]\end{array}$ & None & off & off \\
\hline
\end{tabular}

System - CBComplex Final Oct2014/Station 1 (Rectifier)/Filters 60Hz2

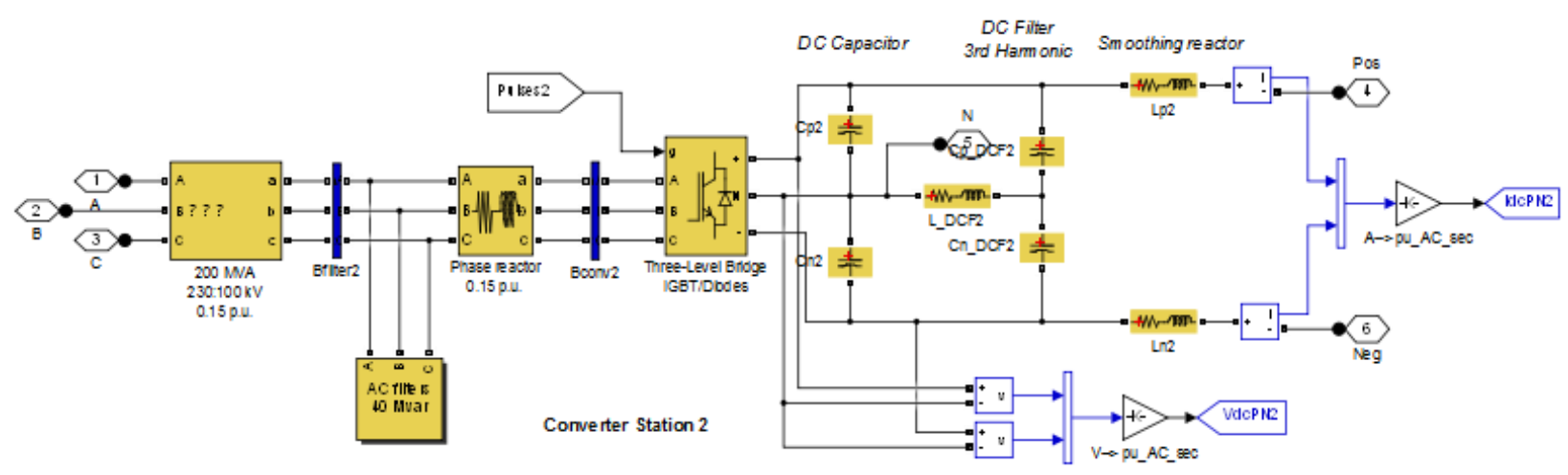

Table 6. Three-Phase Transformer (Two Windings) Block Properties 


\begin{tabular}{|c|c|c|c|c|c|c|c|c|c|c|c|c|c|c|}
\hline Name & $\begin{array}{l}\text { Winding } \\
\text { 1Connection }\end{array}$ & UNITS & $\begin{array}{l}\text { Nominal } \\
\text { Power }\end{array}$ & Winding 1 & $\begin{array}{l}\text { Winding } \\
\text { 2Connection }\end{array}$ & Winding 2 & $\begin{array}{l}\text { Set } \\
\text { Saturation }\end{array}$ & $\mathrm{Rm}$ & Lm & Saturation & Initial Fluxes & Measurements & $\begin{array}{l}\text { Break } \\
\text { Loop }\end{array}$ & $\begin{array}{l}\text { Data } \\
\text { Type }\end{array}$ \\
\hline $\begin{array}{l}200 \text { MVA } \\
230: 100 \\
\text { kV } 0.15 \\
\text { p.u. }\end{array}$ & Yg & $\mathrm{pu}$ & $\begin{array}{l}\text { [200e6 } \\
\text { Fnom] }\end{array}$ & $\begin{array}{l}{[230 \mathrm{e} 3} \\
* 1.015 \\
0.0025 \\
0.075]\end{array}$ & $\begin{array}{l}\text { Delta } \\
\text { (D1) }\end{array}$ & $\begin{array}{l}{[100 \mathrm{e} 3} \\
0.0025 \\
0.075]\end{array}$ & off & 500 & 500 & $\begin{array}{l}{[0,0 ;} \\
0.012,1.25 \\
; 1.012,1.6\end{array}$ & $\begin{array}{l}{[-1.00735070526646} \\
0.511416236666093 \\
0.495934468600514]\end{array}$ & None & off & off \\
\hline
\end{tabular}

Table 7. Three-Phase Harmonic Filter Block Properties

\begin{tabular}{|c|c|c|c|c|c|c|c|}
\hline Name & Filter Type & Filter Connection & Par Nom & Qc & Frd & $\mathbf{Q}$ & Measurements \\
\hline 27th $18 \mathrm{Mvar} \mathrm{Q}=15$ & High-pass & Y (grounded) & [100e3 Fnom] & $40 \mathrm{e} 6 * 0.45$ & {$[11 * 6013 * 60]$} & 15 & None \\
\hline 54th $22 \mathrm{Mvar} Q=15$ & High-pass & Y (grounded) & {$[100 \mathrm{e} 3$, Fnom $]$} & $40 \mathrm{e} 6 * 0.55$ & {$[11 * 6013 * 60]$} & 15 & None \\
\hline
\end{tabular}

Table 8. Discrete VSC-Based HVDC Controller Block Properties

\begin{tabular}{|c|c|c|c|c|c|c|c|c|c|c|}
\hline Name & Mode & Xnom & XP & Xdvco & XQ & Xvco & Xcrc & Xaccc & $\begin{array}{l}\text { Enable } \\
\text { dcvbc }\end{array}$ & Ts Control \\
\hline $\begin{array}{l}\text { Discrete VSC } \\
\text { Controller }\end{array}$ & $\begin{array}{l}\text { Active \& } \\
\text { Reactive Power }\end{array}$ & $\begin{array}{l}{[230 \mathrm{e} 3,100 \mathrm{e} 3,} \\
\text { Fnom, 200e3, } \\
\text { 200e6] }\end{array}$ & $\begin{array}{l}{[20.0,1.0,-} \\
1.0,1.43]\end{array}$ & $\begin{array}{l}{[3.0,3.0,} \\
1.05,0.9]\end{array}$ & $\begin{array}{l}{[20.0,} \\
0.5,-0.5]\end{array}$ & $\begin{array}{l}{[3.0,3.0,} \\
1.05,0.94]\end{array}$ & $\begin{array}{l}{[1.1} \\
0.8]\end{array}$ & $\begin{array}{l}{[0.6,6.0,} \\
0.3]\end{array}$ & off & Ts_Control \\
\hline
\end{tabular}

Table 9. PWM Generator (3-Level) Block Properties

\begin{tabular}{|l|l|l|l|l|l|}
\hline Name & Modulator Type & Modulator Mode & Fc & Modulating Signals & Ts \\
\hline PWM Generator (3-Level) & Three-phase bridge (12 pulses) & Unsynchronized & $27^{*}$ Fnom & off \\
\hline
\end{tabular}

Table 10. Model Functions

\begin{tabular}{|c|c|c|}
\hline Function Name & Parent Blocks & Calling string \\
\hline $\mathrm{Pi}$ & $\begin{array}{l}\text { Phase reactor } 0.15 \text { p.u. } \\
\text { Phase reactor } 0.15 \text { p.u. }\end{array}$ & 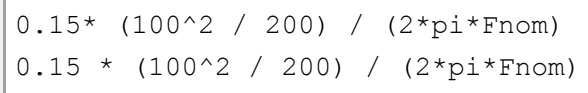 \\
\hline sqrt & $\begin{array}{l}\frac{p u-->V}{p u-->V} \\
\frac{A->p u A C \text { sec }}{\text { V-->pu AC sec }} \\
\text { A-->puAC sec } \\
\text { V-->puAC sec }\end{array}$ & 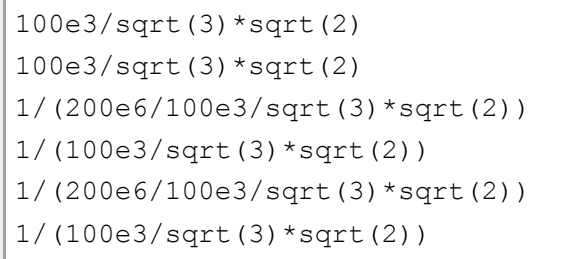 \\
\hline
\end{tabular}

